SERVIÇO DE PÓS-GRADUAÇÃO DO ICMC-USP

Data de Depósito: 19/02/2004

Assinatura: Ltna Yauk ampais Jrefon-

\title{
Ampliando o poder de recuperação de imagens por conteúdo utilizando histogramas adaptados: aplicações em imagens médicas
}

\author{
Camilo Yamauchi Campo \\ Orientadora: Prof ${ }^{a}$. Dr ${ }^{\mathrm{a}}$. Agma Juci Machado Traina \\ Dissertação apresentada ao Instituto de Ciências Matemá- \\ ticas e de Computação - ICMC-USP como parte dos re- \\ quisitos para obtenção do título de Mestre em Ciências de \\ Computação e Matemática Computacional.
}


A Comissão Julgadora:

Profa. Dra. Agma Juci Machado Traina

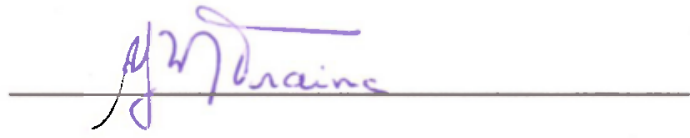

Prof. Dr. João do Espirito Santo Batista Neto

Profa. Dra. Roseli de Deus Lopes

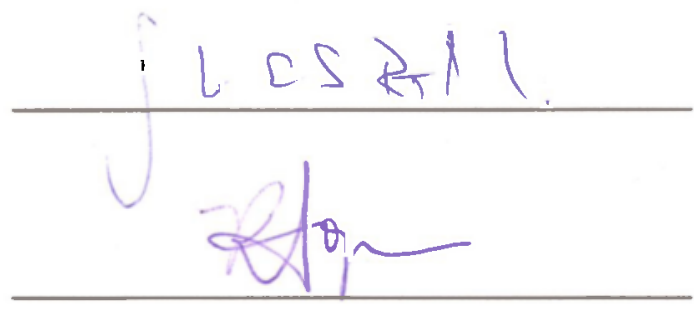


Fste documento foi preparado utilizando o formatador de textos ${ }^{A} \mathrm{~T}_{\mathrm{F}} \mathrm{X}$. Sua bibliografia é gerada autonaticamente pelo $\mathrm{BIBT}_{\mathrm{E}} \mathrm{X}$, utilizando o estilo Apalike.

(c) Copyright 2004 - Camilo Yamauchi Campo

Todos os direitos Rescrvados 


\section{Agradecimentos}

Prineiramente ao meu Senhor Derts por guiar minha vida em clirecóes certas, nos momentos (lifíceis. Obrigato Senhor pola sua prescenca. Aos mels pais que muito ne ajudaran. cnsi-

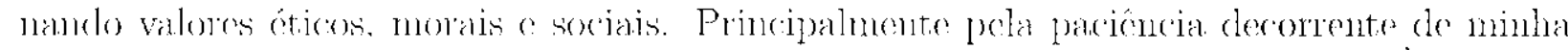
ausência nos finais de semana em que não pude voltar para o aconchego do lar. À Patrícia que sempre me apoiou. estando ao meu laclo nos noment os difíceis do minha vicla. Aos merus mestres que passaram seus conhecinentos do forma humilde o atenciess. $\grave{\Lambda}$ minha orientadora. Profa. Dra. Agna J. M. Traina pela paciencia, confiança e incentivo que motivaram

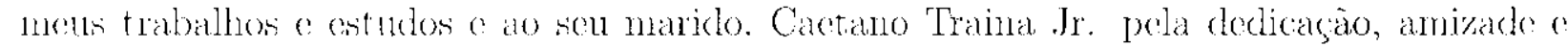
humildade. Aos membros do GBDI polo acolhimento, companheirismo e ensinamentos. Fm

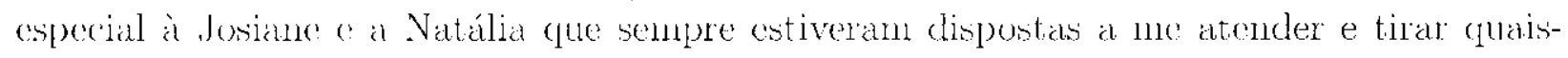
(quer dúvidas com paciencia o sinnpat ia. Aos funcionários do ICAC setor de pós-graduação assistência acadènica, scçâo de alunos da graduação e funcionárias que, semanalmente con-

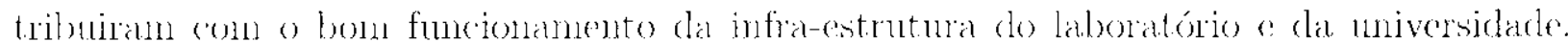
Ao pessoal clo futebol gule. todas as sextas feiras. compareciem "pontualnente" para a peladia. Aos meus companhesires de laboratório. "Beija-Flor" e "Vagoo". A minha turna de Bacharelado en Computaça do 1998 a an mens vetermos de 1997. Nunca os escuecerei. Aos companheiros do conjunto residencial universitário. conhecido cono Alojamento, pelo cspinito fraterno e ao desapego aos bens materiais. Sens chsinanentos foran de grancte valia. Ao pessoal do RUA de São Paulo pela amizade. viagens e festas do longa dada. Aos ments anigos a anigas pelos trabalhus. conversas. projetos, discusónes. debates. renniós, comenno-

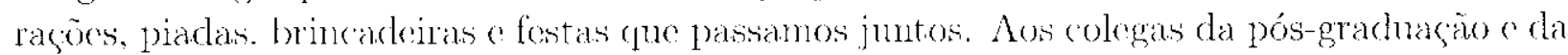
graduação, pelo companhoirimo e unidade em cue tenlıo convivido, em especial à galcra da

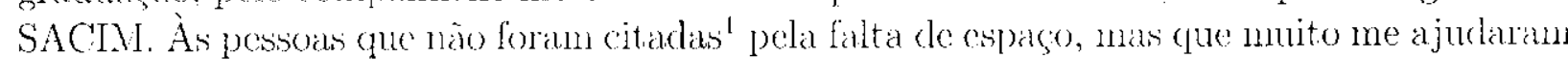
no decorrer da vida. Por fim, ao CNP(1 pela ajuda financeira e confiança depositada neste trabalho.

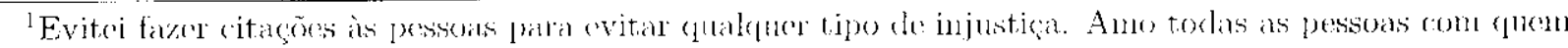
convivo e. enumera-las, seria un trabaho infinitanente mais complexo que esta dissertação. 


\section{Resumo}

Os sistemas de recuperaçāo de imagens baseada em conteúdo (CBIR - Content-Based Image Retrieval) vêm sendo bastante estudados e pesquisados atualmentc. lsso ocorre especialmente devido às áreas de aplicabilidade, entre as quais tem-se a área médica, onde há uma cnorme quantidade de informaçăo armazenada em forma de imagens. Muitas das consultas de interesse dos médicos visam procurar imagens de pacientcs que tenham semelhança entre si. Desse modo, estudos de casos, diagnósticos e tratamentos podern ser verificados e comparados baseando-se apenas na imagem e não em descriçōes textuais sobre elas. Atualmente, os sistemas PACS (Picture Archiving and Communicution Systems) não săo capazcs de realizar consultas de imagens por similaridades. $O$ trabalho aqui apresentado implementa um recurso adicional para um PACS com suporte a consultas por similaridade, ampliando o poder de recuperação de imagens através de histogramas. Este recurso permite que o sistema seja capaz de realizar buscas em imagens mesmo com algumas variações de intensidade de brilho, o que é um problema comum já que a aquisição de imagens é realizada por diversos equipamentos e mesmo con diferentes configurações. 


\begin{abstract}
In the last few years there is a great effort on developing the Content-Based Image Retrieval (CBIR) systems. This is due to their applicability in many ficlds that deal with images, including particularly the medicine, because the ever increasing volume of data gencrated by image exanns. Mary times the physicians try to find images that are similar regarding some specific aspect. Therefore, case studies, diagnosis and treatment can be compared and checked based only on the pictorial information of the images. The traditional Picture Archiving and Communication Systems (PACS) do not support similarity queries. Thus, this work presents a new technique to inprove the execution of similarity queries based on the brightness histogram of images. This technique allows the system to compare, by histograms, images with brightness variations, bypassing a claimed drawback of histograms to characterize images. This brightness variation is a common problem in acquiring images, as different devices and settings can be used to generate them, producing different brightnoss distribution over the whole image.
\end{abstract}




\section{Lista de Abreviaturas}

$\begin{array}{ll}\text { ACR } & \text { American College of Radiology } \\ \text { BIC } & \text { Border/Interior Pixel Classification } \\ \text { BLOB } & \text { Binary Large Object } \\ \text { CBIR } & \text { Content-based Image Retrieval } \\ \text { CCD } & \text { Charge-coupled devices } \\ \text { CCIFM } & \text { Contro de Ciências das Imagens e Física Médica } \\ \text { CR } & \text { Computer Radiography } \\ \text { CT } & \text { Computer Tomography } \\ \text { DICOM } & \text { Digital Imaging and Communications in Medicine } \\ \text { DR } & \text { Direct Radiography } \\ \text { FMRP } & \text { Faculdade de Medicina de Ribeiräo Preto } \\ \text { GBDI } & \text { Grupo de Bases de Dados e de Imagens } \\ \text { HC } & \text { Hospital das Clínicas } \\ \text { HIS } & \text { Hospital Information System } \\ \text { HM } & \text { Histograma Métrico } \\ \text { HSI } & \text { Hue, Saturation and Intensity } \\ \text { ICMC } & \text { Instituto de Ciências Matemáticas e de Computação } \\ \text { JPEC } & \text { Joint Photographic Experts Group } \\ \text { MBB } & \text { Minimum Boundary Box } \\ \text { MAE } & \text { Método de Acesso Fspacial }\end{array}$


MAM Método de Acesso Métrico

MST Minimal Spanning Tree.

MRI Medical Resonance Image

NN Nearest Neighbor

PACS Picture Archiving and Communication System

RAID Redundant Array of Inexpensive Disks

RGB Red, Green and Blue

RGHC Registro Geral do Hospital das Clínicas

RIS Radiology Information System

RM Ressonância Magnética

RMN Ressonância Magnćtica Nuclear

RSNA Radiological Society of North America

SAM Sistema de Arquivo Médico

SGBD Sistema de Gerenciamento de Base de Dados

SRIS Sistema de Recuperação de Imagens por Similaridade

USP Universidade de São Paulo

WORM Write-Only Read-Many 
1 Introdução 1

1.1 Considerações Iniciais . . . . . . . . . . . . . . . . . . . . . . 1

1.2 Motivação . . . . . . . . . . . . . . . . . . . . . . . 3

1.3 Objetivos . . . . . . . . . . . . . . . . . . . . 4

1.4 Apresentação do Trabalho ...................... 5

2 Os Sistemas PACS 6

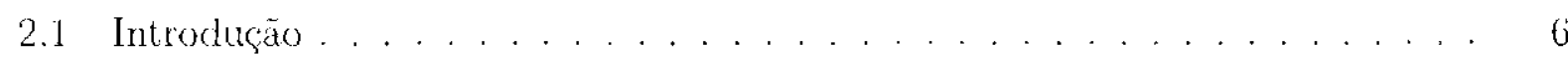

2.2 Tecnologia de Aquisição de Imagens . . . . . . . . . . . . . . . . 9

2.3 Aquisição de Imagens e Interfaces PACS . . . . . . . . . . . . . . . 11

2.4 Tecnologia de Armazenamento no PACS . . . . . . . . . . . . . . . 12

2.5 Exibição de Imagens . . . . . . . . . . . . . . . . . . . . . . . . . . . . 14

2.6 Rede PACS . . . . . . . . . . . . . . . . . . . . . . . 15

2.7 Serviço de Radiologia Digital (fllmless) em Hospital Universitário . . . . . 16

2.8 Sistema de Informação em Radiologia (RIS) do Hospital das Clínicas - HCFMRP 17

2.9 Conclusàt . . . . . . . . . . . . . . . . . . . . . . . . 20

3 Extração de Características de Imagens

3.1 Considerações Iniciais . . . . . . . . . . . . . . . . . . . . . . . . . . . 22

3.2 Definindo uma Imagem . . . . . . . . . . . . . . . . . . . . . 23

3.3 Atributos das Imagens . . . . . . . . . . . . . . . . . . . . . . . . . . 24

3.3 .1 Cor . . . . . . . . . . . . . . . . . . . . . . 25

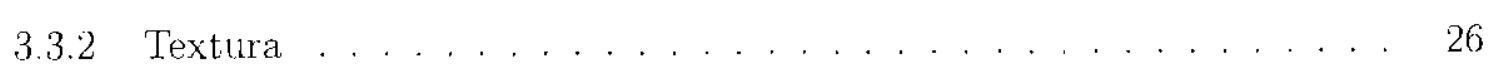


3.3 .3 Forma . . . . . . . . . . . . . . . . . . . . 27

3.3.4 Resumo das características de baixo nível das imagens . . . . . . . 29

3.4 Importância da Extração de Características . . . . . . . . . . . . . . . . . 29

3.5 Algunas Abordagens sobre os sistemas CBIR . . . . . . . . . . . . . . 33

3.5 .1 O Histograma Métrico . . . . . . . . . . . . . . . . . 33

3.5.2 Classificação de Pixels de Borda e Interior - A Técnica BIC . . . . 37

3.6 Considerações Finais . . . . . . . . . . . . . . . . . . . . . . . 39

4 Consultas por Similaridade e Estruturas Métricas $\quad 40$

4.1 Consideraçoes Iniciais . . . . . . . . . . . . . . . . . . . . . . . 40

4.2 Tipos de Buscas por Similaridade . . . . . . . . . . . . . . . . . . 41

4.3 Métodos de Acesso Métricos . . . . . . . . . . . . . . . . . . . . . 42

4.4 Estruturas Estáticas e Dinâmicas . . . . . . . . . . . . . . . . 43

4.5 A Slim-tree . . . . . . . . . . . . . . . . . . . . . . 44

4.6 Inserção de Objetos na Slim-tree . . . . . . . . . . . . . . . . 46

1.7 Tratamento de Sobreposição . . . . . . . . . . . . . . . . . . . 47

4.7.1 Reorganização dos Nós da Árvore - Algoritmo Slim-down . . . . . . . 49

4.7 .2 Visualização dos Dados Armazenados na Slim-tree . . . . . . . . . 49

4.8 Consideraçōes Finais . . . . . . . . . . . . . . . . . . . . . . . . . . . . . 49

5 Trabalho Desenvolvido $\quad 51$

5.1 Considerações Iniciais . . . . . . . . . . . . . . . . . . . . . . 51

5.2 Protótipo de um SRIS bascado no DicomViewer . . . . . . . . . . . . 52

5.2 .1 Formato de arquivos . . . . . . . . . . . . . . . 53

5.2 .2 Filtros e Bordas . . . . . . . . . . . . . . . . . 54

5.2 .3 Visualização e opções . . . . . . . . . . . . . . . 50

5.2 .4 LocalcbPACS . . . . . . . . . . . . . . . . . . 56

$5.2 .5 \mathrm{BIC} \ldots \ldots \ldots \ldots \ldots . \ldots \ldots . \ldots \ldots$

5.3 O Histograma Métrico Adaptado . . . . . . . . . . . . . . . . . . . 58

5.4 O Sistema de Recuperação de Imagens do Hospital das Clínicas de Ribeirão

Preto . . . . . . . . . . . . . . . . . . 63

5.4 .1 Arquitetura do SRIS-IIC . . . . . . . . . . . 65

5.5 Resultiddos . . . . . . . . . . . . . . . . . . . 72

5.6 Considerações Finais . . . . . . . . . . . . . . . . . . . 75 
6 Conclusão e Trabalho Futuros

6.1 Consideraçoes Finais . . . . . . . . . . . . . . . . . . . . 79

6.2 Trabalhos Futuros. . . . . . . . . . . . . . . . . . 80

$\begin{array}{ll}\text { Referências Bibliográficas } & 87\end{array}$

A Demais Resultados 88

A.1 Caso $2 \ldots \ldots \ldots \ldots . \ldots \ldots$

A.2 $\mathrm{Caso}^{3} \ldots \ldots \ldots \ldots \ldots \ldots \ldots \ldots$

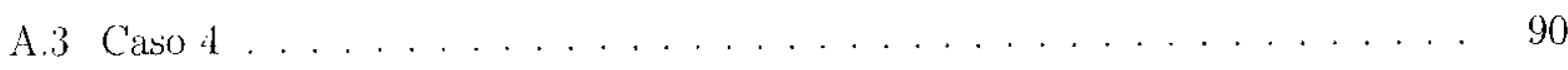




\section{Lista de Figuras}

2.1 Infraestrutura de un PACS cm ambiente hospitalar. . . . . . . . . . . . . 7

2.2 Esquema das funções de um PACS [Rosa, 2002] . . . . . . . . . . . . . 8

2.3 Armazenamento de um PACS combinando arquivamento online, nearline e offine através de um gerenciador de base de dados. . . . . . . . . . . 14

2.4 Tela principal do Sistema RIS do HCFMRP. . . . . . . . . . . . . 17

2.5 Esquema do processo global do RIS ilustrando o fluxo de um exame radiológico $[$ Rosa, 2002]. . . . . . . . . . . . . . . . . . . . 18

3.1 Uma imagem e seu histograma normalizado. . . . . . . . . . . . . . 24

3.2 Exemplos de imagens diferentes $(a, b, c$ e $d)$ que possuem o mesmo histograma

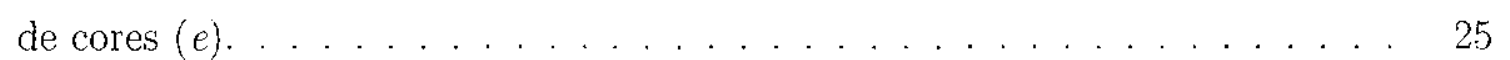

3.3 Exemplo de texturas. . . . . . . . . . . . . . . . . . 26

3.4 Exemplo de uma imagem original en tons de cinza (a) c sua forma segmentada mostrando 4 objetos identificados (b) [Pctrakis and Faloutisos, 1997]. . . . . 28

3.5 Etapas do reconhecimento de padrões de imagens. . . . . . . . . . . . . . 31

3.6 Histograma normalizado com os pontos $\left\langle b_{k}, h_{k}\right\rangle$ que definem os buckets e seu Histograma Métrico correspondente. . . . . . . . . . . . . . . 34

3.7 Obtendo o Histograma Métrico sobre o normalizado. Os pontos de controle são apresentados pelos elementos circulares co Histograma Métrico pola curva que está ao redor do histograma normalizado. . . . . . . . . . . . 
3.8 Imagem original (a), imagem mais semelhante (b) e imagem menos semelhante (c). Os histogramas apresentam a densidade de pixels para 256 níveis de cinza das imagens. . . . . . . . . . . . . . . . . . . . 36

3.9 Distância entre dois Iistogramas Métricos calculando a soma da diferença entre áreas. . . . . . . . . . . . . . . . .

3.10 Análise de imagens pela abordagem BIC. Imagem original (esquerda). Classificação binária entre borda (preto) c interior (branco) (centro). (c) Pixels da borda com suas cores originais e os pixels do interior em branco (direita). .

4.1 A consulta por abrangência (esquerda) seleciona todas as estrelas distantes de um raio $r$ enquanto que a consulta aos vizinhos mais próximos (direita) seleciona as 5 cstrelas mais próximas do elcmento de consulta. . . . . . . . .

4.2 Estrutura lógica dos nós a)índice (indexNode) e b) folla (leafNode) da Slimtree $[$ Traina et al, 2000]. . . . . . . . . . . . . . . . 45

4.3 Representação da Slim-tree armazenando 17 objetos. . . . . . . . . . 45

4.4 Mecanismos de quebras de nós do algoritmo MST. . . . . . . . . . 47

5.1 Interface padrão do DicomViewer, software que serviu de base para a implementaçăo do protótipo. . . . . . . . . . . . .

5.2 Exemplos de ntilização dos filtros do DicomViewer. a)imagem orignial, b)após aplicação do tiltro da mediana com fator 2 , c)após processamento de autolevels e d) com adição de 100 unidades de brilho. . . . . . . . . . . .

5.3 Consulta por similaridade no protótipo adicionado ao DicomViewer. . . . . .

5.4 Imagem de exame de tomografia axial de cabeça humana. (a) imagem original, (b) inagem com o brilho alterado e (c) imagem com o contraste alterado. . . 59

5.5 Ilustração de como é realizado a invariânecia ao brilho no Histograma Métrico.

5.6 Histograma com seu contraste alterado através do stretching simples e seu Histograma Métrico correspondente. A utilização do limite $V_{L}$, elimina os bins irrelevantes, recuperando sua curva original (à direita) . . . . . . . . .

5.7 Ilustraçäo do funcionamento da Warp Distance onde ocorre a "distorção" de área permitindo um melhor cálculo de similaridade entre curvas. . . . . . . 61

5.8 Consulta 32 -Nearest Neighbors utilizando a abordagem BIC . . . . . . . 62

5.9 Consulta 32 -Nearest Neighbors utilizando a abordagem do Histograma Métrico. 62 5.10 Integração SRIS-HC com RIS, HIS e mini-PAC'S do HCFMRP/USP. . . . . 63

5.11 Processo global do Sistema de Recuperação de Imagens Similares - SRIS-HC. 65 
5.12 Arquitetura do SRIS-HC . . . . . . . . . . . . . . . 66

5.13 Interface em que as imagens GBDI são inseridas para validação. . . . . . . 67

5.14 Tela de consulta ao laudos de urn paciente e suas respectivas informações. . . 70

5.15 Tela das imagens em miniatura (thumbnails) do exame e a primeira imagem em tamanho natural. . . . . . . . . . . . . . . . . . . . . . 71

5.16 Tela da apresentação dos logs do banco de imagens. . . . . . . . . . . 72

5.17 Tcla de conexão do usuário com a base de dados e acesso ao SRIS-HC. . . . 72

5.18 Imagem original de crânio (esquerda) e a mesmá com o recorde do MBB (Mnimum Boundary Box). . . . . . . . . . . . . . . . 73

5.19 Imagen de referencia para o primeiro caso. . . . . . . . . . . . . . . 74

5.20 Resultado da consulta aos 40 vizinhos mais próximos utilizando o histograma normalizado. . . . . . . . . . . . . . . . . . . . . 75

5.21 Consulta por abrangência com raio de 0.3 utilizando o histograma normalizado. 76

5.22 Consulta aos vizinhos mais próximos através do Histograma Métrico adaptarlo. 76

5.23 Consulta por abrangência com raio de 0.3 utilizando o Histograma Métrico adaptado. . . . . . . . . . . . . . . . . . . 77

A.1 Imagen de referência do Caso $2 \ldots \ldots \ldots$. . . . . . . . . . . . . . . . . 88

A.2 Consulta aos 40 vizinhos mais próximos utilizando o histograma normalizado. 89

A.3 Consulta por abrangencia $(r=0,3)$ utilizando o histograma normalizado. . . 89

A.4 Consulta aos 40 vizinhos mais próximos utilizando o Histograma Métrico adaptado. . . . . . . . . . . . . . . . . . . . . . . . . . 90 90

A.5 Consulta por abrangencia $(r-0.3)$ utilizando o Histograma. Métrico adaptado. 91

A.6 Imagem de referencia do Caso $3 \ldots \ldots \ldots . \ldots \ldots$. . . . . . . . . .

A.7 Consulta aos 40 vizinhos mais próximos utilizando o histograma normalizado. 92

A.8 Consulta por abrangência $(r=0.3)$ utilizando o histograma normalizado. . . 92

A.9 Consulta aos 40 vizinhos mais próximos utilizando o Histograma Métrico adaptado. . . . . . . . . . . . . . . . . . . . . 93

A.10 Consulta por abrangência $(r=0.3)$ utilizando o Histograma Métrico adaptado. 93

A.11 Imagem de referência do Caso 4. . . . . . . . . . . . . . . . . . . 94

A.12 Consulta aos 40 vizinhos mais próximos utilizando o histograma normalizado. 95

A.13 Consulta por abrangência $(r=0.3)$ utilizando o histograma normalizado. . . 95

A.14 Consulta aos 40 vizinhos mais próximos utilizando o Histograma Métrico adaptado. . . . . . . . . . . . . . . . . . . . . . . 96

A.15 Consulta por abrangência $(r=0.3)$ utilizando o Histograma Métrico adaptado. 96 


\section{Lista de Tabelas}

3.1 Atributos de qualidade das características de baixo nível da imagem [Vailaya, 2000]. . . . . . . . . . . . . . . . . . . . 30

3.2 Taxonomia sobre espaços de características extraídas de imagens[Brown, 1992]. 32

5.1 Tabela de comparação ontre o DicomViewer e as incorporaçöes realizadas. . 54

5.2 Configuração do computador utilizado para os experimentos. . . . . . . . . 74

5.3 Resumo dos resultados obtidos nos experimentos. . . . . . . . . . . . 78 


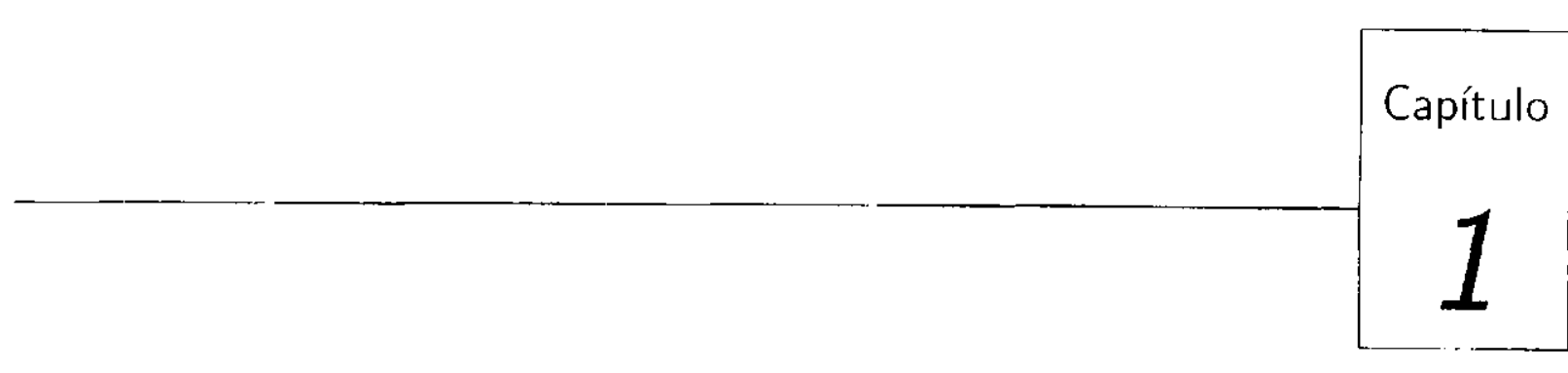

Introdução

\subsection{Considerações Iniciais}

Os Sistemas de Informaçōes Hospitalares (HIS) armazenam informaçöes relativas aos pacicntes destacando-se, entre elas, seu estado de saúde, os cxames realizados e os procedirnentos médicos adotados. Atualmente, a maioria desses sistemas organiza dados text uais e numéricos mas, em alguns casos, já é possível a associação das informações textuais com informações gráficas, provenientes de exames como raio-X, tomografia $\left(\mathrm{CT}^{1}\right.$ ou $\left.\mathrm{RM}^{2}\right)$ e ultra-som. Receutemente, com a introdução dos sistemas PACS (Picture Archiving and Communication System) [Cao and Huang, 2000]] [Siegel, 1999] [Furuie et al., 1999] [Marsh, 1997], cresccu o intercsse por integrar num só sistema todas as informações dos pacientes (textos, imagens, gráficos e dados temporais). Além disso, o custo operacional dos exames de imagens diminui quando se utiliza tecnologia de radiologia sem filme (filmless), o que permite direcionas investimentos maiores para a árra de diagnóstico [Siegel, 1999].

Os sistemas PACS devem permitir a transmissão rápida e o armazenamento organizado para as imagens digitais, tanto $\mathrm{cm}$ termos de disponibilidade do exame em curto prazo como

${ }^{1}$ Tomografia Computadorizada.

${ }^{2}$ Ressisonâncili Magnéticici. 
também no aspecto de multivisualização. Os cirurgiöes devem ser capazes de tomar decisĩes diagnósticas logo após um cxame, bem como acessá-las simultaneamente para discuti-las e analisá-las em salas de ensino ou mesmo durante consultas [Siegel and Kolodner, 1999 ] [Furuie et al., 1999].

Infelizmente, os poucos sistemas PACS comerciais oferecidos atualmente são extremamente caros o não contemplam todas as nocessidades do centro médico [Sung et al., 2000]. Desse modo, o estado da arte na árca resume-se ao desenvolvimento de soluçōes locais, muitas vezes restritas. Alguns centros médicos integrados a unidades de pesquisa optam, via de regra, por adquirir apenas alguns módulos do sistema, desenvolvendo e adaptando outros módulos c criando soluçoes próprias conforme sua necessidade. Assim, o custo é diminuído e podem-se contemplar necessidades e características próprias de cada ambiente.

Como os sistemas PACS organizam as imagens provenientes de exames efetuados sobre os pacientes, seria muito interessante que, através desses sistemas, fosse possível realizar consultas e recuperar tajs imagens baseando-sc apenas no seu contcído. Por exemplo, pode sex necessário recuperar todas as imagens obtidas em exames do tomografias computadorizadas do coração, similares a uma imagem dada. Nesse caso, o cruzamento das informações é independente das chaves de busca tradicionais, baseadas em dados numéricos e textuais, as quais associam exannes e paciontes om um HSI tradicional. A facilidade de recuperação de dados baseada em seu conteúdo é um dos recursos atualnente mais almejados para incorporação aos sistemas PACS [Korn et al., 1996] [Lima et al., 1998]. Através dessa facilidade, podem ser encontrados registros de pacientes cujas imagens associadas apresentam aspectos de similaridade (utilizando padrões gráficos), alćm de se obterem correlações utilizando sintomas previamente registrados e tratamentos efetuados [Marsh, 1997]. Assim, um sistema PACS com tal facilidade torna-se, potencialmente, uma ferramenta bastante eficaz no auxílio ao diagnóstico médico.

Um sistema PACS pode então responder à consultas por similaridade, isto é, a questöes do tipo: Quais săo as 10 imagens mais semelhanles (próximas) de uma dada imagem ou Quais säo as imagens que diferem em até 5 unidades de uma imagem padrão. Vale notar que tanto as imagens quanto a função distância (dissimilaridade) definida são, usualmente, dependentes do domínio de dados e do que é considerado "semelhante".

A similaridade cntre imagens pode ser medida de várias formas. Características como formato, cor e textura podem ser extraídas de imagens em uma base de dados e podem ser utilizadas em cálculos de distância ou dissimilaridade [Aslandogan and Yu, 1999]. 


\subsection{Motivação}

Ao efetuar uma consulta por similaridade em um banco de imagens, o sistema retorna o conjunto de imagens que responde à solicitação efetuada. A consulta é realizada através de uma ou mais estruturas de índices que dão suporte a busca por imagens semelhantes, considerando a distância entre as características extraídas das imagens. Dessa forma, o conjunto de características extraídas das imagens e a função de dissimilaridade (distância) utilizada têm papel preponderante nessa operação de consulta. "Quais são as características extraídas das imagens que melhor contribuem para a comparação e separação entre as imagens mais precisas?" Os especialistas em visão computacional afirmam que, na realidade, a ciência nào sabe dizer como o cérebro humano reconhece as imagens e os objetos que as compõem [Jain and Dubes, 1988]. Porém, existe um consenso de que as principais características sāo baseadas em atributos de cor, forma c textura. Assim, algumas dessas características podem ser obtidas através de histograma para cores [Aslandogan and Yu, 1999], resultados de transformações tais como momentos (singular value decomposition e Karhunen-Loève) [Faloutsos, 1996] para formas, além de coeficientes de transformadas wavelets (principalmente Gabor) [Albuz et al., 2001] para texturas, entre outras técnicas.

Devido à complexidade de algumas técnicas de extração de características, é mais interessante aplicá-las sobre num conjunto de imagens menor ou que tenha sido refinado por um método menos custoso em termos computacionais. Nesse sentido, as técnicas baseadas em cores e, no caso das imagens médicas, em níveis de brilho ou intensidade, deven ser as primeiras utilizadas, pois requerem baixo custo computacional. Isto ocorre pois as informaçōes rolativas a cor são as primeiras a serem lidas em um arquivo de imagem.

Os histogramas de intensidades, que indicam o número de pixels da imagem para cada nível de intensidade, são simples de implementar, baratos en temos computacionais e muito utilizados em sistemas CBIR (Content-Based Image Retrieval). Como os histogramas apresentam a distribuição global dos níveis de cinza da imagem, eles são também altamente suscetíveis a variações de brilho.

Algumas variaçoes com o uso de histogramas são propostas na literatura. Histogramas que armazenam informações espaciais das cores são apresentados em [Yamamoto et al., 1999], [Chua et al., 1997] e [Rao et al., 1999]. A grande maioria de publicações no tratamento de histogramas para recuperação de imagens por conteúdo traz abordagens nas quais são privilegiados fatores como desempenho e precisāo. Nestas abor- 
dagens, as técnicas não se detiveram na redução do numero de bins ${ }^{3}$ de uma imagenn sem perda significativa de informação. Em [Bueno, 2002] [Traina et al., 2002a] foram propostos os Histogramas Métricos (HM) que são invariantes às transfornaçoos gcométricas (escala, rotação e translação) efctuadas nas imagens. Os HMs säo definidos através de uma função de aproximação linear por partes sobre o histograma normalizado da imagem, sendo que tais funçōes podem ser ajustadas e comparadas. O presente projeto explora as propricdades de invariância dos H.Ms c apresenta os resultados que permitem uma melhor discriminação das imagens recupcralas através de seu conteúdo.

O Histograma Métrico é uma forma de reduzir a dimensionalidade do vetor de características, porém atua solve cada vetor de característica da imagem (histograma convencional) de forma independente do conjunto completo, o que permite marter as particularidades de cada imagem. Tal fato não foi explorado por outras técnicas de redução de dimensionalidade de histogramas descritas na literatura da área [Brunelli and Mich, 2001]. Assim, o pressente trabalho compara o grau de eficiencia dos HMs com outros mótodos de redução de dimensionalidade e demonstra gue, con tais características invariantes, os HMs possibilitam um alto grau de recuperaçãa de imagens por conteúdo no âmbito das imagens médicas.

\subsection{Objetivos}

() objetivo deste projeto é esludar e implementar métodos de extração de características bascadas em níveis de intensidade que permitam a comparação entre imagens médicas, sendo Im primeiro passo para dimimuir o conjunto de respostia para busca de imagens similares. Este passo, permitirá que métodos mais sofisticados. como os baseados cun forma, possam ser aplicados a posteriori sobre um volume menor de dados, propiciando uma resposta mais rápida à consulta.

O resultado do extrator de características aplicado a uma imagem é um vetor de características, o qual ó utilizado para comparar as imagens através de funçoos de distância. $\Lambda$ técnica utilizada é baseada no Histograma Métrico (HM) que são invariantes às três transformaçoes geonétricas. Neste trabalho, eles foram expandidos para o tratamento de variaçoes a brilho, tormando-os mais eficientes.

As técnicas desenvolvidas foram validadas no sistema cb-PACS em construção no ICMCUSP e CCIFM-FMRP-USP.

\footnotetext{
${ }^{3}$ A definiçá de bin porde ser entendida como a quantidade estatística de ma determinada cor em uma imagem, asisim uma imagem com 256 cores possuirá um histograma com 256 bins.
} 


\subsection{Apresentação do Trabalho}

Este trabalho está dividido em 6 capítulos $\mathrm{c}$ um apêndice. O primeiro capítulo apresentou algumas considerações iniciais, o contexto no qual se insere este trabalho, a motivação para sen deservolvimento e seus objetivos finais.

No Capítulo 2 c apresentada a estrutura dos sistemas PACS e suas principais características, além de introduzir o sistema em desenvolvimento no Hospital das Clínicas de Ribeirão Preto.

No Capítulo 3 é apresentada uma visão sobre os extratores de características de imagens, unostrando as principais características das imagens uttilizadas em sistemas de recuperação por conteúdo. Dois cxemplos de extratores de características são abordados e analisados. As consultas por similaridade e estruturas métricas são descritas no Capítulo 4

O trabalho desenvolvido, os resultados obtidos o a modificação rcalizada no Histograma Métrico são tratados no Capítulo 5.

Por firn. no Capítulo 6 ć apresentada a conclusāo e os trabalhos futuros e em seguida, a bibliografia. U'm apêndice foi taunbém adicionado para a aprescntação dos demais resultados que não foram detalhados no Capítulo 5. 


\subsection{Introdução}

Desde o surgimento do Raio-X, descoberto por Wilhelm Corad Röntgen em 8 de novembro de 1895, a. utilização de imagens para diagnóstico de doenças faz parte do meio médico. Com o avanço tecnológico, os equipamentos foram incorporando sistemas mais complexos como a tomografia computadorizada e a ressonância magnética.

Com o advento dos sistemas computacionais, o tratamento de informaçôes vem avançando diariamente. Os sistemas computacionais fazem parte, mais do que em qualquer época, da vida cotidiana. (Os computadores são extremamente necessários, principalmente em ambientos em que a quantidade de informaçōes é grande. Exemplos típicos disso são escolas, bancos, cmpresas e hospitais. Este último possui uma peculiaridade dos demais. Além de necessitar gerenciar informações textuais, há também a necessidade de manipular imagens de exames.

Os chamados Sistemas de Comunicaçĩo e Armazenamento de Imagens - PACS, referemse a sistemas computacionais que são usados para capturar, armazcnar, distribuir e exibir imagcrs médicas. São sistemas de arquivamento e comunicação voltados para o diagnóstico por imagen, que perniten o pronto acesso, en qualquer setor do hospital ou clínica, de imagens médicas em formato digital [Siegel, 1999]. 
O termo PACS tem sido usado para denotar sistemas nos departamentos de radiologia que lidam com imagens radiológicas, embora alguns PACS tenham ido além desses limites, contendo imagens de outras fontes, tais como patologia e endoscopia. O PACS tem se tornado rapidamente a opção tecnológica preferida para as tarefas de transmissão, armazenamento, recuperação, visualização e interpretação de grandes volumes de dados. Porém, a implementação de um PACS implica em um trabalho de reengenharia do serviço de radiologia, devido às modificações inseridas na sequência de eventos necessários desde a aquisição da imagem até sua exibição e interpretação [Marques et al., 2000].

Um PACS consiste de pelo menos uma ou múltiplas modalidades (dispositivos de aquisição), uma rede de comunicação, um dispositivo de armazenamento intermediário e/ou de longo período, e uma estação de trabalho para visualização e/ou pós-processamento, conforme esquematizado na Figura 2.1. Um PACS que atende à uma modalidade de exame com imagens, um arquivo e uma estação de trabalho é chamado de mini-PACS ou micro-PACS [Rosa, 2002].

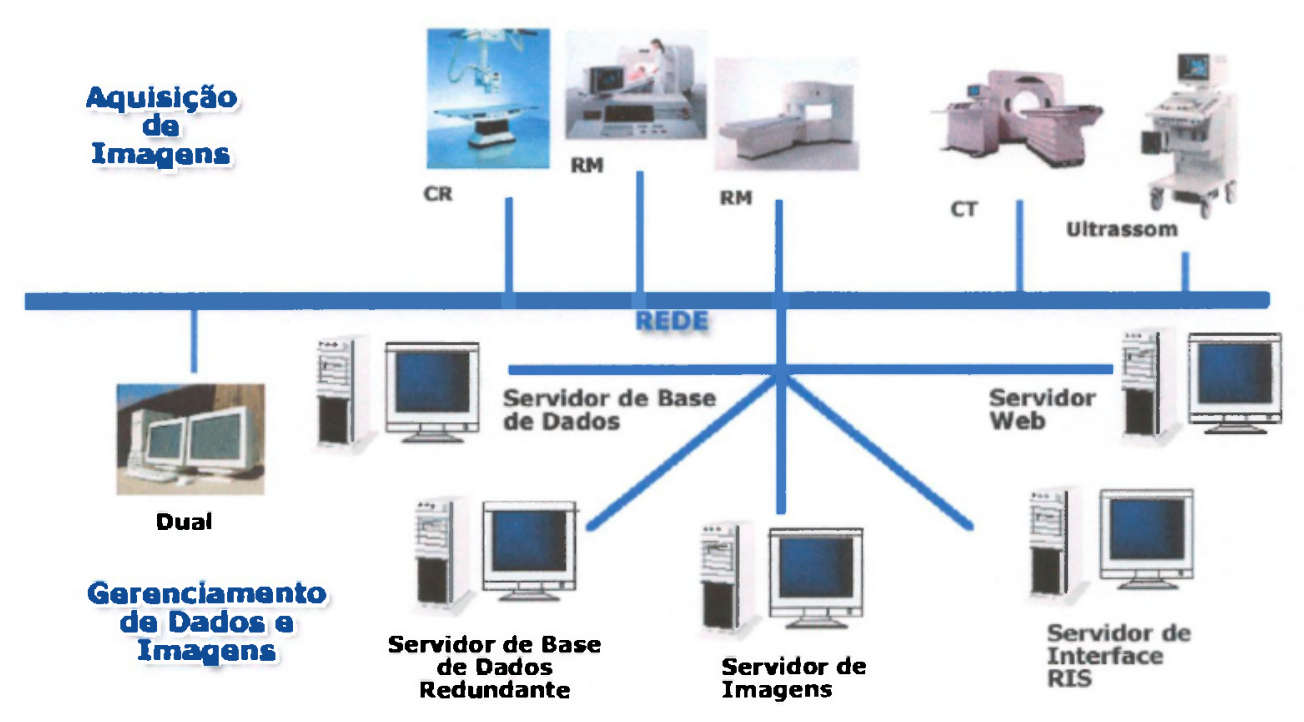

Figura 2.1: Infraestrutura de um PACS em ambiente hospitalar.

Um sistema PACS deve executar as seguintes funções utilizando tecnologia digital [G. Günther, 1999], conforme o esquema elaborado para ilustrar essas funções na Figura 2.2:

- aquisição de imagem

- comunicação de imagens (transferência)

- armazenamento de imagens 
- exibição de imagens

- processamento de imagens

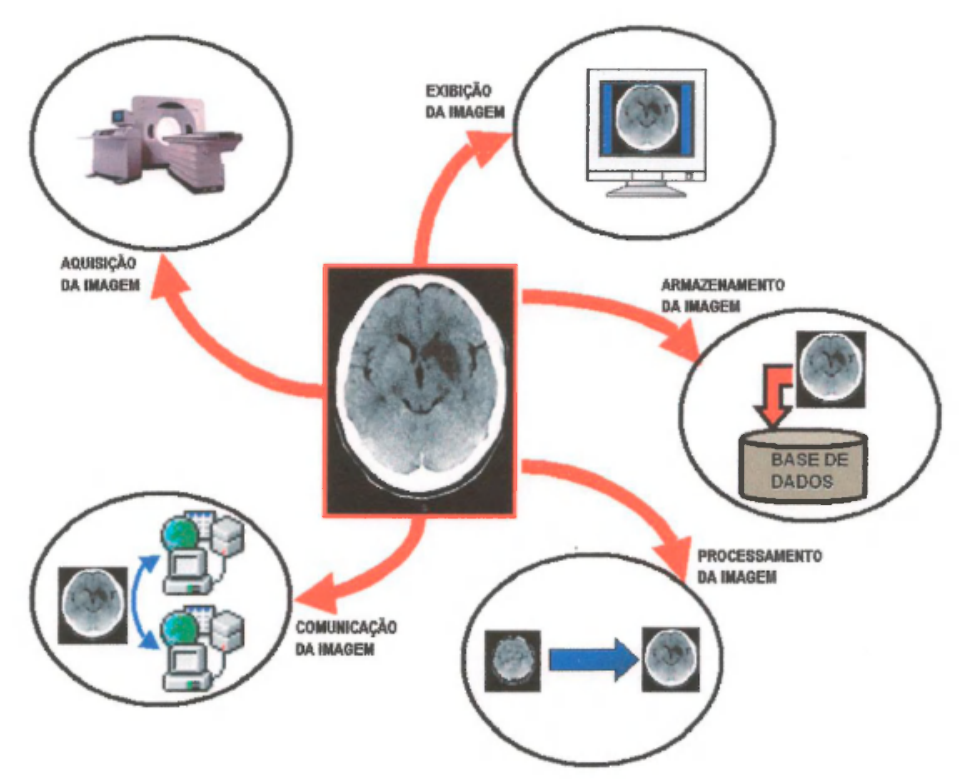

Figura 2.2: Esquema das funções de um PACS [Rosa, 2002].

A tecnologia PACS pode ser utilizada para obter operações sem filme (filmless). Radiologia filmless se refere a um hospital com um ambiente de rede amplo e integrado, no qual o filme foi completamente, ou em grande parte, substituído por sistemas eletrônicos que adquirem, arquivam, disponibilizam e exibem as imagens [Siegel, 1999][Marques et al., 2000]. O PACS em conjunto com os Sistemas de Informação em Radiologia (RIS) e de Informação Hospitalar (HIS) formam a base para um serviço de radiologia filmless [Siegel and Kolodner, 1999] [Marques et al., 2000].

A implantação de um serviço de radiologia sem filme deverá trazer melhorias no que se refere à acessibilidade e integração de informações, pela vinculação de imagens ao registro médico eletrônico do paciente, e no que se refere à aplicação de novas técnicas e desenvolvimentos na aquisição, exibição e processamento de imagens. Segundo a literatura especializada, a maioria dos serviços médicos fará a transição para a radiologia filmless durante os próximos dez ou vinte anos [Siegel and Kolodner, 1999] [Marques et al., 2000].

Um alto nível de integração do PACS na operação dos dados é necessário para garantir sua ótima funcionalidade, o que requer uma quantidade tremenda de planejamento e implementação com analistas de sistemas, engenheiros e a administração e também com os outros 
departamentos clínicos. Isso é muito mais complexo de se obter do que qualquer outro processo de aquisição para o departamento de radiologia e o hospitial [Siegel and Kolodner, 1999].

Un PACS é caracterizado por quatro subsistemas: aquisição, exibição, disponibilizaçāo e armazenamento de imagens [Marques and et. al, 2004], que serão descritos a seguir.

\subsection{Tecnologia de Aquisição de Imagens}

Embora as modalidades mais recentes, tais como imagens de ressonancia magnética (MRI), tomografia computadorizada (CT), ultra-som, angiografia digital, fluoroscopia digital e medicina nuclear, obtenham imagens $\mathrm{cm}$ formato digital, aproximadamente $70 \%$ da carga de trabalho do departamento de radiologia continuam sendo na área de radiografia convencional (filmes/chapas) [Siegel and Reiner, 1999]. Radiografia geral, com seu alto volume do detalhes na imagem, representa um desafio especial para PACS, desafio esse encontrado com a introdução de novas modalidades, tais como radiografia computadorizada, radiografia direta e digitalização de filmes [Siegel and Kolodncr, 1999].

A maioria dos equipamentos para as modalidades digitais, tais como CT, MRI, ultra-som, medicina nuclear, CR, radiografia direta (DR), angiografia e fluoroscopia digital, é atualmente adquirida com interface padrão que utiliza um protocolo de comunicação e formato de imagem conhecido como DICOM (Digital Imaging and Communications in Medicine). O lomato lJICOM ó o padrão para comunicação do imagens médicas e informações associadas, atualmente utilizado por diversas nodalidades de equipamentos de imagens médicas [Caritá, 2002]. Esse protocolo preserva a fidelidade original completa (resolução espacial e contraste) gerado pela modalidade durante a transferência para o PACS. Na ausência de uma interface DICOM, as imagens podem ser capturadas para transmissão para o PACS usando placas de captura de vídeo, que podem digitalizar a saída de vídco de um monitor ou câmera. Desaforturiadamente existe uma boa quantidade de variação na qualidade das unidades de captura de vídco e mesmo os mellores podem introduzir artefatos que degradam a qualidade da imagem. Essas unidades estão limitadas à captura de somente 8 bits (256 niveis de cinza), o que é insuficiente para os 12 bits (4096 níveis de cinza) de modalidades tais como CT c MRI [Siegel, 1999].

Um ambiente sem filme requer um nível muito alto de resolução espacial e contraste, resultando en grandes arquivos de imagens (de 6 a 16 Megabytes). En um ambiente desses, existem somente três métodos atualmente disponíveis para aquisisăa de radiografias em ge- 
ral: Radiografia Computadorizada (CR), Radiografia Direta (DR) e digitalização de filmes [Siegel and Kolodner, 1999].

Radiografia Computadorizada (CR), lambém conhecida como Storage Phosphor Radiography (SP), é atualmente a única solução comercial amplamente disponível para aquisição digital de radiografias convencionais. Nesses sistcmas de radiografias computadorizadas, as imagens digitais são diretamente produzidas em uma placa de imagem à base de fósforo (imaging plate) podendo, nıa seqüência, serem visualizadas em monitores ou convertidas para imagem analógica em filme através de um processador laser. A maior vantagem da CR 6́ sua ampla faixa dinàmica e seu uso de pós-processamento de imagens por computador, que resulta em potencial no decréscimo das taxas de repetição de imagens, o melhoria da qualidade do diagnóstico das radiografias [Siegel and Kolodner, 1999]. Os sistemas CR são compatíveis com a maioria dos sistemas do raios- $\mathrm{X}$ fixos e portáteis, possuindo latitude de exposição bastante larga, o que resulta en imagens com densidade adequada em uma faixa ampla de níveis de exposição, eliminando os problemas de sobre c sub-exposição das imagens [Marques and et. al, 2004]. Porém existem algumas desvantagens, tais como o alto custo de implantaçào e o decréscimo na resolução espacial, que é menor do que a do filme, mas é suficiente para o diagnóstico.

Em Radiografia. Direta (DR), um conjunto de detectores é utilizado para capturar a imagem radiográfica diretamente, eliminando a necessidade do processar ou ler o detector (filme em um sistema convencional, placa de fósforo em um sistema CR) cm outro local. Com um sistema DK totalmente integrado com o sistema de informação do hospital, um técnico pode obter uma série de imagens, revisá-las imediatamente e enviá-las para um PACS. Um sistema sem filme tem a capacidade de aumentar a produtividade. A tecnologia DR também tem a capacidade de aumentar a resolução espacial em comparação com sistemas CR atualmente implementados e diminuir os artefatos associados com os danos físicos que podem ocorrer com o tempo com as placas de fósforo armazenadas. Sua maior desvantagem é 0 alto custo, a alta vulnerabilidade relativa aos danos dos sistemas de detectores, e a carência de portabilidade [Siegel and Kolodner, 1999].

Na ausêneia de um dispositivo de aquisição digital, o filme pode ser digitalizado usando um dispositivo digitalizador de filmes (scmelhante a uma máquina de fax), que varre o filme e cntão envia a imagem eletrônica resultante para um dispositivo de armazenamento ou PACS. Os filmes convencionais, teoricamente podem ser digitalizados em um alto nível de resolução espacial e contraste usando um digilalizador de filme de alta qualidade. Existem muitos tipos de digitalizadores do filmes, incluindo sistcmas com CCD (charge-coupled devices) e varredura 
por feixe de laser. Os digitalizadores de filmes podem ser introduzidos sem grandes alterações na rotina do serviço, possibilitando uma transição suave para um sistema baseado em imagem digital [Siegel and Kolodner, 1999] [Marques and et. al, 2004]. Porém na prática, o processo de digitalizaçào pode introduzir artefatos e degradar a qualidade da imagem c, além disso, a qualidade da imagem é limitada à qualidade do filme original [Siegel and Kolodner, 1999]. O processo de digitalizaçào consome tempo devido à necessidade de identificar cada paciente, o estudo executado, data e hora do exame e fornecer essas informaçcoes à base de dados do PACS [Siegel and Kolodner, 1999]. A percepção dos radiologistas é que a qualidade da imagem é significativamente limitada para os filmes digitalizados, reduzindo a segurança do diagnóstico. Essas limitaçōes têm resultado na adoção de radiografias computadorizadas proferencialmente à digitalização de filmes [Siegel and Kolortner, 1999].

\subsection{Aquisição de Imagens e Interfaces PACS}

Ao se planejar um departamento de radiologia sem filme, ć importante especificar em detalhes que todas as modalidades terão interfaces digitais conı o PACS. Essas interfaces deveriam utilizar o padrão DICOM para comunicação com o PACS, pois o DICOM tem-so firmado como o padrão para imagens médicas. Adicionalmente, os dispositivos de aquisição de imagens deveriam ser adquiridos com a habilidade de permitir a comunicação direta com o sistema de informaçāo hospitalar (HIS) e com o sistema de informação em radiologia (RIS) para facilitar a entrada eletronica de informaçöes do paciente e de estudos do paciente [Siegel and Kolodner, 1999].

Os disposilivos de aquisição de imagens devem ser capazes de enviar imagens ao PACS rapidamente, para minimizar a espera de tempo dos radiologistas e dos médicos, o que requer, por exemplo, que uma inagem de CR seja transmitida em menos que 36 segundos e 60 imagens de CT en menos que 2 minutos [Siegel and Kolodner, 1999]

Uma das mais importantes lições das recentes implementaçōes de PACS têm sido a importância crítica das interfaces funcionando fácil e confiavelmente. Essas interfaces podem ser vistas como uma estrada de comunicação que permite as modalidades, o PACS o os sistemas de informação hospitalar e em radiologia (HIS/RIS) se comunicarem entre si [Sirgel and Kolodner, 1999].

Três tipos de interfaces são necessários para o sucesso da operação de um PACS de larga escala:

- interface das modalidades com o PACS, que perrnite transferir imagens médicas o 
informaçoes de pacientes e estudos de pacientes, dos dispositivos de aquisição (tais como CT scanner) para o PACS e transferir potencialmente as imagens do PACS para as modalidades[Siegel and Kolodner, 1999].

- interface dos sistemas HIS/RIS com o PACS, permitindo transferir informações dos pacientes tais como nome, identificação e tipo de estudos para o PACS e do PACS para os sistemas.

- interface do IIIS/RIS com as modalidades, permitindo comunicação direta entre um dispositivo de imagens médicas e os sistemas HIS/RIS [Siegel and Kolodner, 1999].

\subsection{Tecnologia de Armazenamento no PACS}

Lima vez que as imagenss são obtidas, elas devern ser armazenadas para pesquisa posterior dos médicos e dos radiologistas. O armazenamento das imagens tem se dividido, tradicionalmente, eIn curto período (short-term), o cual inclui armazenamento (magnético) local, e longo período (long-term), o qual envolvo meios de armazenamento óticos entre outros [Sicgel and Kolodner, 1999] [Marques and et. al, 2004], e em alguns casos, om médio período. Existe uma diferença tremenda na velocidade de recupcração entro longo c curto período de armazenamento. Os armazenamentos típicos do PACS têm, a qualquer momento, pelo menos $95 \%$ de suas imagens no armazenamento em longo período, o qual é muito mais lento. É importante por isso utilizar algoritmos inteligentes para maximizar a possibilidade de se ter disponível os estudos c comparaçôs requisitados em um armazenamento em curto período [Siegel and Kolodner, 1999].

O armazenamento local ou magnético, refere-se ao disco rígido (HD) do computador e ammazena as informaçós da imagem digital em um disco magnético para uma recuperação rápida. [Marques and et. al, 2004]. A maioria dos sistemas possui una capacidade de armazenamento de curto periodo na faixa de 20 a 256 gigah)ytes [Siegel and Kolodner, 1999]. Um período curto de armazenamento deveria permitir a conservação das imagens por um período de pelo menos 2 a 3 semanas e deveria ter a capacidade de armazenar pelo menos de 1 a 3 meses de imagens, porém de modo geral, as imagens são mantidas armazenadas em um meio por volta de uma semana, devido ao grande volume de dados e o alto custo dos sistemas magnéticos de alta capacidade [Marques and et. al, 2004]. O tempo de recuperação deveria ser de 2 segundos ou menos para imagens $C R$ e 10 ou menos segundos para 20 imagens de estudos CT: quando recuperando um estudo de um repositório de imagens central (uma ar- 
quitetura PACS central) ou de uma estação de trabalho local (arquitetura PACS distribuída). Essas velocidades são necessárias para manter níveis aceitáveis de produtividade de radiologistas e médicos. O armazenamento local é utilizado tanto nas estações de visualização como também nos servidores do sistema [Marques and et. al, 2004] [Siegel and Kolodner, 1999].

Um período longo de armazenamento refere-se geralmente a discos óticos WORM (uma. escrita, várias leituras). Esses discos possuem variados tamanhos e capacidades, podendo chegar a 10Gb cada e armazenam os dados em um formato de arquivo permancnte e não apagável. Outras opçōes de armazenamento incluem arquivos em fita magnética, cm CDROM, cm DVD ou cu disco ótico-magnético (M/O), que permite armazenar as informaçòes por um periodo de tempo de um mês ou mais e então apagá-las quando não mais necessárias [Marques and et. al, 2004].

O armazenamento por longo prazo deveria ter a capacidade de armazenar pelo menos 5 ou 6 anos de imagens de estudos médicos. Esse período corresponde ao requisito que muitas instituições possuem de relenção de filmes convencionais. O tempo de recuperação de una imagem de CR de um armazcnamento de longo periodo deveria ser menos que 1 minuto e 30 cstudos de imagens de CT deveriam estar disponíveis em 2 minutos. Para agilizar, un método deveria ser usado para transferir os exames antigos de um período longo de armazenamento para um de período curto, quando é provável que eles sejam requisitados, ou sejal após ter sido solicitado um novo exame nos sistemas HIS ou RIS, ou após a admissãa do paciente no hospital, por exemplo. Esse processo ć conhecido como "prefetching" e deveria resultar na obtcnção prévia desses exames antigos.

A maioria dos sistemas PACS de grande escala utilizam uma jukebox ótica para armazenamento de longo período de imagens. A capacidade de armazenamento tipicamente varia de: 20 gigabyles a mais do que 2 terabytes com tempo de recuperação na faixa de 20 segundos a aproximadamente 5 minutos para uma simples imagem de radiografia computadorizada (de 8 magabytes) [Siegel and Kolodner, 1999].

Em [Furuie et al., 1999] os armazenamentos são classificados como:

Online mídia online de até 100 GBytes suportando armazenamento de exames dos últimos 2 rncses, considerando-se 5 Gbytes por dia de imagens (2.5 GB com compressão sem perda).

Nearline (dispositivos automáticos que permitem carregar e descarregar a mídia através de um robô, tais como jukeboxes, com até 3.4 TBytes). A recuperaçäo nearline envolve descarregar automaticamente os arquivos DICOM para a media online, com um tempo 
de pesquisa e carga de cerca de 3 minutos. $\mathrm{O}$ armazenamento nearline permite que as imagens mais recentes dos últimos 3 anos possam ser acessadas automaticamente.

Offline a recuperação offline é baseada em agendamento e carregamento prévio (prefetching) dos dados para a mídia online. Requer a intervenção do operador para carregar o exame ou a fita solicitada.

O gerenciamento desses armazenamentos é feito através de um sistema gerenciador de base de dados que mantém o controle da localização e movimentação das imagens, e dos estados, ou seja, se estão online, nearline ou offline, além de gerenciar a mudança de estado das imagens, ou seja, enviar imagens de um estado para outro, como por exemplo, do estado online para nearline, conforme ilustra a Figura 2.3.

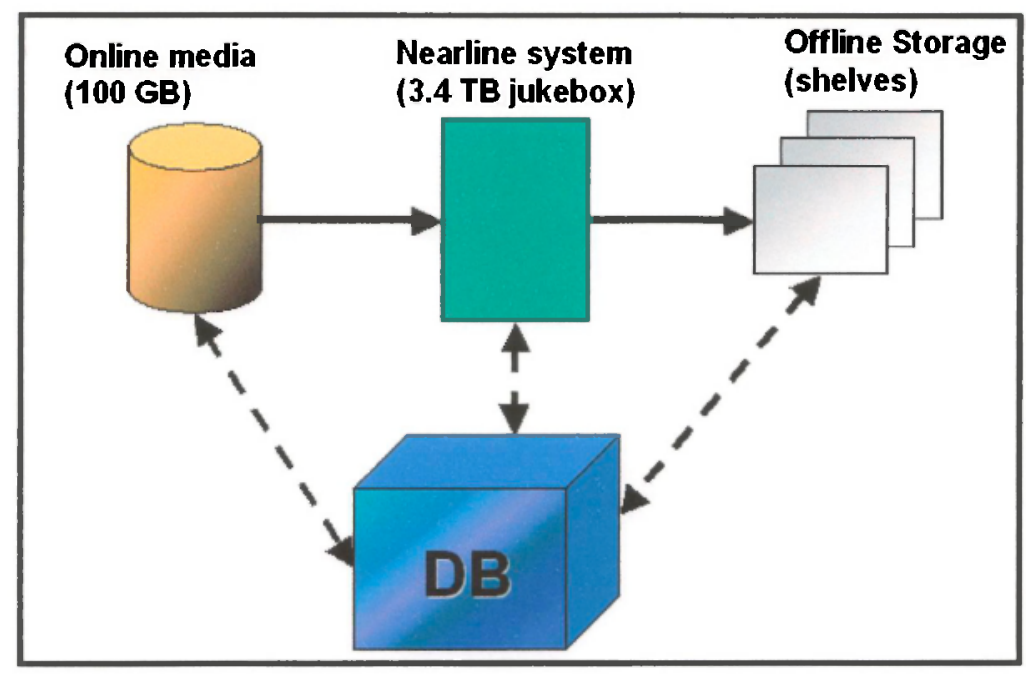

Figura 2.3: Armazenamento de um PACS combinando arquivamento online, nearline e offline através de um gerenciador de base de dados.

\subsection{Exibição de Imagens}

O sistema de exibição de imagens, ou a estação de trabalho, é o componente do PACS que tem recebido mais atenção. De fato, para a maioria dos usuários, é o único componente do PACS que eles irão interagir diretamente.

A estação de trabalho de imagens deve ser capaz de consultar as imagens e obtê-las rápida e facilmente, e permitir uma navegação rápida e intuitiva na base de dados, para permitir a obtenção e comparação de históricos relevantes ou exames relacionados. Os monitores de 
exibição devem ter uma resolução de pelo menos 2000 por 1500 pixels para uso no diagnóstico do radiografias gerais e uma área de exibição comparável em tamanho a filmes convencionais de 14" por 17". O padrão de teleradiologia do American College of Radiology (ACR) sugere que as radiografias convencionais scjam visualizadas usando uma resolução de pelo menos $2 \mathrm{k}$ pixels [Siegel and Kolodner, 1999]. Uma outra sugestão é o uso de uma configuração de 201 4 monitores. Quanto ao software de cxibição e manipulação das imagens, deve ser intuitivo e de fácil uso e aprendizado [Siegel and Kolodner, 1999].

A navegação das imagens, ou a habilidade de recuperar e exibir imagens com a intenção de comparar exames atuais ou parecidos, tem sido relativamente desapontadora na maioria dos sistemas PACS, embora isso tenha melhorado consideravelmente durante os últimos 2 anos [Siegel and Kolodner, 1999]. Atualmente muitos passos são necessários para obter estudos antigos para comparação com os exames atuais, além de que muitos sistemas não suportam facilmente nem habilmente a comparação entre subníveis, tais como seqüências individuais de imagens MRI com imagens de outros exames [Siegel and Kolodner, 1999]

A tendência futura é a existencia de um contínuo aumento na velocidade de gráficos e na atuação global das estaçoes de trabalho utilizadas para a exibição das imagens, permitindo assim uma manipulação mais rápida das imagens, e no uso de computadores pessoais como estaçócs de trabalho, executando sistemas como o Windows NT [Siegel and Kolodner, 1999].

\subsection{Rede PACS}

As redes PACS podem ser vistas como uma estrada que tem sido construida para carregar imagens das modalidades de aquisição para os PACS, e dos PACS para as estaçoos de trabalho, sendo a porta de comunicação do HIS/RIS e o arquivo de imagens. As redes podem ser projotadas utilizando-se ou uma arquitetura central ou distribuída [Siegel and Kolodner, 1999].

Em um PACS com uma arquitctura central, as imagens estão disponiveis utilizando dispositivos compartilhados de armazenamento de um curto período (tipicamente un RAID, ou 1 m vetor de discos baratos). A vantagem dessa arquitetura é que todas as imagens de um período curto de armazenamento estão disponíveis $\mathrm{cm}$ todas as estaçöes de trabalho tipicamente com uma taxa de recuperação muito rápida. A desvantagem é a vulnerabilidade dessa configuraçāo [Siegel and Kolodnor, 1999].

Uma alternativa é um PACS com una arquitetura distribuída, na qual as imagens est.ão armazenadas em múltiplos servidores distribuídos en todo o ambiente hospitalar. $\Lambda$ 
maior desvantagem ó a necessidade do enviar as imagens automaticannente on manualmonte para os servidores individuais ou estações de trabalho, para obter uma atuação aceitável [Sicgel and Kolodner, 1999].

As redes PACS devem ser capazos de suportar vários usuários simultaneamente, sem urna. dogradaça significativa da redo. Devem também proporcionar um alto nível de segurança para garantir que somente usuários autorizados tenham acesso as informações dos pacientes. Uma das limitações con relação à atuação da rede é a infra-estrutura limitada dos hospit,ais, que têm sido tradicionalmente projetados para textos e números, e não para imagens [Sicgel and Kolodner, 1999].

A implantação do uma rede PACS completa é um projeto bastante caro c complexo, sendo necessário o descnvolvimento de um planejamento bem organizado e inteligente para sua exccução, principalnnente devido à necessidade do ajuste das estruturas de rede de computadores geralmente inadequadas [Marques et al., 2000].

\subsection{Serviço de Radiologia Digital (filmless) cm Hospital Universitário}

O Centro de Ciencias das Imagens o Física Médica (CCIFM) da Faculdade de Medicina do Ribcirão Preto (PMRP/USP) vem trabalhando no sentido de iniciar o processo de transiçũo do Serviço de Radiodiagnóstico do Hospital das Clínicas da Faculdade de Medicina do Ribeirão Preto para a radiologia filmless. Esse processo tem envolvido [Marques et al., 2000j [Marques et al., 2000]:

- conexão de equipamentos em rede (tais como Tomografia Computadorizada- CT e Ressoniancia Magnética Nuclear - RMN);

- armazenamento de imagens em incio cletrônico (CD-ROM) para posterior disponibilização;

- desenvolvimento e implantação de um Sistema de Informação em Radiologia (RIS), sobre o qual será desenvolvido este trabalho.

O) departamento de radiologia do Hospital das Clínicas conta atualmonte com os seguintes aparelhos DICOM compativeis: 1 equipamento de Tomogratia Computadorizada (CT), 1 de Ressonância Magnética Nuclèar (RM) e 2 de ultra-som, conectados em rede, e gerenciados pelo sistema Magic View 300 da Siemens, que permite que um computador do tipo PC (com 
sistema operacional Windows NT) funcione como um console auxiliar podendo manipular, arquivar e gravar em CD-ROM e disponibilizar imagens através do servidor. Os exames são gravados diariamente em CDs, que ficam guardados para consultas posteriores. Possui também um disk-array Data Force de 50Gbytes, o que possibilita disponibilizar imagens para consultas correspondentes a um período aproximado de 2 meses, porém está em fase de testes, e as imagens têm que ser recuperadas diretamente dos CDs.

Além disso está sendo configurado um servidor RSNA (Radiological Society of North America) que será utilizado como o servidor DICOM para os testes do PACS, utilizando a interface de visualização de imagens cujo desenvolvimento está descrito em [Caritá, 2002].

\subsection{Sistema de Informação em Radiologia (RIS) do Hospital das Clínicas - HCFMRP}

O RIS do HCFMRP, também denominado Sistema de Laudo Eletrônico (Figura 2.4), foi desenvolvido e implantado em parceria entre o Centro de Ciências das Imagens e Física Médica (CCIFM) da Faculdade de Medicina de Ribeirão Preto (FMRP/USP) e o Centro de Informações e Análises do Hospital das Clínicas da Faculdade de Medicina de Ribeirão Preto (HCFMRP), e está em uso desde 1999 [Marques et al., 2000].

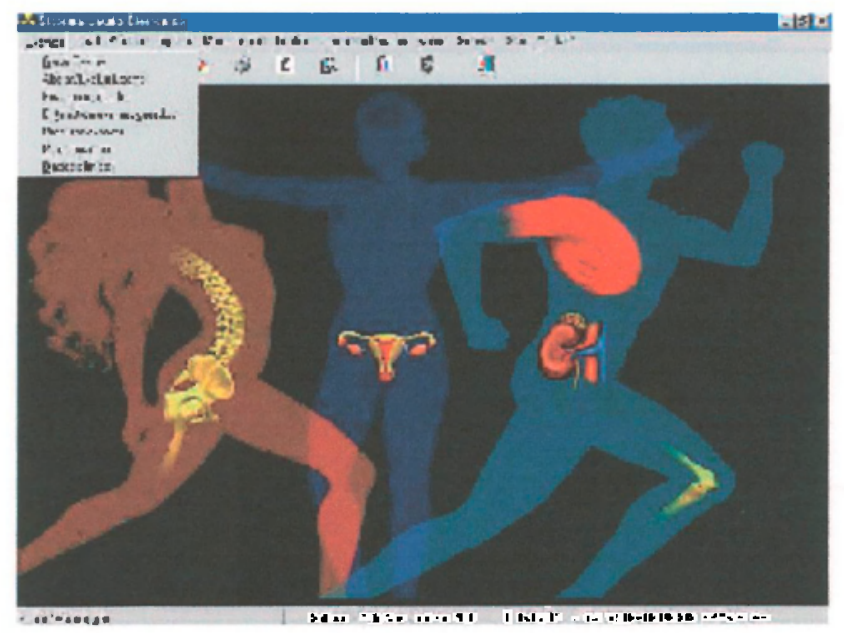

Figura 2.4: Tela principal do Sistema RIS do HCFMRP.

O sistema foi desenvolvido com a finalidade de otimização no processo de disponibilização e consulta de laudo através da rede ethernet do hospital, uma vez que existia um tempo de espera de três a quatro dias para a disponibilização dos laudos no Serviço de Arquivo 
Médico (SAM). Esse tempo era necessário, pois os laudos eram emitidos de forma manual em um formulário que acompanhava o pedido de exame, sendo conferidos posteriormente pelo especialista, encaminhados para digitação, impressos, corrigidos, re-impressos, assinados e finalmente encaminhados ao SAM, conforme esquematizado na Figura 2.5. Existia uma procura bastante alta no Setor de Radiodiagnóstico por laudos ainda não disponíveis no SAM. Com a implantação do RIS esse tempo de espera foi bastante minimizado, uma vez que, assim que os exames são laudados, eles já se encontram disponíveis para consultas online além de que o mesmo passa a ser impresso diretamente no SAM, utilizando assinatura eletrônica, agilizando assim o processo de distribuição destes junto aos prontuários dos pacientes [Marques et al., 2000].

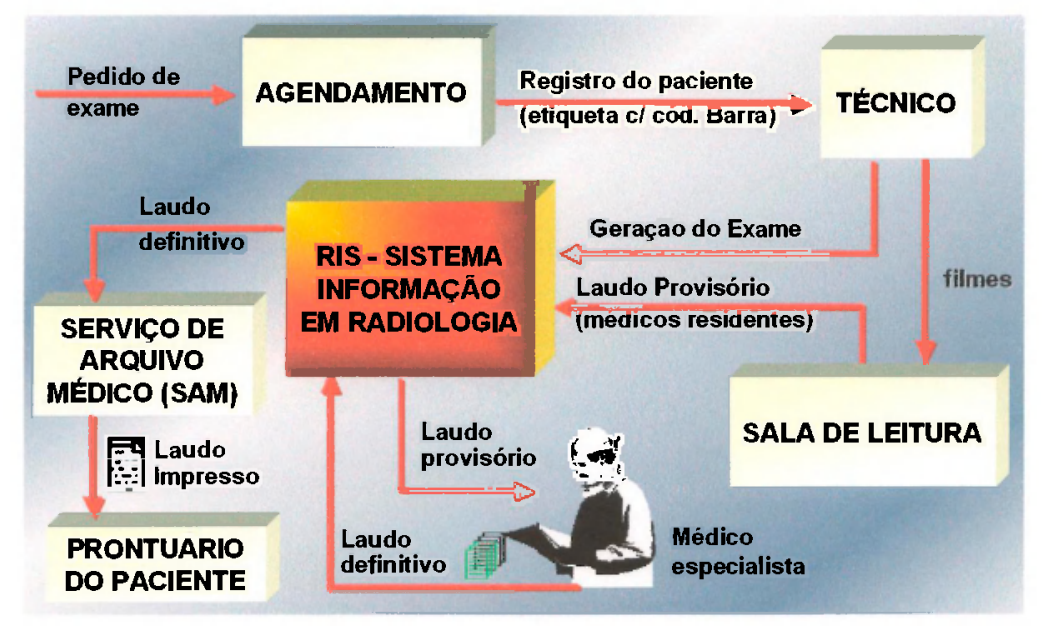

Figura 2.5: Esquema do processo global do RIS ilustrando o fluxo de um exame radiológico [Rosa, 2002].

O núcleo do sistema é o exame, ao qual estão associados um número de identificação e outras informações referentes ao paciente, tipo de exame e região anatômica, sala e aparelho de sua realização, técnica utilizada, quantidade de exposições realizadas, quantidade de filmes utilizados, quantidade de filmes rejeitados e o motivo de rejeição, laudos e médicos responsáveis pelos laudos (residente e supervisor). O programa permite a emissão de relatórios de produtividade e técnicos, facilitando o gerenciamento e controle da qualidade do serviço. O RIS trabalha sobre uma plataforma de base de dados ORACLE, com interface ao usuário feita em DELPHI, permitindo consulta online de laudos através de microcomputadores conectados à rede ethernet do Hospital [Marques et al., 2000].

O processo global do sistema pode ser descrito conforme a Figura 2.5, e inicia-se com a solicitação de um exame para um paciente junto ao serviço de agendamento do hospital. 
É gerado então uma etiç1reta contendo um código de barras com o número de registro $\mathrm{HC}$ do paciente e a clínica solicitante, que o técnico irá utilizar, no momento da realização do cxame, para gerar eletronicamente o exame no sistema através da leitura desse código de barras e da inserção manual de informaçōes referentes ao tipo de exame, região anatômica, técnica cmpregada, sala de realização, reveladora utilizada, tipo c quantidade de filmes expostos, se houve rejeições e o motivo. Após a realização do exame e sua geração eletrônica no sistema, os filmes são encaminhados para uma sala de leitura para serem avaliados e laudados, inicialmente como provisórios pelos médicos residentes, e posteriormente conferidos e corrigidos, se necessário, pelos módicos especialistas e então gravados como definitivos. Os laudos definitivos são impressos diretamentc no Serviço de Arquivo Médico (SAM) para serem incluídos no prontuário do paciente. Os laudos gerados podem ser consultados on-line, através de qualquer computador disponível no hospital, sem a possibilidade de alteração dos laudos. Essa consulta, feita através do fornecimento do registro do paciente ou nome, exibe uma lista com todos os exames do paciente, suas condições (não laudados, laudados provisórios ou definitivos), bastando então selecionar o exame de interesse para acessar seu laudo. Pode-se também fazer uma busca por patologia, cuja pesquisa será feita pesquisando palavras chaves presentes nas descriçôes dos laudos de exames realizados dentro de um período estabelecido pelo usuário [Marques et al., 2000].

De modo geral, pode-se dividir o RIS em quatro módulos principais [Marques et al., 2000]:

Módulo de Exames: módulo que permite gerar, alterar, excluir ou mesmo consultar exames realizados.

Módulo de Geração de Laudos: gera laudos provisórios e definitivos para os exames gerados no sistcma.

Módulo de Consultas de Laudos: permite consultas à lista do exames e respectivos laudos dos pacientes (busca por registro ou nome do paciente fornecido) além de consultar por patologias todos os laudos que contenham em sua descrição palavras-chave fornecidas.

Módulo de Gerenciamento: permite a crnissão de relatórios técnicos (consumo de filmes, rrjeição de filmes e suas causas, rejeição por reveladora, por sala ou por equipamento, e outros), administrativos (número total de exames realizados, exames por modalidade. por técnicos, exames laudados por médico, laudos atrasados, e assim por diante) 
A segurança do sistema é garantida através do acesso restrito a cada módulo do sistema de acordo com os direitos atribuídos a cada um dos usuários cadastrados. Cada usuário possui direitos específicos, de acordo com sua função dentro do fluxo de atividades do serviço e, para ter acesso ao sistema, o usuário necessita informar seu nome de usuário e sua senha. Toda operaçăo realizada pelo sisterna fica armazenada em conjunto com o código do usuário solicitante.

O Sistema de Laudo Eletrônico contém atualmente somente informações textuais, porém en [Caritá and Marques, 2000] [Caritá, 2002] foi desenvolvido um projcto piloto para vinculação, recuperação e visualização das imagens dos exames de Ressonância Magnética e Tomografia Computadorizada do HCFMRP/USP. O processo de vinculação das imagens consistiu em extrair as informaçōes dos exames, necessárias para relacionar as imagens com os exames do RIS, contidas nas "tags" dos arquivos DICOM das imagens, e inserí-las automaticamente na base de dados responsável pelo gerenciamento das imagens. Na base de dados as imagens são armazenadas no formato DICOM original [Rosa, 2002].

Uma das grandes contribuições do trabalho de vinculação das imagens com os exames radiológicos do RIS foi a utilização de uma tag do DICOM para armazenar a chave do exanne no RIS. Com isso, adotou-se um padrão para a realização dos exames e aquisiçāo das imagens: os técnicos entram com as informações do exame no RIS, que irá gerar um número único de identificação do exame. Esse número é entăo inscrido manualmente junto com as demais informaçoes do paciente nas tags dos arquivos DICOM das imagens. Sendo assim, as novas imagens adquiridas contêm em seu interior, o número do exame que permite vinculá-las ao RIS [Rosa, 2002]

Foi a partir do RIS e da utilização do novo protocolo para a realização dos exames, além da conscientização dos lécnicos e médicos da importância de preencher corretamente as informaçoss do paciente, principalmente a chave do exame (RGIIC), que o SRIS-HCl foi deservolvido originalmente.

\subsection{Conclusão}

Os atuais PACS do larga escala estão comcçando a se bencficiar do tremendo avanço nas tecnologias de rede e computadores. A radiologia scm filme proporciona uma alteração radical no modo comı o diagnóstico cm radiologia é praticado, o que resultará em uma completa renodelagem das salas de leitura dos radiologistas e a localização das áreas de

${ }^{1}$ Sistema de Rccuperação de Imagens por Sinilaridade do Hospital das Clínicas. 
leitura dos radiologistas no hospital e em todas as empresas de saúde.

No futuro os PACS se tornarão diretamente integrados com as empresas de tratamento de saúde, resultando na disponibilidade dos registros médicos eletrônicos dos pacientess bem como uma vasta biblioteca de imagens e texto. Haverá acesso instantâneo a qualquer imagem do sistema de saúde a qualquer momento, com uma melhor segurança das imagens e uma qualidade mais alta e mais imagens de diagnósticos, e uma nova geração de ferramentas para os radiologistas. Essas ferramentas irão permitir aos radiologistas molhorar a qualidade das imagens existentes e combinar múltiplas imagens de uma ou mais modalidades cm uma única imagem ou est udo para melhorar a exatidão do diagnóstico. Finalmente, um novo conjunto de características de suporte a decisão estarão disponíveis no futuro, que usará informaçoes clínicas do registro eletrônico médico cm conjunto com as imagens da base de dados dos radiologistas e irá combiná-las com as informaçôes clínicas e imagens associadas com um novo estudo para ajudar a encontrar ou mesmo sugerir o diagnóstico.

Uma vez que as imagens médicas ainda não estão integradas ao Sistema de Informação em Radiologia - RIS, e nem intermodalidades, as soluçôes isoladas adotadas pelo Hospital das Clínicas da Faculdade de Medicina de Ribeirão Preto não caracterizam um PACS completo, mas sim um resulıado inicial de um projeto de pesquisa que visa a implantação de um serviço de radiologia sem filnue junto ao hospital. 


\section{Extração de Características de Imagens}

\subsection{Considerações Iniciais}

A extração de características utilizando histogramas é o ponto central deste trabalho. Com o processamento de histogramas, será gerado um espaço baseado nos vetores de características (feature vectors), a serem utilizados para indexação e recuperação de imagens.

Um vetor de características ć uma representação numćrica suscinta do uma imagem ou parte da innagem (um objeto) representando medições sobre scus aspectos representativos. O vetor de características é um vetor $n$-dimensional que contém essas medidas. Essa nova representação da imagem pode ser armazenada em uma base de dados e assim permitir uma recuperação rápida da imagem. O objetivo central destec capítulo é: Darla uma imagem, ou uma regiäo dentro da imagem, gerar as características que representem esta imagcm, as quais seräo organizadas numa estrutura de indexaçáo métrica, para o qual tem-se que considerar os seguintes aspectos do processo [Loew, 2000]:

- Reduzir a dimensionalidade dos dados.

- Rcssaltar propriedades da imagem para facilitar a percepção humana.

- Tratar os aspectos de invariâncida às transformaçöes da imagerr. 
Neste Capítulo será descrito o funcionamento dos extratores de caracteristicas. Será dada una introdução sobre as características de imagens e seus principais atributos, scguida das consultas por similaridade e a classificação das estruturas métricas.

\subsection{Definindo uma Imagem}

As imagens são representadas como conjuntos de elementos (pixel) que são colocados cm uma grade regular. Os valores associados a cada pixel são aqueles obtidos do processo de quantizaçăo e correspondem ao valor de intensidade (brilho), no caso de inagens monocromáticas. Assim, formalmente, uma imagem pode ser definida da seguinte forma:

Definição 3.1 - Uma imagem $A$ é uma funçäo definida sobre uma faixa bidimensional $C=\left[0, x_{0}\right] \times\left[0, y_{0}\right]$ tomando valores no conjunto de possiveis luminosidades $V=\left[0, v_{11}\right]$. Isto ¿. $A=\{(x, y: v(x, y)) /(x, y) \in G$ ev $\in V\}$.

Um histograma de imagem é composto por um número de bins que depende da resolução de quantização da imagem. Geralmente este valor é dado em potência de 2, isto é: 64, 128, 256, etc. De qualquer forma, para o olho humano, é difícil enxorgar os detalhes e diferenças nas intensidades e, na prática, $v_{0}=32$ ou 16 é suficiente para representar as imagens [Theodoridis and Koutroumbas, 1999]. Fm imagens médicas, dentro de um mesmo domínio, usualmente este valor é fixo. Formalmente, um histograma pode ser explicitado através da seguinte definição:

Definição 3.2 - O histograma normalizado $H N_{A}(z)$ de uma imagem A fornece a freqüência de cada valor de intensidade $z$ na imagem, a qual é dada em porcentagem. O histograma normalizado de uma imagem com l níveis de intensidade é lambém representado por um vetor com $t$ elemcntos.

Deve-se observar que o histograma normalizado é invariante em relação às transformaçõos geométricas (escala, rotação e translação). Seria interessante conseguir um histograma que fosse tambem invariante em relação às transformaçès lineares do brilho. A Figura 3.1 apresenta urna imagem de tomografia de cabeça humana e o histograma normalizado dessa imagem. Os histogramas normalizados permitem comparaçós entre imagens de qualquer tamanho, assimn, transformacòes geométricas realizadas sobre as imagens fontes fornecerão os mesmos histogramas. 


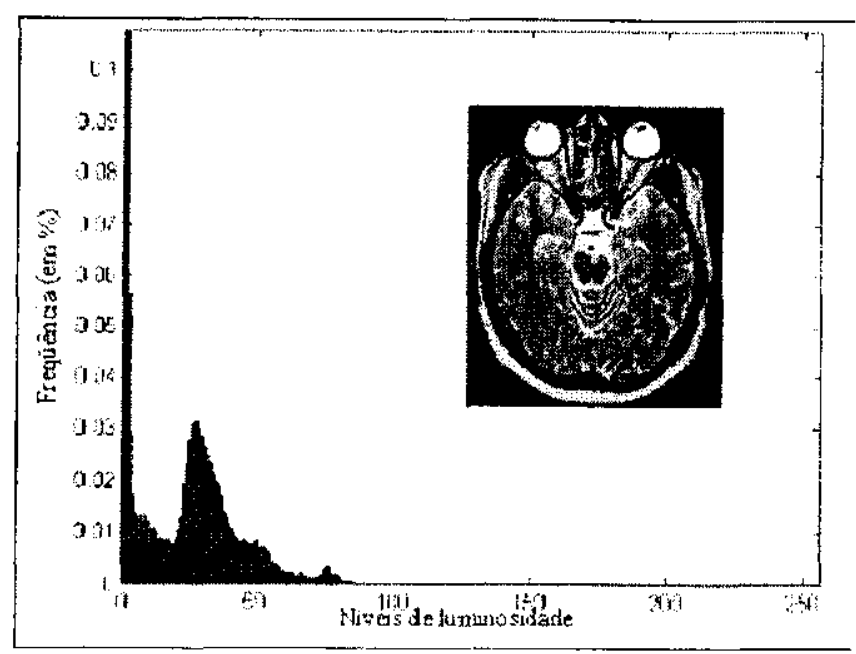

Fignura 3.1: Uma imagem e seu histograma normalizado.

A necessidade de gerar vetores de características se faz necessária pela dificuldade de poder trabalhar com o total de informação da imagem, que são dados muito grandes. Por exemplo, para uma imagem de dimensão $64 \times 64$, o número de pixels ć de 1096. Pura o caso de sistemas de recuperação de innagens baseado em conteúdo, este número é muito alto, alćm disso a comparação pixel a pixel, em muitos casos, não ć significativa. Então a geração do vetor de características é um processo que calcula novas variáveis a partir da imagem original $A(m, n)$. Este processo procura gerar características que tragam informações a respeito da imagem (ou objetos da imagem).

\subsection{Atributos das Imagens}

Muitos dos sistemas de recuperação de imagens utilizan a forma, textura e cor para representar uma imagem[Stehling et al., 2000], [Krishnamachari and Abdel-Mottaleb, 1998] [Chua et al., 1997]. Sua recupcração está bascada na similaridade das características derivadlas delas. Embora a cor seja un atributo confiável na recuperação de imagens, situações onde a informação de cor não as discrimina bem requerem o uso do atributos de forma e/ou textura para a recuperaçĩo de imagens. Além disso, os sistemas baseados num único atributo da imagem podem não alcançar níveis de recuperação adequados, motivo pelo qual os sist.emas procuram utilizar múltiplos atributos das imagens para a sua indexação e recuperação Vailaya, 2000] 


\subsubsection{Cor}

As cores presentes em uma inagem possuem um papel significativo na sua indexação e recuperação. Fxistem diferentes representações de cores que incluem desde o tradicional RGB (red, green, blue), o modelo mais simples que mapeia diretamente as características físicas do dispositivo de exibição, até o HSI (hue, saturation, intensity) que reflete mais precisamente o modelo de cores para a percepção humana.

Muitos trabalhos recentes de extração de características baseadas em distribuição de cores estão concentrados nos histogramas de cor ${ }^{1}$. Alguns dos trabalhos da literatura incluíram a indexação de cor usando intersecção de histogramas [Swain and Ballard, 1991] [Moghaddam et al., 2000], assinaturas [Chla et al., 1997] [Rubner and Tomasi, 2000] e o trabalho recente de [Bueno, 2002] produz uma função linear por partes baseada em histogramas, que foi nomeada de Histogramas Mótricos, sendo utilizados na recuperação de imagens similares. Os histogramas de cor são invariantes à translação e rotação das imagens, sendo que, com a normalização dos histogramas, obtém-se também a invariância à escala. De qualquer forma, os histogramas de cor não indicam a localização espacial dos pixels na imagem, podendo trazer incoerência entre scmelhança de imagens, como visto na Figura 3.2. Outras abordagens como a recuperação baseada em distribuição espacial de cores [Yamamoto et al., 1999] [Moghaddam et al., 2000] eliminam esse tipo de incoerência, mas aumentam o custo computacional por utilizarem diversos histogramas em suas consultas.

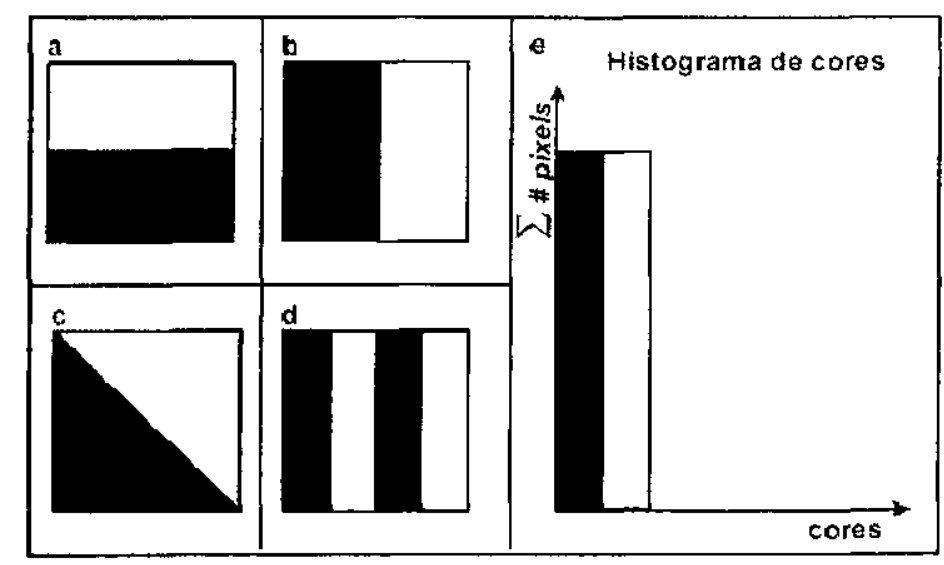

Figura 3.2: Exemplos de imagens diferentes $(a, b, c$ e $d)$ que possuem o mesmo histograma de cores $(c)$.

Esta abordagem apresenta algumas dificuldades pelo próprio (aráter não invariante do

'Para imagens monocromáticas, histogramas de cor são correspondentes aos histogramas de brilho ou intensidades. 
histograma de cores. Além disso, se a imagem contém um número alto de cores, então o vetor de características será maior e a indexação de vetores com tal dimensão se torna problemática.

\subsubsection{Textura}

Não existe uma definição clara de textura, mas os autores concorlam em defini-la como as mudanças na intensidade da imagem que formam determinados padrões repetitivos [Tuceryan and Jain, 1993]. Uma textura é um padrão visual onde há um grande número de elementos visíveis arranjados de forma cquânime com densidades variadas. Um elemento de textura é uma região de intensidade uniforme do formas simples que se repete dentro de um intervalo, como exemlificado na Figura 3.3. Assim, uma textura pode ser analisada dentro de um intervalo (janela), denominada "análise estatística". Se o procedimento for realizado no elemento da textura, é então denominado "análise estrutural". Geralmente, utiliza-se a análise estrutural sempre que os elementos da textura possam ser claramente identificados. Por outro lado, aplica-se a análise estatística para texturas pequenas e não muito regulares.

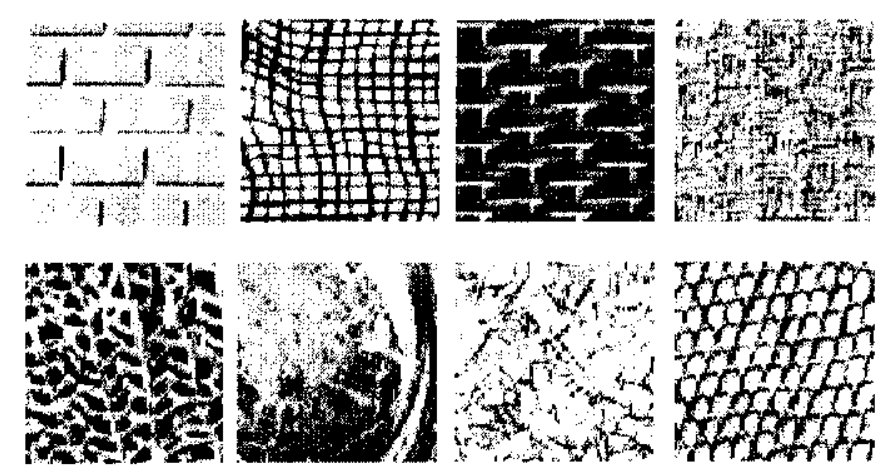

Figura 3.3: Exemplo de texturas.

Medidas estatísticas buscam caracterizar a variação de intensidade em una janela de textura. Exemplos de tais medidas são contraste (alto contraste: textura de pele de zebra, versus baixo contraste, textura da pele de um elefante); granularidade (tiamanho dos elementos do padrão) e direcionalidade (cstampa de padrão de xadrez em um tecido versus um padrão liso). Uma ferramenta para a manipulação de padrões estatísticos é o espectro de Fourier. Através da transformada de Fourier realizada sobre uma janela de textura gera-se uma assinatura. Janelas que possuam assinaturas próximas ou bastante similares podem. então, ser agrupadas. 
A análise estrutural de texturas obtém os elementos de textura presentes na imagem, determinando seus formatos e estimando as regras de posicionamento. As regras de posicionamento descrevern como os clcmentos de textura são colocados com relação aos demais, além de estabelecer o relacionanento de vizinhança (conexidade), o número de elementos por unidade espacial (densidade) o sla regularidade (homogeneidade).

Estas características servem como medida para a diferenciação de texturas que não seguem um determinado padrão de repetitividade, fornecendo informações relevantes para a classificação.

O tratamento de textura difere do realizado sobre cores devido an fato de que as texturas são definidas sobre janelas on regiōes da imagem e não sobre pixels, como as cores. A segmontação de uma imagem utilizando textura determina quais regiões possuem textura uniforme. Depois que as regiões são detcrminadas, os retângulos que as envolvem (Minimum Bounded Box $-M B B)$ podem ser utilizados para construir uma estrutura de indexação tipo R-Trec [Guttman, 1981].

Em [Haralick et al., 1973] é descrita uma metodologia de classificação de imagens a partir do uso da abordagem estatística de segunda ordem, onde são definidas diversas características advindas do cáleulo de matrizes de co-ocomencia, que são matrizes que contam as ocorrências de níveis de cinza em uma imagem. Essas matrizes são utilizadas para detectar uniformidade cm imagens, classificando cssas texturas. A utilização de texturas pode ser muito útil cm sistemas hospitalares na deteç̧ão de tumores ou no diagnóstico através de imagens [Chan and McCarty, 1990]. Além disso, a textura é muito utilizada para realizar a segmentação de imagens médicas, como descrito em [Claude et al., 2001].

\subsubsection{Forma}

A recuperação de imagens baseada em forma é um dos problemas mais difíceis de serem tratados pelos sistemas de recuperação de imagens bascadia em conteúdo. Isto se deve, principalmente, à dificuldade de segmentar automaticamente os objetos de interesse presentes na imagem, levando a recuperação por formas ser tipicamente limitada aos poucos objctos melhor discriminados que estão presentes na mesma.

A imagem a ser indexada deve ser pré-processada para possibilitar a busca e a determinaçio das bordas que estão nela presentes. Os filtros ou algoritmos de pré-processamento dependem do domínio da aplicação das imagens em questão. Objetos tajs como tumores cerebrais e lesões de pele demandam um conjunto específico de algoritmos que são difercntes dos utilizados para localizar objetos como aviōes, carros etc. Isto porque o primeiro domí- 
nio de imagens não pode se valer de formas pré-definidas que possam auxiliar no processo de reconhecimento de informações morfológicas presentes na imagem. Por outro lado no segundo domínio, as imagens possuem formas baseadas em geometria, podendo-se valer da utilizaçäo de modelos descritos antecipadamente. O tratamento de imagens mais complexas demanda muitas vezes também o tratamento e remoção de ruídos em uma ctapa de pré-processamento. A Figura 3.4 exemplifica a detecção de formas, onde são esperados a detecção do fígado, da espinha dorsal e do corpo. Qualquer objeto detectado dentro do contorno do fígado é considerado um tumor[Petrakis and Faloutsos, 1997].

Após o objeto scr encontrado, sua borda precisa ser detectada utilizando algoritmos de detecção de contorno. O processo de detccção de bordas e formas fica mais difícil e comprometido em cenas complexas onde há, além do ruído, oclusão parcial de objetos ou sombras sobre regiões das imagens.

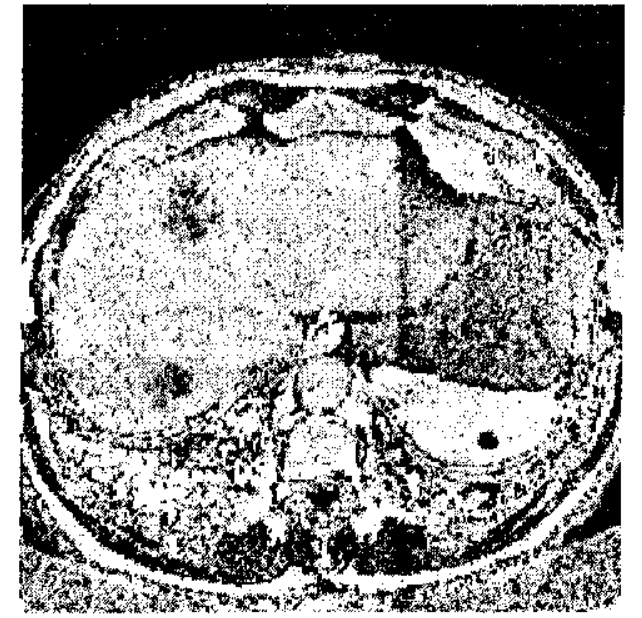

a)

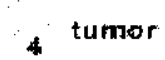

\section{figado}

tumor

contorno

0

Figura 3.4: Exemplo de uma imagem original em tons de cinza $(a)$ e sua forma segmentada mostrando 4 objetos identificados (b) (Petrakis and Faloutsos, 1997).

Os atributos de forma dos objetos presentes na imagem são também representados através de vetores reais embora aqui cada vetor possa ter uma dimensão ${ }^{2}$. Nesse caso, um conjunto de vetores rrão tem uma dimensão característica apesar de poderem ser vistos como elementos de um espaço métrico e serem indexados dessisa forma. Outra técnica ć a de aproximar as formas encontradas por outras mais simples e fáceis de manusear. Por exemplo, a triangulação on aproximação por retângulos de contorno (bounding boxes) podem ser utilizada para representar formas irregulares. Além disso, tem-se a vantagem de que os requisitos de

${ }^{2}$ espaços dimensionais serão tratados no Capítulo 4 
armazenagem são menores e a comparação fica mais simples, melhorando scu processanento.

\subsubsection{Resumo das características de baixo nível das imagens}

Na Tabela 3.1 são brevemente descritos os tipos de características de baixo nível da imagem que têm sido amplamentê usadas na recuperação de imagens bascadas no conteúdo, considerando suas vantigens e limitaçôs. Em termos de cor, a característica mais utilizada sāo os histogramas [Swain and Ballard, 1991] [Bueno, 2002], momentos [Stricker and Dimai, 1996] c vetores de cocrencia de cor [Pass et al., 1996]. Essas características descrevem as propriedades globais de uma imagem e podem ser facilmente extraídas. Uma grande limitação é a sua impossibilidade de representar adequadamente a informação de localização espacial ou de objetos na imagem. As características de forma suplantann essa deficiência o descrevem melhor os objetos da imagen. Pode-se descrever a forma e as características de contorno do objetos basicamente de três maneiras: por aproximação polinomial, por momentos invariantes e por descritores de Fourier. As características de forma outorgam um alto nível de abstração em termos do formato dos objetos numa inagem, mas isso requer o uso do bons algoritmos de segmentação para extrair objetos de interesse de uma imagem. As características de textura outorgam um nível intermediário de abstração numa imagem, assim como as características da cor. Ambas podem ser extraídas automaticamente de uma imagem, apesar da extração de textura ter major complexidade computacional [Vailaya, 2000].

\subsection{Importância da Extração de Características}

$\Lambda$ extrayàno de características é o núcleo para a recuperação de imagens baseada em conteúdo. Estas características podem ser textuais (palavras chaves, anotaçōes, etc.) e visuais (cor, textura, forma, faces, etc.). As características visuais podem ser gerais (cor, textura, forma) ou específicas para domínios (faces humanas, impressões digitais). Essas últimas podem abranger uma grande quanticlade de conhecimento a respeito do domínio objetivado.

Considerando faces humanas como exemplo, as características mais utilizadas são as medidas de distância entre os principais componentes da face, tais como: separação entre centros e bordas dos olhos, boca, olhos, queixo e nariz.

A importância do processo de extração de características de imagens deve-se ao fato de que clas sintetizam propriedades inerentes da imagem, que scrão utilizadas no processo de indexação e recuperação do conjunto de inagens [Traina, 2001]. 


\begin{tabular}{|c|c|c|c|}
\hline $\begin{array}{l}\text { Atributo } \\
\text { da Ima- } \\
\text { gem }\end{array}$ & $\begin{array}{l}\text { Características } \\
\text { da Imagem }\end{array}$ & Vantagens & Limitações \\
\hline Cor & $\begin{array}{l}\text { Histogramas, } \\
\text { Momentos e } \\
\text { vetores de coc- } \\
\text { rência. }\end{array}$ & $\begin{array}{l}\text { Podem ser extraídos anito- } \\
\text { maticamente. Computa- } \\
\text { cionalmente baratos. Re- } \\
\text { presentam as propricdades } \\
\text { globais da imagem. }\end{array}$ & $\begin{array}{l}\text { Nã̃o têm possibilidade de } \\
\text { representar informaçóes } \\
\text { de localização espacial. } \\
\text { Descrição limitada da } \\
\text { semântica da imagem. }\end{array}$ \\
\hline Textura & $\begin{array}{l}\text { Matrizes de } \\
\text { co-ocorrencia, } \\
\text { características } \\
\text { de multi-escala e } \\
\text { características de } \\
\text { filtros de Gabor. }\end{array}$ & $\begin{array}{l}\text { Podem ser automatica- } \\
\text { mente extraídos da ima- } \\
\text { gen. Outorgam informa- } \\
\text { ção global assim como lo- } \\
\text { cal. }\end{array}$ & $\begin{array}{l}\text { Podem scr computacional- } \\
\text { mente caros (extração e } \\
\text { casamento de característi- } \\
\text { cas) e difíceis de definir. } \\
\text { Descrição limitada da sc- } \\
\text { mântica da imagem. }\end{array}$ \\
\hline Forma & $\begin{array}{l}\text { Aproximação po- } \\
\text { ligonal, momen- } \\
\text { tos invariantes } \\
\text { e descritores de } \\
\text { Fourier. }\end{array}$ & $\begin{array}{l}\text { Consegue obter um alto } \\
\text { nível de abstração em ter- } \\
\text { mos de forma dos objetos } \\
\text { locais. Permitem consul- } \\
\text { tas en nívol de objetos. }\end{array}$ & $\begin{array}{l}\text { Não podem ser automa- } \\
\text { ticamente extraídos (pro- } \\
\text { cisam de bons algoritmos } \\
\text { de segmentação para ex- } \\
\text { trair os objetos de inte- } \\
\text { resse). Computacional- } \\
\text { mente caros para lograr } \\
\text { invariância às mudanças } \\
\text { do objeto rígido. }\end{array}$ \\
\hline
\end{tabular}

Tabela 3.1: Atributos de qualidade das características de baixo nível da imagem [Vailaya, 2000].

O processo de extraçāo de características de imagens é apresentado na literatura da área de processimento de imagens como um dos passos para se efetuar o roconhecimento de padrōes existentes em imagens [Theodoridis and Kontroumbas, 1999], [Gonzalez and Woods, 1993] e [Russ, 1995]. O reconhecimento de padrões assume que a imagem pode conter um ou mais objetos e que cada objeto pertence a um tipo (de um conjunto previamente definido de muitos tipos) e a uma ou mais categorias ou classes do padrões pré-detcrminados. Segundo Castleman [Castleman, 1996], dada uma imagem contendo vários objetos, o processo de reconhecimento de padrões consiste basicamente de três fases, excmplificadas na Figura 3.5:

- Segmentação de imagem: na qual cada objeto contido na imagem é localizado e isolado do resto da cena.

- Extração de características: quando são calculados valores que descrevam algumia 


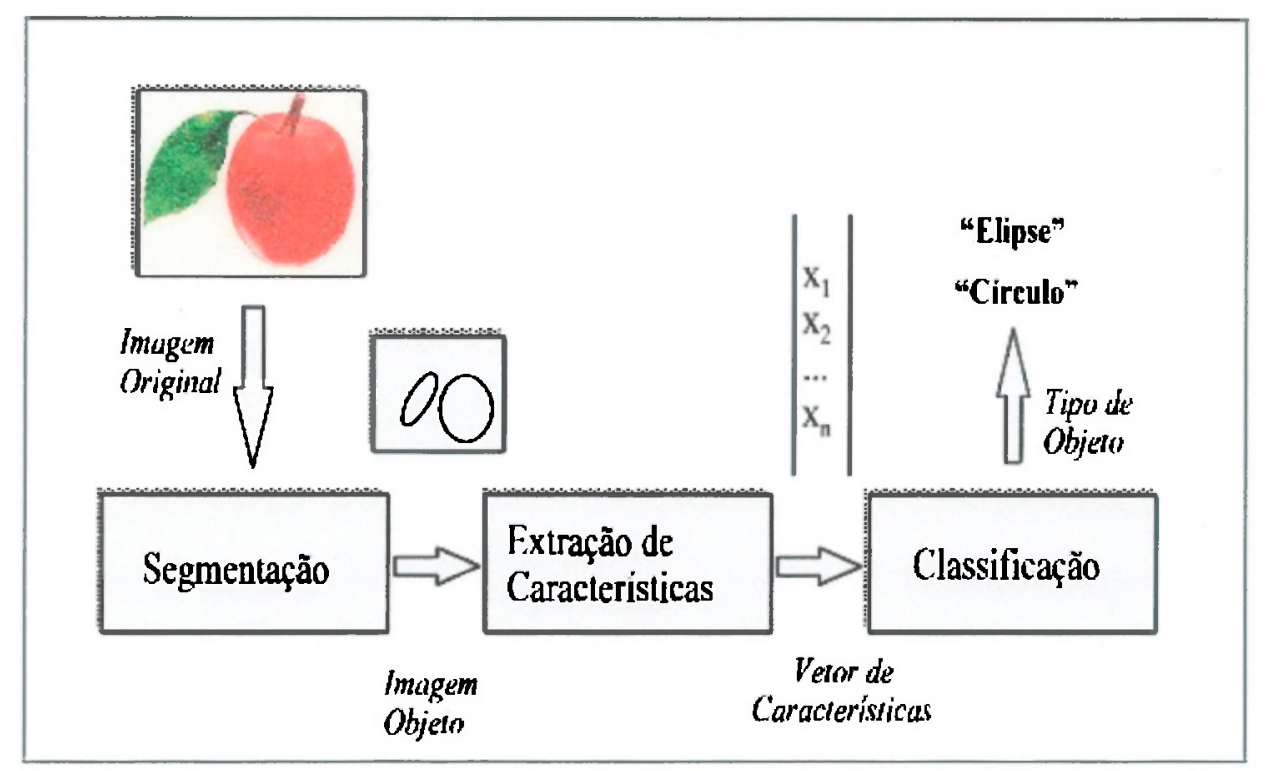

Figura 3.5: Etapas de reconhecimento de padrões de imagens.

propriedade quantitativa ou qualitativa dos objetos. Uma característica é uma função de uma ou mais medidas, calculadas de forma que quantifique alguma propriedade do objeto. Este processo produz um conjunto de $n$ características que, juntas, formam o vetor de características de uma imagem. Pode-se então pensar em um espaço $n$-dimensional no qual todos os $n$-elementos deste vetor possam ser localizados. Assim, qualquer objeto corresponde a um ponto deste espaço, denominado espaço de características. Após uma imagem ser segmentada em regiões, geralmente convém representar e descrever o conjunto resultante de pixels segmentados em uma forma adequada para processamento. Há dois modos de representar uma região: baseando-se nas características externas (isto é, suas fronteiras) ou nas internas (os pixels contidos na região) [Gonzalez and Woods, 1993]. Geralmente, opta-se por uma representação externa quando o foco são as características morfológicas ou formas que estão presentes na imagem. Por outro lado, a representação interna é mais utilizada quando há interesse em propriedades refletivas, tais como cor e textura. Em ambos os casos é importante que as características selecionadas como descritoras sejam tão insensíveis quanto possível à variações de tamanho, translação e rotação.

- Classificação da imagem: O resultado desta etapa baseia-se na decisão a respeito da classe à qual pertence cada objeto da imagem. É reconhecido o tipo de cada objeto e o reconhecimento é implementado como um processo de classificação. Cada 
objeto é associado a um dos diversos grupos pré-estabelecidos que representam todos os possiveis tipos de objetos que se espera existir na imagem.

Brown em [Brown, 1992] apresenta uma taxonomia sobre quais são os atributos mais utilizados no processo de extração de características e agrupa-os em cinco espaços. A Tabela 3.2 sumariza tais espaços e os atributos associados. É interessante notar que os atributos mais cfetivos em sistemas de recuperação de imagens baseada em conteúdo, porém mais caros computacionalmente, são aqucles que usam características de bordas o características de alto nível [Smeulders et al., 2000], como grafos [Gudivada and Raghavan, 1995] [Petrakis and Faloutsos, 1997], e distribuição espacial de padrões [Petrakis et al., 2001].

\begin{tabular}{|c|c|}
\hline $\begin{array}{l}\text { Espaço de } \\
\text { Características }\end{array}$ & Atributos \\
\hline $\begin{array}{l}\text { 1.Intensidade } \\
\text { (raw intensity) }\end{array}$ & Baseiam-se ras intensidades dos pixels. \\
\hline 2. Bordas & $\begin{array}{l}\text { Estrutura intrínseca, menos sensivel a ruídos. Incluem } \\
\text { contorno e superfícies. }\end{array}$ \\
\hline $\begin{array}{l}\text { 3. Características } \\
\text { Salientes }\end{array}$ & $\begin{array}{l}\text { Estrutura intrínseca, posicionamento preciso. Incluem } \\
\text { intersecção de linhas, cantos, pontos de alta curvatura. }\end{array}$ \\
\hline $\begin{array}{l}\text { 4. Características } \\
\text { Estatísticas }\end{array}$ & $\begin{array}{l}\text { Usa toda informação presente na imagem, bons resulta- } \\
\text { dos para transformaçôes rígidas, suporte a suposiçōes. } \\
\text { Inchucm momentos invariantes, cixos principais, técni- } \\
\text { cas como singular value decompasition o centróides. }\end{array}$ \\
\hline $\begin{array}{l}\text { 5. Características do } \\
\text { Alto Nível }\end{array}$ & $\begin{array}{l}\text { Utilizam relaçôcs e informação de alto nível, bons re- } \\
\text { sultados para matching local e impreciso. Incluem ca- } \\
\text { racterísticas estruturais (grafos de configurações de sub- } \\
\text { padrōes) e sintáticas (gramáticas compostas a partir de } \\
\text { padrões) e redes semânticas (regiōes de cena e suas rela- } \\
\text { çoes). Podem criar técnicas de assinatura para indexar } \\
\text { imagens. }\end{array}$ \\
\hline
\end{tabular}

Tabela 3.2: Taxonomia sobre espaços de características extraídas de imagens[Brown, 1992].

As características estatisticas (histograma de intensidades, média, desvio-padrão, entre outras), por representarem um comportamento mais global da imagem e por serem mais baratas computacionalmente, são mais adequadas nos primeiros passos do seleção ou eliminação de candidatos. Já as características baseadas nas intensidades dos pixels em si, só valen quando se busca imagens exatamente iguais, o que näo é o caso geral em consultas por similaridade. 


\subsection{Algumas Abordagens sobre os sistemas CBIR}

Por obter a distribuição de cores ou níveis de intensidade de imagens com baixo custo computacional, histogramas de intensidade tîm sido as grandes "vedetes" em sistemas de recuperação de imagens por contcúdo sendo utilizados em muitos doles. Nesta seção serão apresentados dois sistemas que serão utilizados neste trabalho. O Histograma Métrico foi usado no sistema base para a implementação deste trabalho, como poderá ser visto no Capítulo 5. A técnica BIC foi utilizada como suporte à comparação de resultados e, assim, verificar o desempenho do presente trabalho.

\subsubsection{O Histograma Métrico}

Uma abordagem de extração de características baseada em intensidade de cor foi tratada em [Bueno, 2002]. O Histograma Métrico (HM) reduz o número de bins, conscrvando a curva original do histograma, não trazendo perdas significativas de informação. Formalmente, o Histograna Métrico é definido como:

Definição 3.3 - Um Histograma Métrico $H M_{A}(z)$ de uma imagem $A$ é definido como $H_{M}(A)=\left\{N_{A},<b_{k}, h_{k}>\mid 0<k<N_{A}\right\}$, que a um conjunto de $N_{A}$ recipientes (buckets) formados por pares $\left\langle b_{k}, h_{k}\right\rangle$ consecutivos, onde $b_{k}$ indica a largura e $h_{k}$ a altura de cada recipiente.

Um histograma normalizado é composto por um número de bins (conforme visto na definição 3.2. Este número depende da resolução de intensidades (luminosidade) da imagem, sendo un número fixo. Enn um Histograna Métrico, o equivalente ao bin do histogramá é chamado um bucket. Cada bucket correspondo a uma linha na aproximação do histograma normalizado. Os buckets não precisam ser regularmente espaçados. O número $N_{A}$ de buckets em um Histograma Métrico depende do erro de aceitação no processo de aproximação da curva linear por partes sobre o histograma. Cada bucket $k$ corresponde a dois pares consecutivos $\left\langle b_{k}, 1 ; h_{k-1}>\mathrm{e}<b_{k}, h_{k}\right\rangle$ para $1 \leq k \leq N_{A}$, onde $<b_{k}, h_{k}>$ é o índice do bin mais à direita do histograma original representado no bucket $k, c<b_{k, 1}, h_{k-1}>$ é o valor normalizado do bin mais à esquerda representado no bucket $k$. Note que $b_{0}$ é sompre zero, pois é o início do Histograma Métrico. Para simplificar a notação, indica-se o recipiente $b_{k}$ do Histograma Métrico da imagem $A$ como $A_{b k}$, c o valor normalizado $h_{k}$ do Histograma Métrico da imagem $A$ como $A_{h k}$. A Figura 3.6 representa graficarnente os buckets c os bins de um Histograma Métrico. 


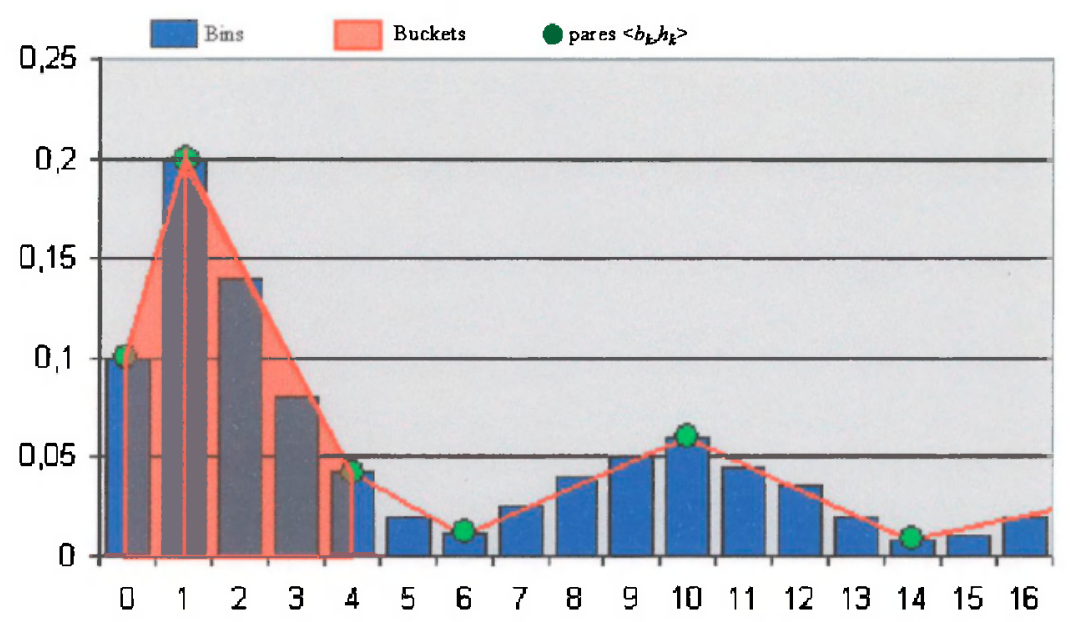

Figura 3.6: Histograma normalizado com os pontos $\left\langle b_{k}, h_{k}\right\rangle$ que definem os buckets e seu Histograma Métrico correspondente.

Para se obter um Histograma Métrico que mais se aproxime do histograma original, primeiramente é preciso obter os pontos máximos e mínimos da função que o representa. Através desses pontos a curva de aproximação sobre os mesmos é obtida. E importante observar que o número de buckets dos Histogramas Métricos, bem como sua largura, é variável e depende de características inerentes de cada imagem. Dessa forma, a comparação entre Histogramas Métricos não pode ser feita pelas funções de distância tradicionais, como é feito sobre histogramas convencionais. A Figura 3.7 exemplifica graficamente a implementação do Histograma Métrico.

Uma imagem com 8 bits por pixel possui um histograma normalizado de $256\left(2^{8}\right)$ bins ou níveis de cinza. Em um conjunto muito grande de imagens, o seu processamento gera um custo computacional muito alto, tornando a resposta à busca lenta. Dessa forma, o surgimento do HM vem contribuir significativamente à redução desse custo.

Uma nova função de distância, denominada Distância Métrica $\operatorname{DM}($ ), foi desenvolvida para comparar Histogramas Métricos e se baseia no cálculo da diferença de áreas entre os dois histogramas [Traina et al., 2002a]. Os Histogramas Métricos e sua aplicabilidade em recuperação de imagens são apresentados em detalhes em [Bueno, 2002].

\section{A Distância Métrica}

Histogramas de imagens semelhantes possuem distribuições parecidas como pode ser visto na Figura 3.8. Normalmente, o cálculo de dissimilaridade entre histogramas é dado pelo somatório da diferença entre os bins de dois histogramas. Com relação aos Histogramas 


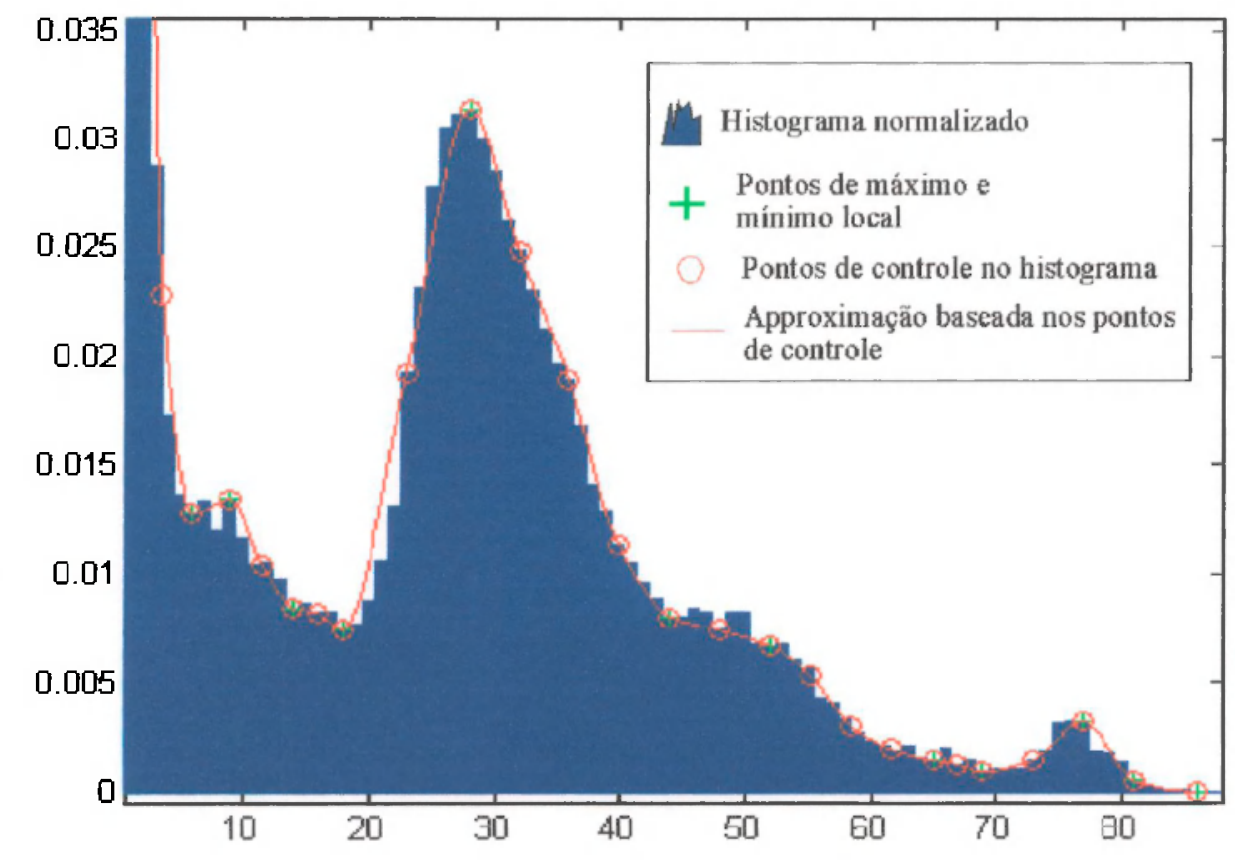

Figura 3.7: Obtendo o Histograma Métrico sobre o normalizado. Os pontos de controle são apresentados pelos elementos circulares e o Histograma Métrico pela curva que está ao redor do histograma normalizado.

Métricos a questão é como compará-los, uma vez que o número de buckets e a distribuição dos buckets de diferentes histogramas são variáveis. Os Histogramas Métricos, que possuem dimensionalidade variável, não permitem o cálculo de distância utilizando técnicas usuais como a Euclideana ou qualquer distância $L_{p}$ [Wilson and Martinez, 1997], pois não é possível calcular a subtração dos pares de elementos dos vetores dos Histogramas Métricos para todos os pares de elementos. Por exemplo, como calcular a distância Euclideana entre um histograma com 30 buckets com largura variável de outro com 20? Isto porque, considerando os histogramas tradicionais como um conjunto de pares cartesianos, os valores em $x$ serão sempre os mesmos para todos os histogramas, o que não ocorre com os Histogramas Métricos.

Portanto, para fazer o cálculo da distância entre Histogramas Métricos, foi desenvolvido um novo algoritmo baseado no cálculo da diferença entre histogramas, considerando que cada um deles ocupa uma área caracterizada pela distribuição de pixels e que a diferença entre estas áreas indica quão dissimilares são os histogramas.

Utilizando esta concepção, pode-se concluir que, quando dois histogramas similares são comparados, a diferença entre suas áreas de distribuição é pequena. Formalmente a distância 


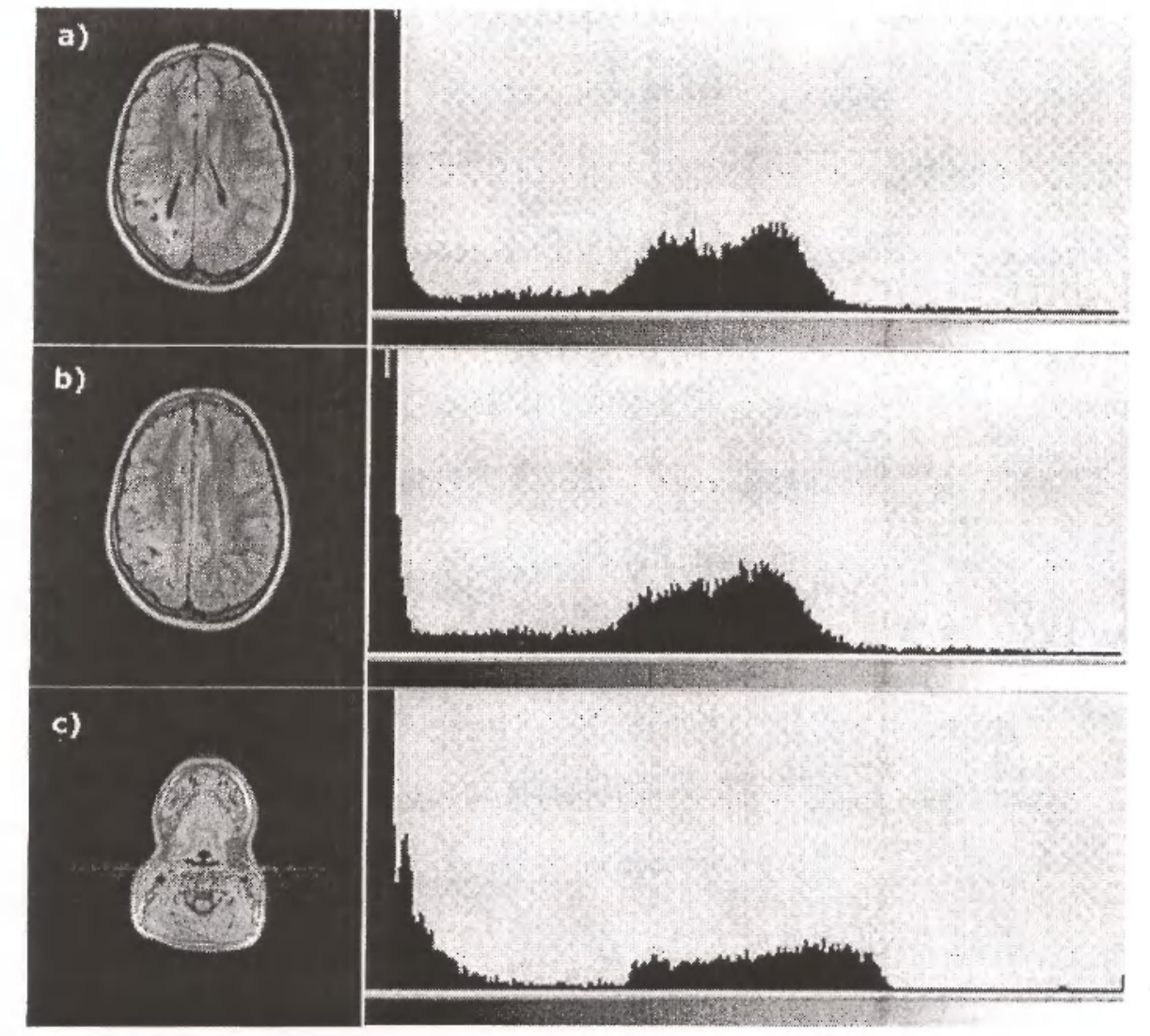

Figura 3.8: Imagem original (a), imagem mais semelhante (b) e imagem menos semelhante (c). Os histogramas apresentam a densidade de pixels para 256 níveis de cinza das imagens.

por diferença de área é dada por:

Definição 3.4 - A distância $D M()$ entre dois Histogramas Métricos $H_{M}(A)$ e $H_{M}(B)$ é dada pela área não sobreposta entre as duas curvas que representam os Histogramas Métricos, isto é:

$$
D M\left(H_{M}(A), H_{M}(B)\right)=\int_{0}^{b m}\left|H_{M}(A, x)-H_{M}(B, x)\right| d x
$$

onde $b m=\operatorname{máx}\left(b_{N A-1}, b_{N B-1}\right)$ e $H_{M}(\operatorname{Imagem}, x)$ é a função continua que representa o Histograma Métrico.

Ao realizar a soma das áreas, o processo encontra duas situações: quando existem áreas em formato de trapézio ou quando as áreas estão em formato triangular. Ao encontrar o trapézio ou o triângulo, o sistema realiza o cálculo da área e soma às áreas já calculadas 


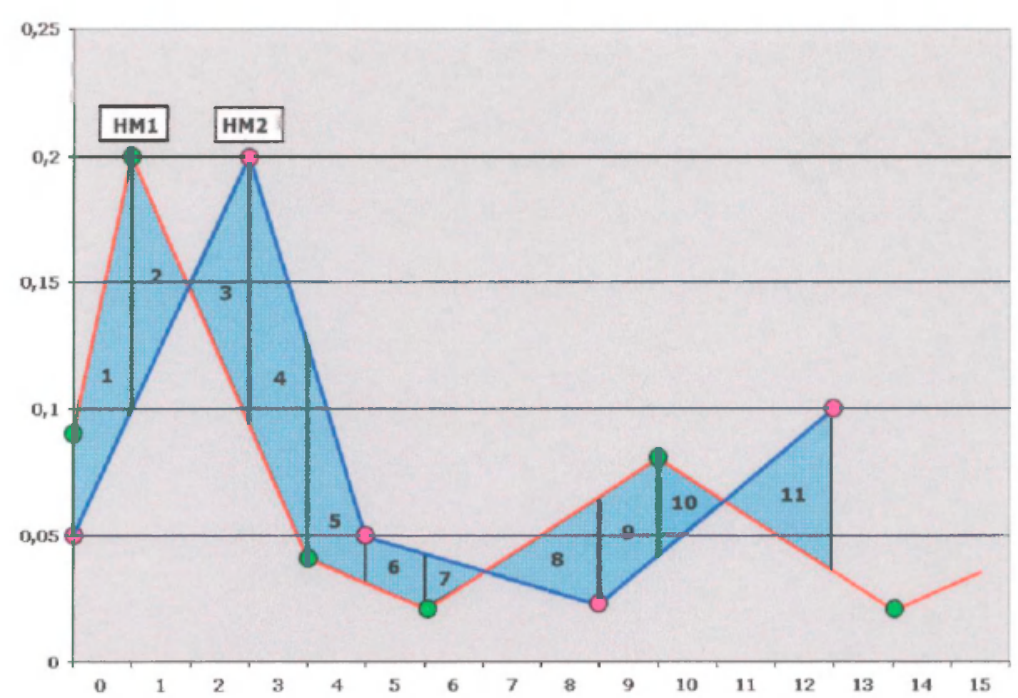

Figura 3.9: Distância entre dois Histogramas Métricos calculando a soma da diferença entre áreas.

anteriormente. Esse processo vai se repetindo até acabar um dos buckets do histograma. A Figura 3.9 fornece um exemplo de como calcular a distância entre dois Histogramas Métricos.

Note que o número de passos é maior ou igual ao número de buckets do histograma com menos buckets. Isso ocorre devido ao fato da largura dos buckets ser variável: em algumas ocasiões eles devem ser divididos, a fim de obter a área entre os dois histogramas considerados. Quando um dos Histogramas Métricos termina antes do outro, o cálculo da distância também pára.

\subsubsection{Classificação de Pixels de Borda e Interior - A Técnica BIC}

Em [Stehling et al., 2002] é proposto o BIC (Border/Interior Pixel Classification), uma abordagem para a recuperação de imagens por conteúdo em grandes coleções de imagens coloridas heterogêneas. A abordagem BIC utiliza técnicas simples, porém poderosas cujos resultados podem ser preservados durante as etapas do processo de recuperação de imagens. A abordagem BIC possui três componentes principais:

1. um algoritmo simples, eficiente e poderoso para a análise do conteúdo visual das imagens,

2. uma nova função de distância logarítmica para a comparação de histogramas de cores e 
3. uma representação compacta para as características visuais extraídas das imagens.

O algoritmo de análise de imagens da abordagem BIC utiliza o espaço de cores RGB uniformemente quantizado em $4 \times 4 \times 4=64$ cores. Após a quantização do espaço de cores, é feita uma classificação binária dos pixels da imagem de entrada. Cada pixel é classificado como borda ou interior. Um pixel é considerado borda se ao menos um de seus quatro vizinhos (superior, inferior, direito e esquerdo) possui uma cor quantizada diferente da sua. Caso contrário, o pixel é classificado como interior. Após a classificação dos pixels, são calculados dois histogramas de cores: um considerando apenas pixels classificados como borda e outro, considerando-se apenas pixels classificados como interior. A Figura 3.10 exemplifica a classificação dos pixels de borda de uma imagem.

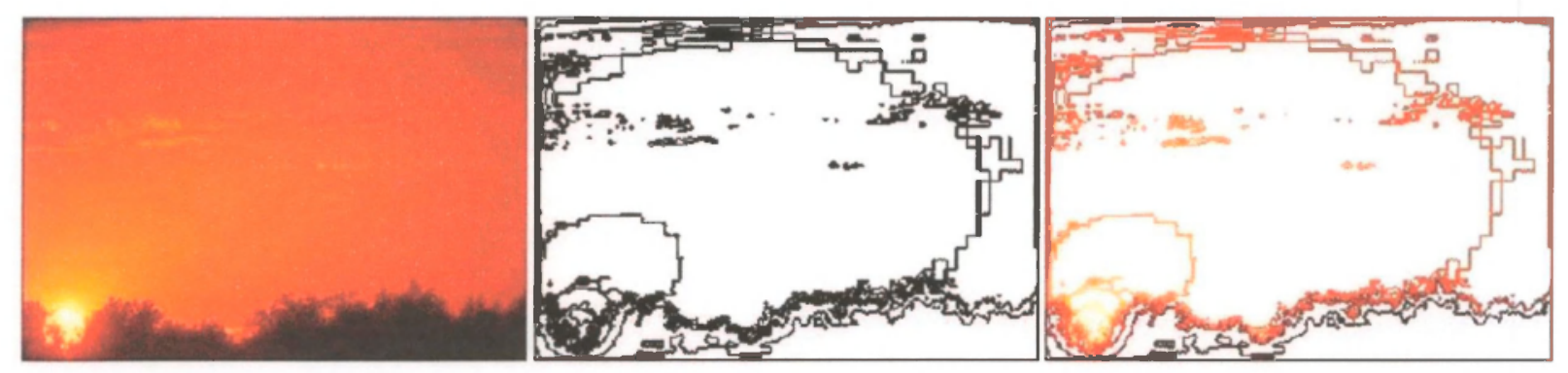

Figura 3.10: Análise de imagens pela abordagem BIC. Imagem original (esquerda). Classificação binária entre borda (preto) e interior (branco) (centro). (c) Pixels da borda com suas cores originais e os pixels do interior em branco (direita).

Os histogramas que representam as imagens na abordagem BIC são comparados utilizando-se uma distância denominada $d \log$. A função $d \log$ calcula a diferença entre o logaritmo dos elementos do histograma. O objetivo dessa operação é reduzir o efeito negativo introduzido quando um único elemento do histograma possui valor muito alto. Este elemento do histograma, com valor muito alto, domina a diferença entre histogramas mas, em geral, tal elemento está associado ao fundo da imagem o qual possui pouca informação semântica e, como consequência, possui pouca importância no julgamento de similaridade feito pelo usuário. A função $d \log$ atenua essa influência artificial e é definida como:

$$
\begin{array}{r}
d \log (q, d)=\sum_{i=0}^{i<M}|f(q[i])-f(d[i])| \\
f(x)=\left\{\begin{array}{lr}
0, & \text { se } x=0 \\
1, & \text { se } 0<x \leq 1 ; \\
\left\lceil\log _{2} x\right\rceil+1, & \text { caso contrário }
\end{array}\right.
\end{array}
$$


A utilização da função dLog para comparar histogramas, além de aumentar a efetividade do sistema, permitc armazenar os histogramas em metade do espaço originalmente necessário. Essa reduçăo é possível armazenando-se o valor do log ao invés do valor original dos elementos do histograma. No caso da abordagem BIC, é possível representar o conteúdo visual de qualquer imagem om apenas 64 bytes de memória. Como conseqüência, é possível manter em memória principal as características visuais de grandes coleções de imagens, eliminando completamonte a recessidade de métodos de acesso a disco para agilizar o processamento de consultas visuais.

\subsection{Considerações Finais}

Neste Capitulo foram descritas as principais propriedades de imagens digitais, assim como o processo de extrair características de imagens e algumas das principais técnicas. O sistema de extração de características pode ser considerado um primeiro passo para o armazenamento de imagens em um sistema de base de dados para imagens.

O maior problema, no que se refere ao processo de extração de características, é a procura daquele esjaço de características mais representativo do domínio de imagens, para assim permitir a recuperação de imagens de maneira micis eficiente. A extração de histogramas possui grandes vantagens, dentre clas, o baixo custo computacional. Sua popularização em sistemas CBIR vem sendo bastante utilizada e muitas abordagens sobre o assunto surgem rapidamente

Após a extração de características, é necessário agrupá-las com o intuito de roalizar buscas rápidas e precisas. Para tanto, os conceitos sobre busca por similaridades e estruturas métricas se fazem neccssários e serão descritos no próximo capítulo. 


\section{Consultas por Similaridade e Estruturas}

Métricas

\subsection{Considerações Iniciais}

Ao se trabalhar com a base de dados do cadastro de pacientes de um hospital, é comum recuperar dados considerando algum critério de filtragem. Um exemplo simples de consulta seria: levantar os resultados dos exames de todos os pacientes com dengue atendidos após o início do último verão. No caso, o critério é composto pola especificação do uma doença [doença $=$ "denguc"] $\mathrm{c}$ de um intervalo de tempo [data atendimento $>21 / 12 / 2002$ ]. A resposta fornecida pelo SGBD é composta pelos resultados dos cxames em conformidade com as condiçōes especificadas. Critérios como esse são caracterizados por envolver: igualdade, onde o interesse é por valores exatamente coincidentes; e ordem, onde o interesse é por valores maiores ou menores que um valor fornecido. Os tipos de dados em questão são tidos por convencionais e incluem, basicamente, valores numéricos (quantidades: datas, horas, etc.) e textuais (cadeias de caracteres: palavras, nomes, endereços, etc.).

No entanto, critérios bascados con igualdade e ordem săo inadequados para bancos de dados que trabalhan com tipos de dados complexos. Ou seja, não há sentido em realizar 
consultas como por exemplo: obter o cadastro dos pacientes com tumor no cérebro cuja tomografia seja igual à do paciente cm cstudo. Dificilmente (provavelmente nunca) as tomografias de dois tumores serão exatamente iguais, mesmo que os tumores tenham a mesma classificação. () critćrio mais adequado para casos assim é o de similaridade. A consultat, então, faria mais sentido se definida como: obter o carlastro dos pacientes cuja tomografia sc assemelhe à do paciente em estudo.

A similaridade entre os dados é definida através de uma função distância, ou função de "dissimilaridade" $d\left(O_{i}, O_{j}\right)$, que rotorna zero, se ambos os objetos $O_{i}$ e $O_{j}$ forem identicos on um valor positivo: que aumenta quanto maior for a distancia (ou dissimilaridade) entre os objetos.

\subsection{Tipos de Buscas por Similaridade}

Como visto, as consultas por similaridade retornam objetos ordenados por semelhança. Este resultado é, em geral, obtido através de dois tipos de consultas: a consulta por abrangência (range query) o a consulta aos vizinhos mais próximos (k-nearest neighbors query). Tais consultas são definidas a seguir:

Definição 4.1 - Consulta por Abrangência (range-query) - Dados um conjunto de objetos $O=\{O 1, O 2, \ldots, O n\}$ pertencentes a um domínio $\mathcal{D}$, uma funçăo de distância métrica $d()$, um objeto de consulta $\mathcal{Q} \in \mathcal{D}$ e uma distância de busca máxima $r(\mathcal{Q})$, a consulta por abrangência range $(\mathcal{Q}, r(\mathcal{Q}))=\left\{O_{i} \mid O_{i} \in \mathcal{D}\right.$ ed $\left.\left(O_{i}, \mathcal{Q}\right) \leq r(\mathcal{Q})\right\}$ seleciona todos os objetos $O_{i}$ do conjunto de dados que estejam dentro da distância $r(\mathcal{Q})$ do objeto de busca.

Um exemplo deste tipo de consulta seria: "Encontre as estrelas que estão até 10 unos-huz de distância do Sol". Nesse caso o objeto de consulta é "Sol", o clomínio $\mathcal{D}$ é o conjunto de estrelas do Universo e o rajo de busca (distância máxima) é 10 anos-luz. A distância utilizada é a medicla astronomica que mede o espaço em anos-luz.

Definição 4.2 - Consulta aos $k$ Vizinhos mais Próximos (k-nearest nefighbors), $k$ NN - Dados um conjunto de objetos $O=O_{1}, O_{2}, \ldots, O_{n}$ de um dominio $\mathcal{D}$, uma funçüo distância métrica $d()$, um objeto de consulta $\mathcal{Q} \in \mathcal{D}$ e um número inteiro $k \geq 1$, a consulta $k-N N$ seleciona os $k$ objetos do conjunto de dados que estäo mais próximos de $\mathcal{Q}$. Isto é, $k-N N(\mathcal{Q})=\left\{\Lambda_{i}\left|A_{i} \in \mathcal{A}, \mathcal{A} \subseteq \mathcal{O},\right| \mathcal{A} \mid=k e \forall A_{i} \in \mathcal{A}, O_{i} \in \mathcal{O}-\mathcal{A}, d\left(\mathcal{Q}, \Lambda_{i}\right) \leq d\left(\mathcal{Q}, O_{i}\right)\right\}$ 
Em caso de empate de distâncias na maior distância obtida, pode-se selecionar apenas o número necessário de objetos que satisfazem a regra ou criar uma lista de empates. Utilizando o exemplo anterior, a consulta "Selecione as 5 estrelas mais próximas do Sol" é uma busca $5 N N$ para o objeto "Sol" sobre o mesmo domínio de objetos da consulta-exemplo anterior.

A Figura 4.1 ilustra os dois tipos de consultas, sendo que a por abrangência, utiliza a distância Euclideana conhecida também como $L_{2}$.

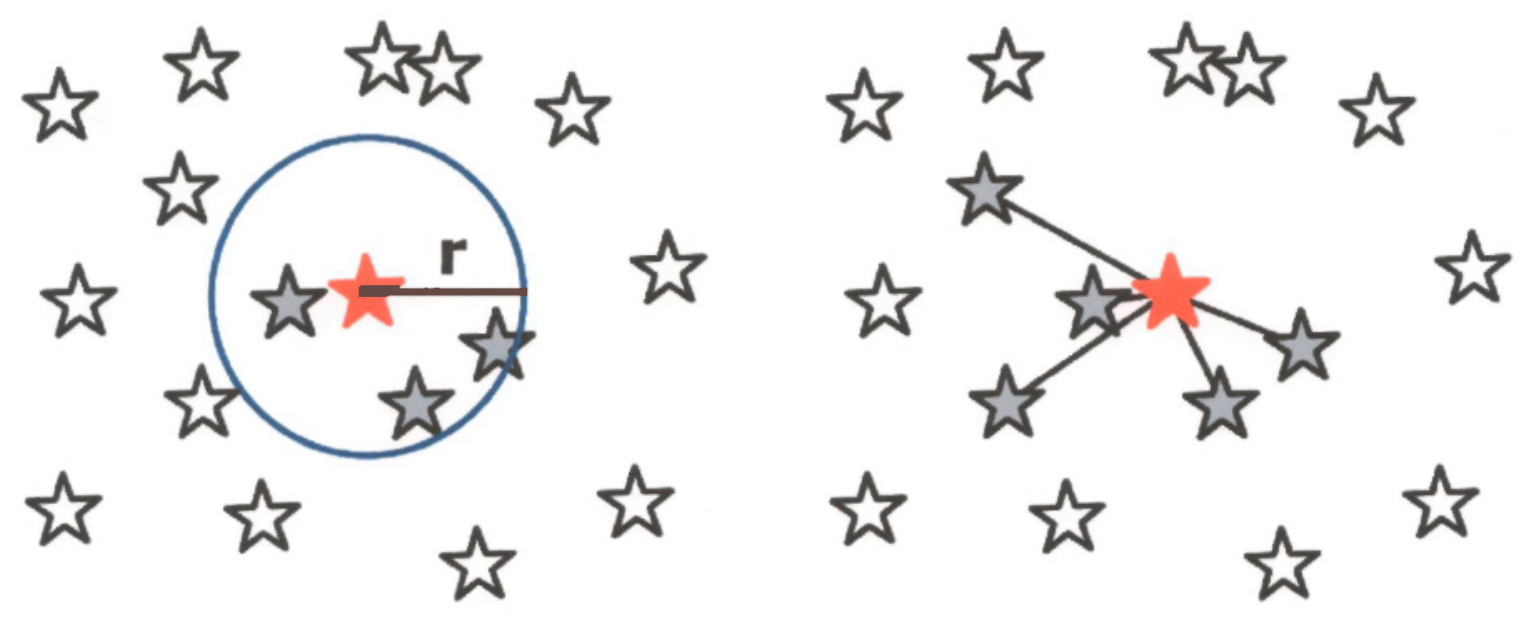

Figura 4.1: A consulta por abrangência (esquerda) seleciona todas as estrelas distantes de um raio $r$ enquanto que a consulta aos vizinhos mais próximos (direita) seleciona as 5 estrelas mais próximas do elemento de consulta.

\subsection{Métodos de Acesso Métricos}

Os dois tipos de consultas por similaridade podem ser respondidos examinando todo o conjunto de dados, o que não é eficiente. Se não existir um índice para os dados, ou não for possível construir, então a busca seqüencial é a única maneira para responder às consultas. Um algoritmo de indexação é um procedimento para construir antecipadamente um índice projetado para minimizar o custo de acesso aos dados. $O$ índice pode ser custoso de se construir em um primeiro momento, mas seu custo pode ser amortizado com a economia de cálculos de distâncias e acessos a disco sobre várias consultas na base de dados. Estruturas de indexação para espaços métricos (que englobam tanto dados espaciais com dimensão definida quanto dados adimensionais) foram propostas [Chávez et al., 2001] para dar suporte às buscas por similaridade.

Os Métodos de Acesso Multidimensionais, também conhecidos por Métodos de Acesso Espaciais - MAE , são utilizados para indexar objetos multidimensionais. Em geral, 
um conjunto de objetos ć dito multidimensional, ou n-dimensional, se um objeto qualquer desse conjunto podo ser localizado por uma série de $n$ coordenadas. Os MAEs têm como premissa o fato dos dados manipulados pertencerem ao domínio dos dados espaciais ou a um espaço de dimensão n. Neste cspaço, cała dimensão é representada por uma chave da relação.

Entretanto, para dados em espaços de altas dimensões, as MAEs não se mostraram muito eficientess, além de não suportarem a indexação de dados adimensionais. Desta forma cstruturas de indexação métricas foram propostas com o objctivo de suprir esta deficiência. Estas estruturas, que foram chamadas de Métodos de Acesso Métricos - MAM, suportam buscas por similaridade em espaços métricos ${ }^{1}$, onde a similaridade entre os dados é definida através de uma função de dissimilaridade ou também chamada de função distância métrica.

Os Métodos de Acesso Métrico, dão suporte natural às consultas por proximidade ou similaridade, além de se mostrarem eficientes para dados de climensões altas. Dessa forma, é bastante apropriado utilizar un MAM para indexar imagens ou, mais especificamente, as características que foram extraídas das imagens, suportando consultas por similaridade. Com base nas caractcrísticas extraídas previamente da imagem, um MAM constrói a estrutura de indices calculando as distâncias entre clas, procedimento que deve corresponder à comparaçào entre as imagens originais.

Formalmente, um espaço métrico é um par $M=(\mathcal{D}, d)$, onde $\mathcal{D}$ é o domínio do vetor de características - que são as chaves de indexação, e $d()$ é uma função distância métrica que satisfaz as seguintes propriedades:

1. Simetria: $d\left(O_{i}, O_{j}\right)=d\left(O_{j}, O_{i}\right)$;

2. Não negatividade: $0<d\left(O_{i}, O_{j}\right)<\infty, O_{i} \neq O_{j}$ e $d\left(O_{i}, O_{i}\right)=0$;

3. Desigualdade triangular: $d\left(O_{i}, O_{j}\right) \leq d\left(O_{i}, O_{k}\right)+d\left(O_{k}, O_{j}\right)$.

onde: $O_{i}, O_{j}$ e $O_{k}$ são objetos pertencentes a espaço $\mathcal{D}$.

\subsection{Estruturas Estáticas e Dinâmicas}

As estruturas métricas estáticas não permitcm inscrçồ ou remoçôs posteriores à construção da árvore. É o caso das primeiras estruturas propostas (vp-tree, mvp-tree, entre outras),

\footnotetext{
${ }^{2}$ Espaços métricos engloban tanto dados espaciais com dimonsão definida quanto dados adimensionais.
} 
que apesar de terem sido desenvolvidas para dar suporte a consultas por similaridade, são estáticas.

A primeira estrutura métrica dinâmica (permite inserçôes c remoções após a construção da árvore), M-Trce [Ciaccia et al., 1997b], foi desenvolvida utilizando uma técnica de construção de baixo para cima (bottom-up), que ao mesmo tempo mantém a árvore balanceada e possibilita ainda novas inserções após a construção da árvore. A . M-Tree possui dois tipos diferentes de nós:

- Nós internos, que armazenam o objeto centro deste nó e a distância dele para seu nó pai (essa distância não cxiste para o nó raiz da árvore), o raio de cobertura da regiāo indexada por essa sub-árvore, c um vetor de ponteiros para suas sub-árvores.

- Nós folhas, que armazenam objetos, possuem seus identificadores de objetos (OIds) e o vetor de características que estão sendo utilizadas na indexaçào do conjunto de dados.

Neste projeto a estrutura a ser utilizada para armazenar as informações das imagens será a Slim-tree que, por ser dinâmica, permite inserções postcriores c̀ criação da árvore.

\subsection{A Slim-tree}

Proposta por Traina ut. al cm [Traina et al., 2000], esta é a mais nova representante de estruturas métricas dinâmicas, sendo também uma estrutura balanceada e permitindo inserçōes posteriores à criação da árvore. A Slim-tree, comparada com a M-tree nas mesmas condiçôes, sempre a sobrepujou, tanto em temos de número de acessos a disco quanto em termos de número de distâncias calculadas para responder consultas por abrangência (range queries) e, portanto, também em tempo total de execução.

A Slim-tree possui tamanho fixo da página que armazena cada nó, e cada nó pode armazenar un número máximo de objetos C (Capacidade), e é constituída de :

- nós internos (indexnodes): cuja estrutura é representada por: indexnode (vetor de $\left\langle o_{i}, d\left(o_{r c p}, o_{i}\right), \operatorname{Ptr}\left(T o_{i}\right), R_{i}, \operatorname{NEnt}\left(\operatorname{Ptr}\left(T o_{i}\right)\right)>\right]$, onde $o_{i}$ armazena o objeto que é o centro da sub-árvore apontada por $\operatorname{Ptr}\left(T o_{i}\right)$, e $R_{i}$ é o raio de cobertura da região. A distância entre $o_{i}$ e o objcto representativo deste nó $\operatorname{Rep}\left(o_{i}\right)$ é armazenada en $d\left(o_{i}, \operatorname{Rep}\left(o_{i}\right)\right)$. O ponteiro $\operatorname{Ptr}\left(T o_{i}\right)$ indica o nó raiz da sub-árvore cuja raiz é $o_{i}$. O número de entradas presentes no nó apontado por $P \operatorname{Pt}\left(T O_{i}\right)$ ó armazenado em NEntries $\left(\operatorname{Ptr}\left(T o_{i}\right)\right)$. Na Figura 4.2 é possivel visualizar a estrutura interna da Slimtree. 


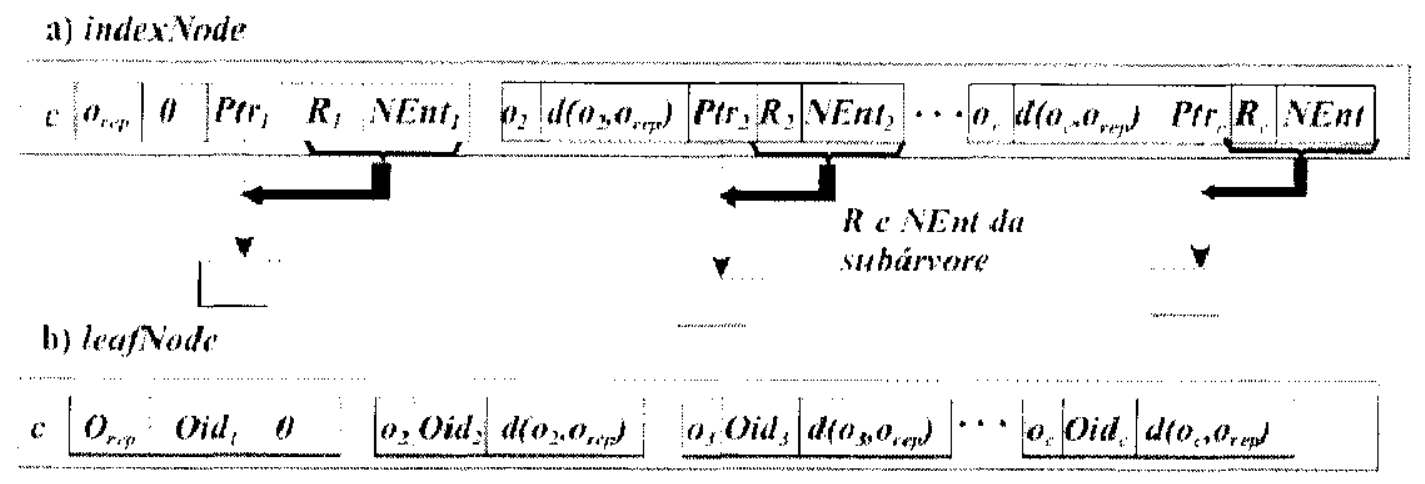

Figura 4.2: Estrutura lógica dos nós a)índice (indexNode) a b)folha (leafNode) rla Slimstrec [Traina et al., 2000?

- nós folha (leafnodes), com estrutura representada por: leafnode jvetor de $<o_{i}, O I d_{i}$, $d\left(o_{r c p}, o_{i}\right)>_{j}$, onde OId ó identificador do objeto, $o_{i}$ e $d\left(o_{i}, R c p\left(o_{i}\right)\right)$ é a distânéia centre o objeto $o_{i}$ o o objeto central (representativo) deste nó folha $R e p\left(o_{i}\right)$.

A Figura 4.3 fornece uma visão geral da organização de 17 objetos, rotulados de $\mathrm{A}$ até $\mathrm{Q}$. armazenados numa Slin-tree de 3 níveis, onde a raiz encontra-se no nível zero e os objetos no nível das follass (nível 2).

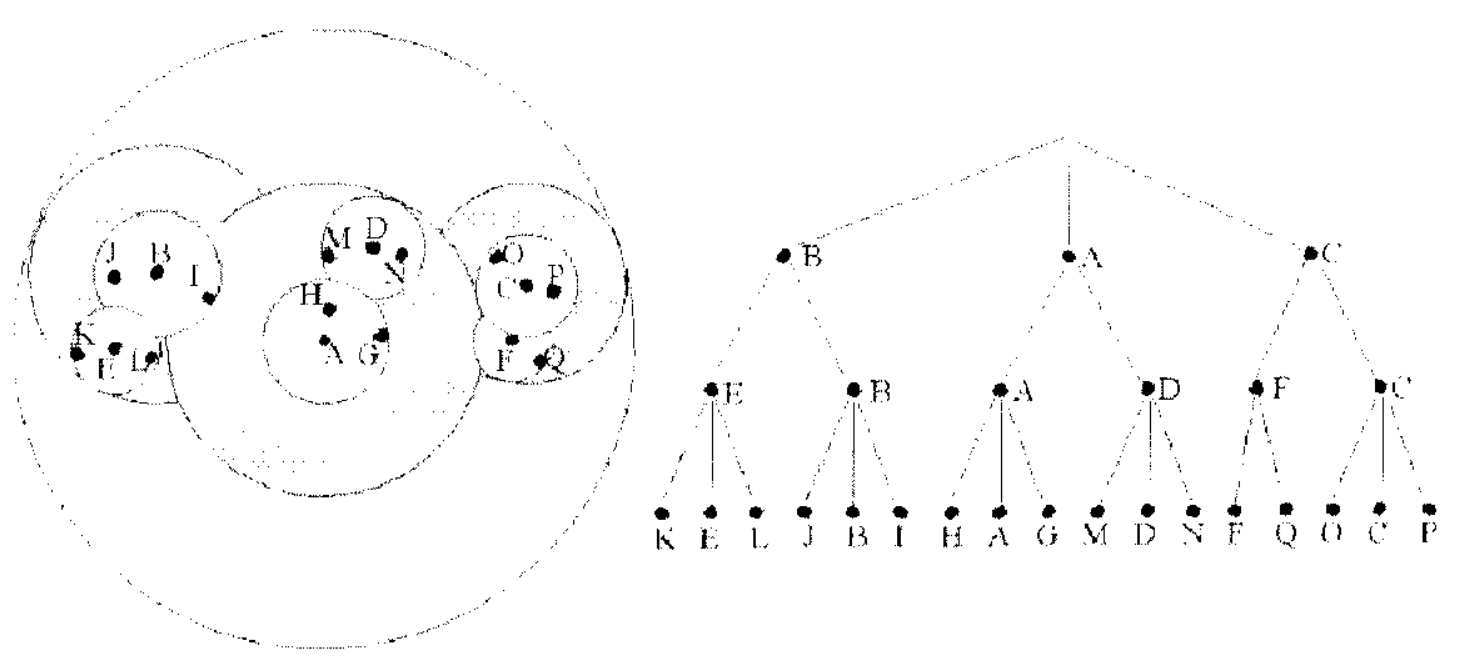

Figura 4.3: Representação da Slint-tree armazcuando 17 objetos. 


\subsection{Inserção de Objetos na Slim-tree}

A partir do nó raiz, o algoritmo tenta localizar um nó que possa receber o novo objeto. Se nenhum nó se qualifica, seleciona-se o nó cujo centro está mais perto do novo objeto. Caso mais de um nó se qualifique, é executado o algoritmo ChooseSubtree para selecionar o nó onde será inserido o novo objeto. Este processo é aplicado recursivamente para todos os níveis da árvore. Existem três opções para o algoritmo ChooseSubtree:

random seleciona aleatoriamente o nó para inserir o novo objeto entre os que se qualificaram.

mindist scleciona o nó cuja distância de seu representativo (cuntro) para o novo objeto seja a menor.

minoccup seleciona o nó que esteja com o menor número de objetos armazenados, dentre os que se qualificaram. O campo NEntries presente em todo nó intermediário (indexnode) da Slim-tree é utilizado pelo algoritmo minoccup, para selecionar o nó com menor valor de NEntries. Com o uso da opçáo minoccup do algoritmo ChooseSubtree, obtém-se árvores mais compactas (maior taxa de ocupação dos nós), redundando em um número menor de acessos a disco para responder consultas por similaridades.

Durante a inscrção de objetos pode acontecer do nó escolhido já estar completo (com taxa de ocupação máxima), sendo necessário alocar um novo nó no mesmo nível do anterior, e os objetos que estavan nesse nó, mais o novo nó a ser inserido, devem ser entäo redistribuídos cntre os dois nós. A Slim-tree cresce de um nível quando a raiz da árvore está completa e necessita-se inserir um novo clemento, pois a raiz divide-se e uma nova raiz deve ser criada com dois representativos, aumentando-se assim um nível da árvore.

A Slim-tree possui os seguintes algoritmos para efetuar a quebra de nós (splitting)

random - seleciona aleatoriamente os dois objetos representativos para os novos nós, e os demais objetos são distribuídos entre eles pela menor distância entre o objeto e o representativo, devendo-se respeitar a taxa de ocupação mínina dos nós.

minMax - consideram-se como candidatos representativos, todos os possíveis pares de objetos e, para cada par possível, associa-se os demais objetos a um dos representativos. O par de objetos que minimizar o raio de cobertura da sub-árvore scrá escolhido como representativo. Esse algoritmo tem complexidare $O\left(C^{13}\right)$. onde $C$ é a capacidade dos 
nós. Apesar do ser un algoritmo bastante custoso, ele conseguc obter árvores que possibilitam consiltas mais eficientes [Ciaccia and Patella, 1998].

MST - constrói-se a árvore do caminho mínimo (minimal spanning tree - MST) [Kruskal, 1956] o um dos arcos mais longos da MST é removido. Obtém-se assim dois agrupanentos, que scrāo os objetos associados a cada nó. A complexidado desses algoritmo é $\mathrm{O}\left(\mathrm{C}^{2} \log C\right)$, com $\mathrm{O}\left(\mathrm{C}^{2}\right)$ cáleulos de distânucia. Com o uso desse algoritmo a posivivel construir Slim-tres praticamente cepuivalentes às construídas com o uso do algoritmo de quebra de nós minMax, porén em muito menos tempo.

A Figura 4.4 ilustra o mecanismo de quebra de nós utilizando MST:

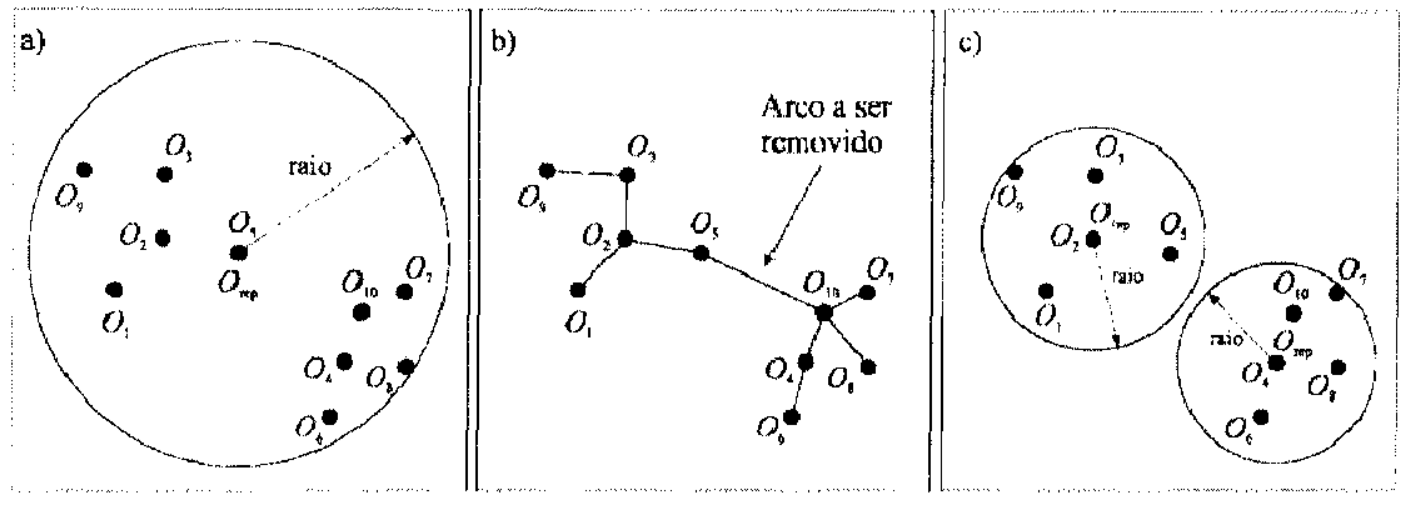

Figura 4.4: Mecanismos de queloras de nós do algoritmo MST.

\subsection{Tratamento de Sobreposição}

A sobreposicáa contre nós ocorre tanto nas estruturas mótricass quanto na maioria dos métodos do acesso espacial como, por exemplo, a família R-tree. Idealmente, os nós de uma árvore para indexação de dados não deveriam se sobrepor, permitindo podiar todos os nós que nào possizan objetos candidatos a responder comsultals por similaridado, porém isso não ocorre e assim como nos demais MAM, na slint-tree os nós das regiões também podem ser solorepostos.

O aumento de sobreposiçào entre os nós do uma estrut ura de ínclices dininui sua eficiência en responder consultas, pois mais nós da árvore serä́o consultados (todos os que estäo se sobrepondo à regiáno de consulta) prejucticandes a poda de sub-írvores. A Slim-tree foi desnnvolvida com o objetivo de diminuir a sobreposição entre os nós da árvore, e também oferecer mecanismos para verificação da porcentagem de sobreposição existente na árvore. 
Até a apresentação da Slim-tree, cra considcrado impossível medir a sobreposição entre nós cm estruturas métricas [Ciaccia et al., 1997a]. Nos métodos de acesso espacial mede-se a intersecção calculando-se o "hiper-volume" da intersecção entre nós sobrepostos (como é feito na R*-tree [Beckmann et al., 1990]). Porém, em espaços métricos não há como calcular volume ou árcas, portanto na Slim-tree, ao invés de calcular o "volume" da intersecção entre nós sobrepostos, é computado o número de objetos que se cncontram cobertos por mais de uma região (nó), obtendo-se a sobreposição entre dois nós internos de uma árvore métrica através do número de objetos cobertos por ambas as regiōes (sub-árvores) dividido pelo número total de objetos presentes nas duas sub-árvores. Com isso, pode-se ter una estimativa de quão apropriada ou boa é uma árvore para um conjunto de dados [Faloutsos and Kamel, 1994]. Tornou-se então possível definir o fator de sobreposição em uma árvore métrica alravés do fat-factor [Traina et al., 2002b], que no melhor caso (quando é zero) tem-se umárvore ideal, sem sobreposiçốs, cuja busca a un objeto já indexado deveria levar a acessar apenas um nó a cada nível da árvore, ou seja, para uma consulta pontual (uma consulta por abrangência com raio zero) em uma árvore ideal com, por exemplo, três níveis, somente três nós deveriam ser acessados. E no pior caso, quando todos os nós tivessem que ser acessados para responder à una consulia pontual, o fat-factor é igual a um

Podc-se medir a cquantidade de sobreposição presente em uma dada árvore métrica $\mathrm{T}$ utilizando o absolute fat-factor. Porém ele não permite a comparação entre árvores diferentes construídas sobre o mesmo conjunto de dados, ou seja, métodos de quebra de nós ou opções do algoritmo de seleção de nós (ChooseSubTree) levam muitas vezes a árvores com número de nós $\mathrm{M}$ e altura de árvore $\mathrm{H}$ diferentes. Para permitir a comparação entre árvores distintas construídas sobre o mesmo conjunto de dados, fez-se necessário uma abordagem diferente, permitindo definir uma nova medida, o relative fat-factor que, ao invés de considerar o número de nós e a altura da árvore, considera o número do nós acessados para responder uma consulta pontual sobre todos os objetos da árvore real, sobre a altura e número de nós de uma árvore canônica (que possui o menor númcro possívcl de nós, ou seja, tem todos os nós completos, com a possível exceção de um nó em cada nívcl, o também com altura mínima).

Tanto o absolute fat-factor quanto o relative fat-factor cstão diretamente relacionados com a taxa de sobreposição entre regiōes do mesmo nível de uma árvore, sendo que o absolute fat-factor indica quão boa uma dada árvore é com respeito a sua quantidade de sobreposição, não se preocupando sc os nós estão bem ocupados ou não, o que leva à otimização de espaço em disco se os nós estiverem com alta taxa de ocupação: enquanto que o relative fat-factor 
permite a comparação entre duas árvores para o mesmo conjunto de dados, considerando tanto a quantidade de sobreposição quanto a ocupação eficiente de espaço em disco para armazenar os dados.

\subsubsection{Reorganização dos Nós da Árvore - Algoritmo Slim-down}

$\Lambda$ reorganização permite melhorar uma árvore métrica já construída para um conjunto de dados. Através dos fatores de sobreposição absolute fal-faclor e relative fat-factor, tornouse possível verificar a quantidade de sobreposição entre nós da árvore e avaliar se tal árvore pode ser melhorada cm termos de diminuição do número de acessos a disco para responder às consultas por similaridade. Com isso, se o desejável é que as árvores construídas apresentem o menor valor possível do fator absolute fat-factor, ou seja, que o número de objetos nas regiões de sobreposição seja o monor possível, o que um algoritmo de reorganização da árvore deveria fazer em primeiro lugar é diminuir o número de objetos nas intersecçōes de nós de mesmo nível; e em segundo lugar diminuir o número de nós da árvore. Foi então proposto cm [Traina et al., 2000] o algoritmo Slim-down, que atua sobre uma árvore métrica já construídá

\subsubsection{Visualização dos Dados Armazenados na Slim-tree}

O módulo visualizador é uma ferramenta muito interessante anexada à Slim-tree, que permite "ver" o conjunto de dados indexado, juntamente com a estrutura de nós formada pela hierarquia da árvore, permitindo o tratamento de conjuntos de dados métricos adimensionais (por exemplo um conjunto de palavras) de uma forma mais intuitiva ou prática. O visualizador auxilia tanto na inspeção visual para verificação de como a árvore está, como em ferramentas para mineração de dados (data mining) visuais c interativas.

\subsection{Considerações Finais}

Como foi visto, as inovações da estrutura Slim-tree sobre as estruturas métricas tradicionais são: o fat-factor; que possibilita indicar se a estrutura de índices construída sobre um determinado conjunto de dados é eficiente ou não; o algoritmo Slim-doun, que efetua a reorganização dos dalos organizados por elic, de forma a minimizar a taxa de acesso a disco quando efetuando consultas por similaridade; possibilidade de visualizar a organização da informação armazenada, permitindo ao usuário perceber onde estão os aglomerados e 
dementos de exceção pertencentes ao conjunto de dados, além do inter-relacionamento entre os elementos de dados, que possibilita também o acompanhamento visual das consultas efetuadas sobre a base de imagens. 


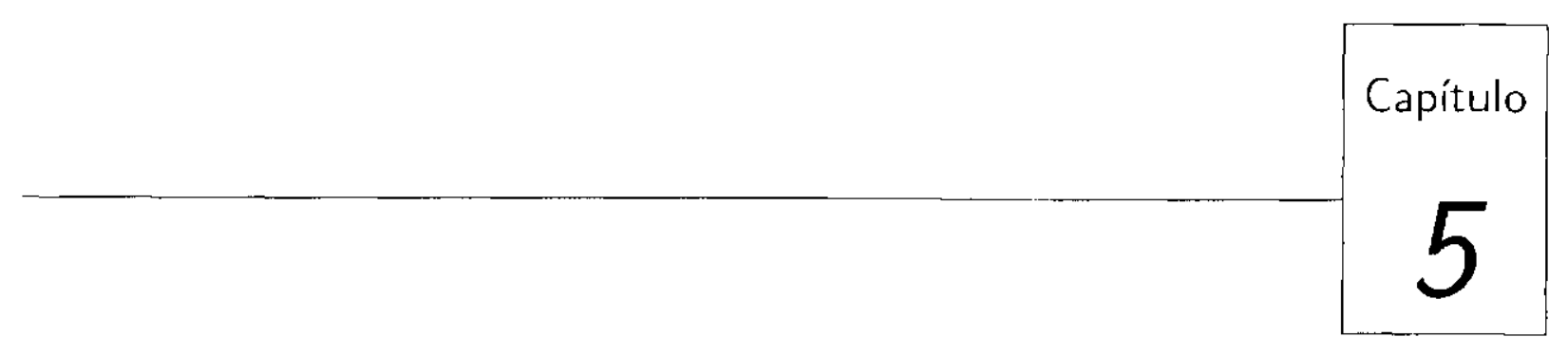

\section{Trabalho Desenvolvido}

\subsection{Considerações Iniciais}

Os sistemas hospitalares trabalham com um grande volume de informação gerada muitas vezes por aparelhos distintos. Essas informações são basicamente os laudos dos paciontes, contendo, por exemplo: diagnóstico, medicação, sintomas e imagens de exarnes. $\Lambda$ aquisição de imagens é realizada por equipamentos relativamente caros e de diferentes fabricantes. Como cada marca possui seu próprio meio para aquisiçāo, imagens provindas de diferentes cquipamentos comunente trazem diferenças entre elas. A alteração mais frequente nas imagens é a variaçăo de brilho (tonalidades de cinza). Esse tipo de alteração afeta profindamente os sistemas de recuperação de imagens bascados $\mathrm{cm}$ cores.

Visando a solução para esse problema, foi realizada uma pesquisa bibliográfica sobre o assinto em [Campo, 2002]. As abordagens vistas trabalham com as cores das imagens e, em sua maioria, utilizam imagens coloridas em seu banco de imagens. Nenhuma das abordagens tratou, de maneira cxclusiva, imagens em níveis de cinza e, muito menos, as de exarnes médicos. Como o Grupo de Bases de Dados e de Imagens - GBDI/USP estava trabalhando com o Histograna Métrico, sua modificaçäo foi proposta em [Campo, 2002] c será apresentida rıeste capítulo. 
() desenvolvimento do sistema proposto foi dividido en três etapas:

Pesquisa bibliográfica: onde foi verificado o estado-da-arte na área e possíveis soluções. além do estudo das bibliotecas e aplicativos que foram utilizados.

Protótipo: onde foi implementado e testadas algumas soluções descritas na seção 3.5.1 e 3.5.2, além de inscrir novos recursos para a manipulação e tratamento de imagons.

SRIS-HC: implementação do sistema final, incorporando partes do protótipo ao Sistema de Recuperação de Imagens Similares do Hospitial das Clínicas de Rỉbeirão Preto.

\subsection{Protótipo de um SRIS baseado no DicomViewer}

Quando um cliente observa a necessidade de fazer um software, ele tem um objetivo firal, mas raramente todos os requisitos estão bem definidos e claros para o programador. Há sempre a necessidade de inclusão de algum reguisito, ou da portalsilidade, ou ainda mesmo a interface com o usuário [Pressman, 2002].

A prototipação é um método que o programador utiliza para poder encontrar a melhor alternativa, os requisitos e os dados nocessários para a construção do melhor programa para o usuário. Existem três possibilidades distintas:

1. Un rascunho, desenho em urn papel, que demonstre a interatividade com o usuário, o também os resultados que o programa trará

2. Um protótipo que tenha algumas funçôes (algoritmos) que executem o procedimento requerido pclo usuário, como forma de demonstração de desempenho parcial, demonstração de solução do problema, ou algo do gênero.

3. Um programa que execute parte ou toda a função requerida pelo usuário apenas como demonstração, como por exemplo, relatórios, mas que causarão un exforço de programaçäo posterior para a inelltoria do mesino.

Primeiramente, um protótipo foi criado para a realização de testes e validação de abordagens. O sistema foi desenvolvido tendo como base o software DicomViewer, implementado pelo Grupo de Bases de Dados e Imagens do ICMC - USP. O DicomViewer é um software para visualização e tratamento de imagens médicas, incorporando o suporte para imagens no formato DICOM e o formato proprietário GBJDI. A interface padrão do DicomVicwer pode ser vista na Figura 5.1.

Os recursos á existentes e os que foram agora implementados são descritos na Tabela 5.1. 


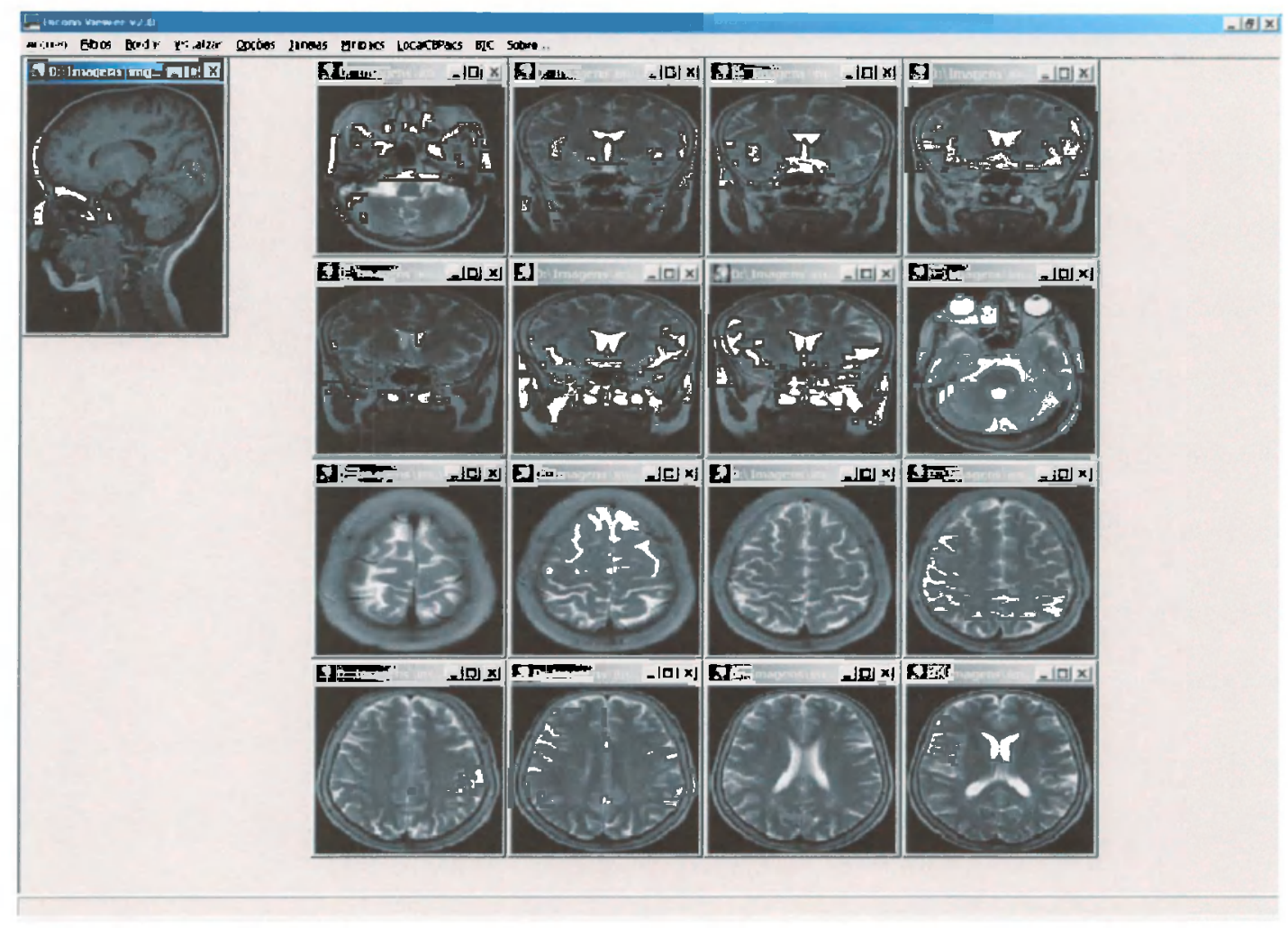

Figura 5.1: Interface padrão do DicomViewer, software que serviu de base para a implementação do protótipo.

\subsubsection{Formato de arquivos}

Na maioria dos sistemas que processam imagens, o último nível é, quase sempre, a matriz de pixels. Essa matriz possui tamanho $W \times H$ onde $W$ é sua largura e $H$ sua altura e o valor em uma determinada posição $V[i, j]$ com $i<W$ e $j<H$ determina a cor utilizada ou, no caso de imagens monocromáticas, a intensidade do nível de cinza. Tanto o formato GBDI quanto o formato DICOM utilizam a biblioteca em constante desenvolvimento pelo GBDI denominada DicomLib ${ }^{1}$. Essa biblioteca possui diversos métodos que auxiliam na manipulação das imagens, além de incorporar o Histograma Métrico e a busca por similaridade.

A abordagem BIC utiliza imagens JPEG e como a DicomLib não tinha, originalmente, suporte para este formato, sua implementação fez-se necessária. Primeiramente foi realizada uma pesquisa a respeito do formato JPEG e, por se tratar de um técnica complexa, optou-se em utilizar bibliotecas prontas que dão suporte a esse formato.

${ }^{1}$ Maiores detalhes sobre a DicomLib pode ser encontrada em http://gbdi.icmc.usp.br/devhelp/docs/dicomlib/. 


\begin{tabular}{|c|c|c|}
\hline \multicolumn{3}{|c|}{ Dicomviewer } \\
\hline & Recursos já existentes & Novos recursos incorporado \\
\hline $\begin{array}{l}\text { Formato de arciri- } \\
\text { vos }\end{array}$ & $\begin{array}{l}\text { Abre arquivos DICOM e } \\
\text { GBDI. Exporta em formato } \\
\text { BMP }\end{array}$ & $\begin{array}{l}\text { Abre arquivos JPEG. Salva nos for- } \\
\text { matos GBDI e JPEG. }\end{array}$ \\
\hline Filtros e bordas & $\begin{array}{l}\text { Modiana, auto-levels, blend } \\
\text { alpha composite, encontrar } \\
\text { borda }\end{array}$ & $\begin{array}{l}\text { Alteração de brilho, recorte da árca } \\
\text { útil por arquivo. }\end{array}$ \\
\hline Visualização & $\begin{array}{l}\text { Histograma, Histograma } \\
\text { Métrico, informaçôes da } \\
\text { imagem }\end{array}$ & $\begin{array}{l}\text { Visualizar a imagem em seu tamanho } \\
\text { original. }\end{array}$ \\
\hline Opções & $\begin{array}{l}\text { Auto-levels automático, co- } \\
\text { lor mapping view }\end{array}$ & Brilho automático, thumbnails. \\
\hline LocalcbPACS & - & $\begin{array}{l}\text { Conversão batch em JPEG, processa- } \\
\text { mento e arquivamento de caracterís- } \\
\text { ticas sob a abordagem do histograma } \\
\text { tradicional e métrico, busca por simi- } \\
\text { laridade. }\end{array}$ \\
\hline $\mathrm{BIC}$ & - & $\begin{array}{l}\text { Procksimento e arquivamento de ca- } \\
\text { racterísticas sob a abordagem BIC, } \\
\text { busca por similaridade. }\end{array}$ \\
\hline
\end{tabular}

Tabela 5.1: Tabela de comparação entre o DicomViewer e as incorporações realizadas.

\subsubsection{Filtros e Bordas}

As imagens médicas que foram adotadas para este estudo possuem a característica de serem predominantemente escuras. Assim, uma boa visualização não é realizada quando a imagem é visualizada com suas cores originais. Uma maneira de contornar essá deficiência ć a utilização de filtros digitais. A função Aulo-Levels rcaliza o que é conhecido como "stretching" no histograma de cores, ou seja, o menor valor de pixel da imagem é posicionado como sendo de valor 0 no histograma e o pixel de maior valor é posicionado como o de maior intensidado de branco (valor 255). Os pixels intermediários são alterados proporcionalmente, permitindo una visualizaçăo da imagem com melhor contraste.

O filtro da mediana suaviza a imagem, resultanıdo na aparência de que ela foi "borrada". O Blend/Alpha Composite gera uma imagem a partir de duas podendo determinar perrentualmente qual das imagens terá maior ou menor visibilidade. Além desses filtros há o incremento de brilho na imagem além de funçōes de recorte da imagem. $\Lambda$ imagem é recortada para maximizar a busca, realizando a extração de características no retângulo (MBR - 
minimum boundary box) da área útil da inagem. Alguns exemplos da utilização dos filtros presentes no DicomViewer são apresentados na Figura 5.2.
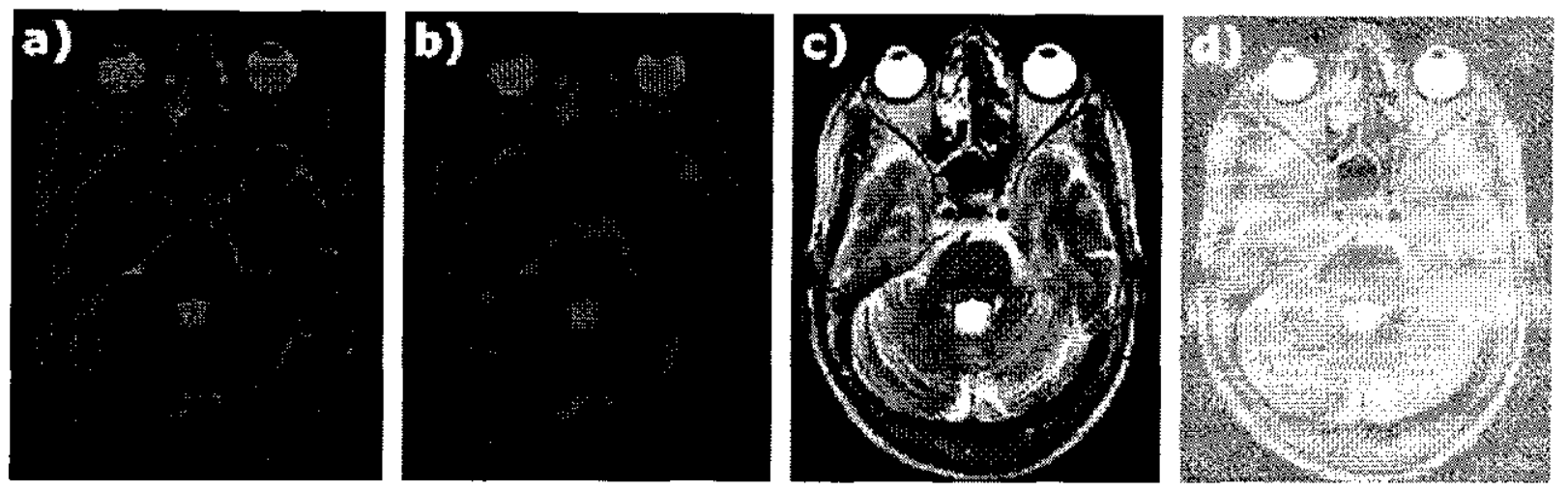

Figura 5.2: Exemplos de utilização dos filtros do DicomViewer. a) imagem original, b)após aplicação do filtro da mediana com fator 2, c)após processamento do auto-levels e d) com adica de de 100 unidades de brilho.

\subsubsection{Visualização e opções}

Na cutrada Visualização, o usuário pode ter acesso à visualizayăo do Histograma Métrico o do histograma normalizado, além de poder visualizar as informaçoes das inagens DICOM. Caso a imagem em questão não soja do tipo DICOM, mma mensagon de erro será retomada para o usuário. A funcão "visualizar tamanho original" é útil nas consultas em che săo apresent ados thumbnails'. A utilização de thumbnails ó muito útil na apresentação de resultados de busca jái (ue não ocupa muito espaço em memória e a visualizaçăo fica mais adequada quando săo a) resentadas muitias inagens na tela.

Uma outra função importante no sistema é a "Opçoes" a qual se poole escolher proviamente cun que modo as imagens serão abertas. Essas opções inchuem o auto-levels automático. brilho automático e o color mapping view que adiciona cores à imagem de acordo com sule luminosidade. Esse tipo de visualizaçào ó comumente observado em mapas de mediçás de temperatura, onde as temperaturas mais quentes säo coloridas do cores fortes como o vermelho o temperaturas mais amenas com tom mais suaves como o aznl.

\footnotetext{
${ }^{2}$ imagem minimizada. jeguena, que representa uma maior con mais detalhes, imagem en forma de slides.
} 


\subsubsection{LocalcbPACS}

A função LocalcbPACS é responsável pelo módulo de recuperação de imagens por conteúdo. Como foi visto no Capítulo 3, as imagens devem passar por um pré-processamento onde: suas características sào extraídas e armazenadas em un vetor de característica. A função "processar imagens" realiza esse trabalho. Quando o usuário a seleciona o sistema informa que o processamento das imagens pode demorar, evitando assim que, com a demora do processo, se pense que o sistema não está processando as imagens. O tempo gasto, em média, para processar cerca de 5000 imagens foi de 15 minutos. Esse tempo varia de acordo com o tamanho da imagemı já que a extração do histograma necessita a leitura completa da imagern. Após o processamento, as informaçöes são salvas em um arquivo binário contendo os nomes dos arquivos das imagens o sens respectivos histogramas. $A$ escolha do histograma (métrico ou normalizado) ó feita na hora de selccionar o formato do arquivo a ser salvo, portanto, existe um arquivo para cada tipo de histograma.

Por ter sido construído como um protótipo, o armazenamento foi feito de modo linear e a recuperação de imagens é realizada através de uma busca seqüencial. Como as informaçoes depois de lidas no arquivo são armazenadas em memória, o sen processamento é rápido. Em um conjunto maior de imagens seria necessário utilizar outra maneira de armazenar os dados para realizar a consulta, isto é uma estrutura de indexaçäo agilizaria a consulta.

$\Lambda$ pós as imagens terem sido processadas, pode-se realizar a consulta por similaridade. Uma imagem deve ser aberta e estar ativa na tela do usuário. Esta imagem deverá ser a imagem objeto para a consulta. A função "Vizinhos mais próximos" lề o arquivo de dados e en seguida (xtrai os dados da imagem ativa, comparando-a com todas as outras gravadas no arcuivo. Como pode ser observado, cssa implementaçño não prevê um grande número de imagens na base de dados e serve simplesmente para a validação dos resultados esperados. O usuário pode cscolher entre a visualização em thumbnails on en tabela, que apresenta as imagens en ordem de similaridade e o valor da distância em relação à imagem de consulta. Una consulta dos 16 vizinbos mais próximos utilizando o Histograma Métrico é apresentada na Figura 5.3 .

Foi criado também um conversor em lote para imagens JPEG. Fste conversor foi necessário para utilizar a abordagem $\mathrm{BIC}$, como será descrito a seguir. 


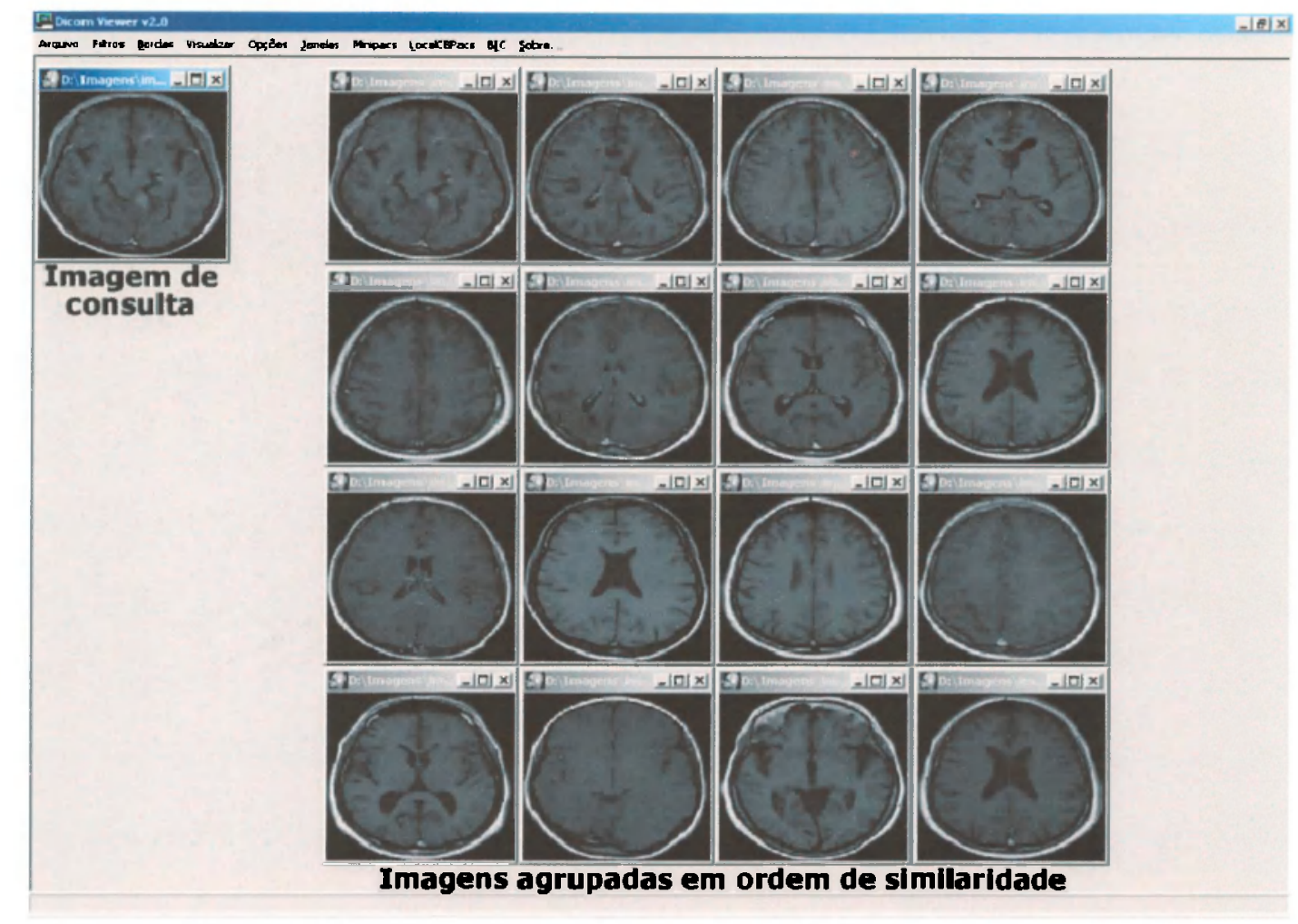

Figura 5.3: Consulta por similaridade no protótipo adicionado ao DicomViewer.

\subsubsection{BIC}

A abordagem BIC, como apresentada na seção 3.5.2 (página 37), foi implementada para realizar comparações com os resultados do Histograma Métrico. A implementação foi adaptada para imagens monocromáticas, já que essa abordagem foi proposta para imagens coloridas. A dificuldade de encontrar sistemas em que utilizem exclusivamente imagens em tons de cinza foi grande e, após análise de várias abordagens, optou-se para a BIC pois trazia resultados muito animadores.

Da mesma maneira que o processamento das imagens foi necessário no histograma normalizado e métrico, na BIC faz-se necessário também. O armazenamento das informações foi realizado em um arquivo binário e a busca seguiu o mesmo procedimento do Histograma Métrico. A grande vantagem da utilização do BIC foi a economia de espaço para armazenamento das informações em disco.

A abordagem BIC, por ser mais adequada ao tratamento de imagens heterogêneas e coloridas teve um desempenho muito limitado, trazendo resultados pouco satisfatórios em comparação com o Histograma Métrico [Campo and Traina, 2003], como será visto na pró- 
xima seção.

\subsection{O Histograma Métrico Adaptado}

Os PACS são ambientes complexos, que recebon imagens de diversas modalidades e periféricos, armazcnando-os e transmitindo-os entre clientes e servidores. A variedade de equipamentos, procedimentos e pessoal técnico que os manuseiam tornam o processo de aquisição de imagens uma das partes mais delicadas deste processo, pois dependendo de como a imagem foi adquirida ela se torna mais escura (menos brilho) ou mesmo saturada (brilho em demasia). Tais variações dificultam a comparação cntre imagens. Logo, a calibração do dispositivo de tomografia bem como a precisão do equipamento podem trazer mudanças consideráveis na imagem final. Essas mudanças são, normalmente, variaçōes no brilho e no contraste da imagem. Os principais sistemas de recuperação de imagens por conteúdo baseado em cor não suportam essas variações, não recuperando de mancira eficiente a mesma imagem que tenha sofrido variações de brilho $\mathrm{c} / \mathrm{ou}$ contraste [Campo and Traina, 2003].

O Histograma Métrico original tem a característica de ser invariante às transformações geométricas (escala, rotação e translação), mas apesar de intrinsecamente ser invariante também a transformaçōes de brilho, isso nāo havia sido efetivamente testarlo e aviliado. Nènhuma técnica na literatura trata de mancira eficiente a questão da variação de brilho, o este trabalho visa a preencher csta lacuna. A Figura 5.4 ilustra três imagens onde ocorre variação de brilho e contrastc e seus respectivos histogramas. Essa invariância a transformações de brilho é muito importante, porque imagens de mesmo paciente e exame ao serem adquiridas em situações diferentes tendem a variar o brihho. Assim pesquisas diretas por histogramas convencionais não recuperariam tais imagens que são inerentemente muito semelhantes.

Como pode-se observar pela Figura 5.4, a variação de brilho em uma imagem afeta diretamente seu histograma. Além disso, verificou-se que a variação de contraste o altera trazendo Jacunas entre seus bins. Isto ocorre quando é utilizada a técnica conhecida como esticamento ou "stretching" do histograma. Tal técnica identifica os maiores e menores valores da tonalidade de cinza e os posicionam em seus extremos, ou seja, o branco e o negro mais intenso. Os valores dus pixels intermediários são posicionados proporcionalmente aos seus extremos, através de uma simples regra de três. Como os valores resultantes sāo inteiros. lacunas de dados são formadas. Quando isso ocorre, a performance do Histograma Métrico fica seriamente compronctida pois essas lacunas tornam-se o valor de mínimo local, produzindo buckets a cada par de bin. 

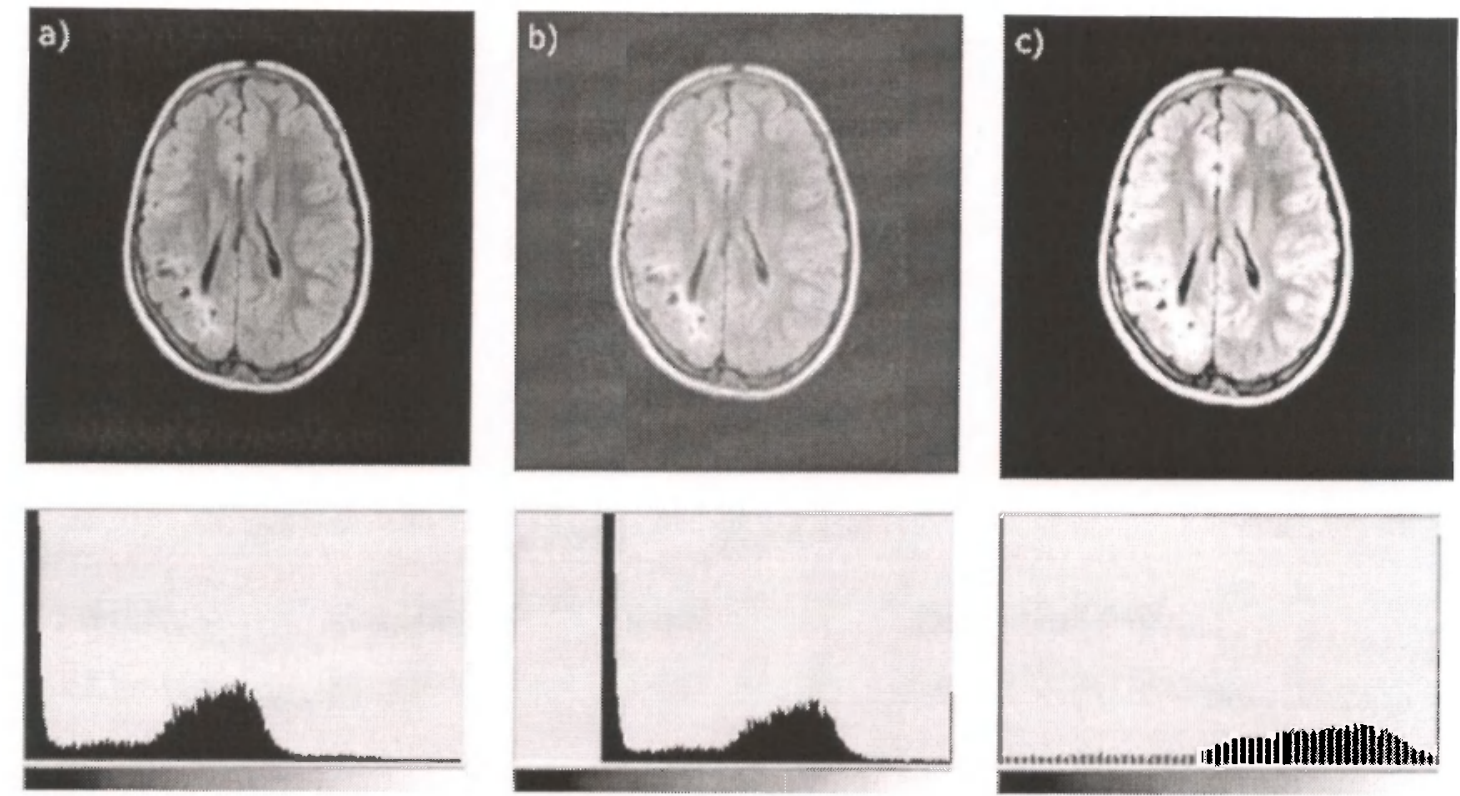

Figura 5.4: Imagem de exame de tomografia axial de cabeça humana. (a) imagem original, (b) imagem com o brilho alterado e (c) imagem com o contraste alterado.

Seria interessante se houvesse uma solução em que os dois problemas pudessem ser resolvidos de maneira simples e eficiente.

A implementação do Histograma Métrico foi alterada, tornando-a livre das variações lineares de brilho, atendendo à comparação de imagens adquiridas por equipamentos diferentes. O procedimento consiste em eliminar bins onde seus valores sejam desprezíveis sem causar prejuízo à curva do histograma. Esta eliminação de informação deve ser feita nos bins iniciais e finais do histograma analisado. Além disso, é possível realizar a eliminação no meio do histograma, tornando-o assim inerente a variações de contraste.

Como o Histograma Métrico é gerado a partir do histograma normalizado, na construção do mesmo, estipula-se um valor limite $\left(V_{L}\right)$ e qualquer valor abaixo deste é ignorado. Assim, imagens com variações de brilho mas com a mesma distribuição de cores, são consideradas semelhantes. A escolha do $V_{L}$ é de fundamental importância para o bom funcionamento do sistema. Esse valor de tolerância pode ser estipulado de acordo com as características do equipamento em que foi realizado o exame ou obtendo-se uma média dos valores não significativos de cores dos histogramas das imagens. Assim, após o processo de construção, o HM resultante é o mesmo de um sem a variação de brilho. A Figura 5.5 exemplifica um histograma onde ocorre variação de brilho com um $V_{L}$ apropriado e o histograma resultante do processo. Nos experimentos realizados, foi utilizado um $V_{L}$ de 0,0005 que corresponde a $0,05 \%$ do valor máximo que um bin pode assumir. 

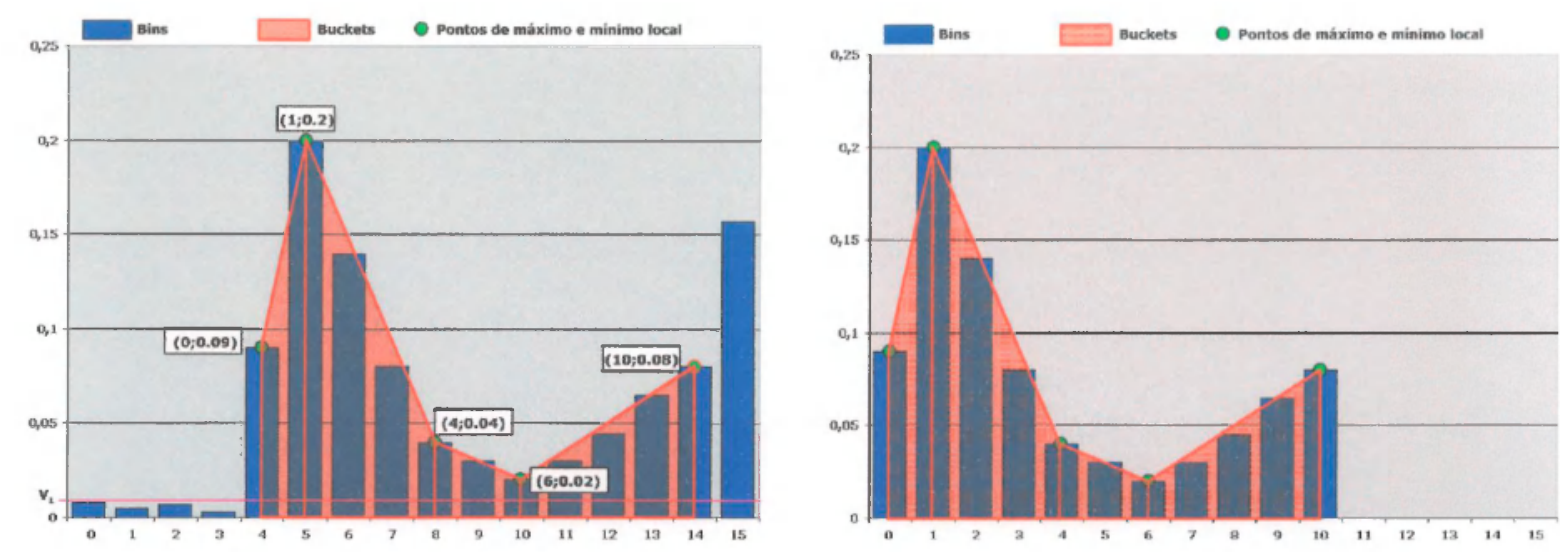

Figura 5.5: Ilustração de como é realizado a invariância ao brilho no Histograma Métrico.

Em se tratando de variações de contraste, a abordagem presente só funciona caso a sua alteração tenha sido feita em uma etapa posterior à aquisição da imagem e através do stretching. Assim como na invariância a brilho, é necessário estipular um valor limite $\left(V_{L}\right)$. A invariância a contraste é ilustrada na Figura 5.6.
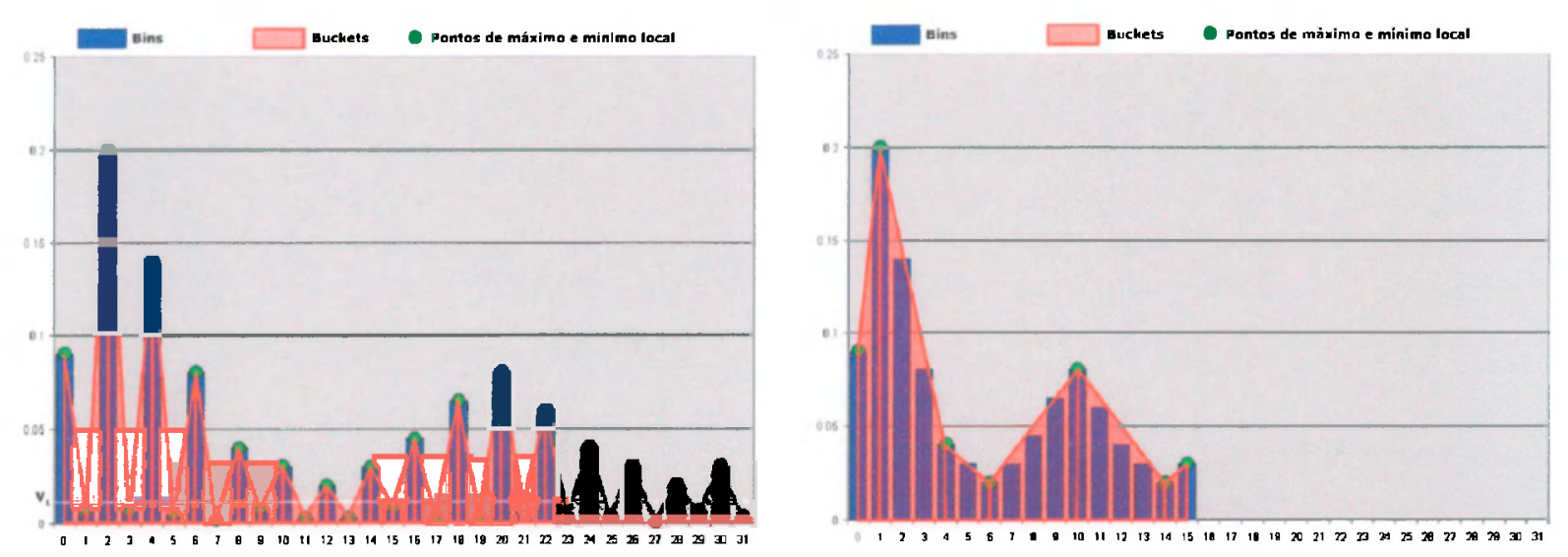

Figura 5.6: Histograma com seu contraste alterado através do stretching simples e seu Histograma Métrico correspondente. A utilização do limite $V_{L}$ elimina os bins irrelevantes, recuperando sua curva original (à direita).

Imagens similares com seu contraste alterado possuem predominantemente o mesmo formato da curva do histograma. Para o reconhecimento da forma da curva e armazenamento deste como vetor de característica outras técnicas são necessárias e não foram abordadas neste trabalho.

Uma abordagem apresentada em [Keogh, 2002], utiliza uma distância denominada de "Warp Distance" a qual foi implementada no protótipo. Tal abordagem utiliza uma aproximação entre duas curvas, distorcendo a área formada por elas e, assim, realizando uma 
mediçăo preservando a curva do objeto a ser medido. A Figura 5.7 ilustra duas curvas onde ocorre a "distorção" do áreas para melhor desempenho da distancia. Na proposta original a distáncial apresentou-se cficiente para séries lemporais e potencialmente, é útil para a mediça de similaridade entre histogramas. Infelizmente os resultades preliminares ná foran satisfatórios, trazendo como resultados das consultas elementos ben distintos do procurardo. Esta abordagem faz parte do estudo de um aluno de doutorado do GBDI/ICMC-USP e foi testada e implenentada no protótipo descrito na seção 5.2.
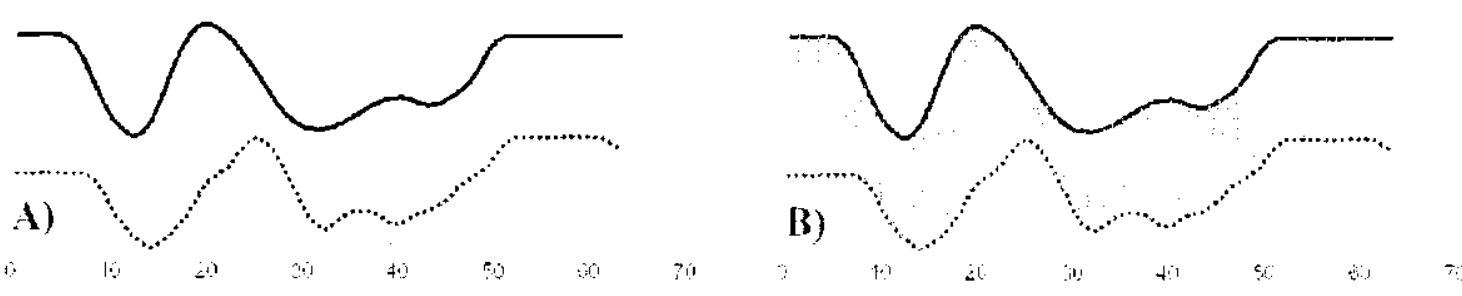

Figura 5.7: Ilustração do funcionamento da Warp Distance onde ocorre a "distorção" de áreat permitindo un melhor cálculo de similaridade ontre curvas.

\section{Resultados preliminares}

Foran realizados experimentos prolininares para avaliar a eficácia tas comsult as por similaridade ntilizando o Histograma Métrice nodificalo para suporte a variaços de brilho. Assim. analina-se o núnero de imagents corretats rotomadas pelo processo automático de busca. Para uma boa avaliação de busca, é necessário que o especialista agrupe as imagens em conjunlos, mantendo as que säo similares entre si. No entanto, pode-se observar sua similariflade

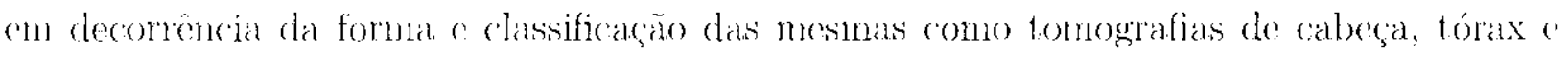
menmbros.

Os experimentos efetuados utilizaram un conjunto de 8.848 imagens médieas de diferentes estruturas corpóreas, cedidas pelo Hospital das Clínicas de Ribeirão l'reto la Universidade de São P'aulo. Essse conjunto é constitúlélo por dois subconjuntos: 4.424 inngens originais c 4.424 inagens com hrilho alterato que correspondem as inagens originais do primeiro subconjunto. Foram buscadas as 32 imagens mais similarest, utilizado o Histograma Métrico com invariancia a brilho e a abordagem BIC.

Por ser mais adequada ao tratamento de imagens heterogeneas e coloridas, a abordagem BIC teve um desempenho muito limitado, trazendo resultados pouco satisfatórios cm comparacio com o Histograma Métrico. A Figura 5.8 mostra um exemplo de comsulta utilizando tal abordagen. 


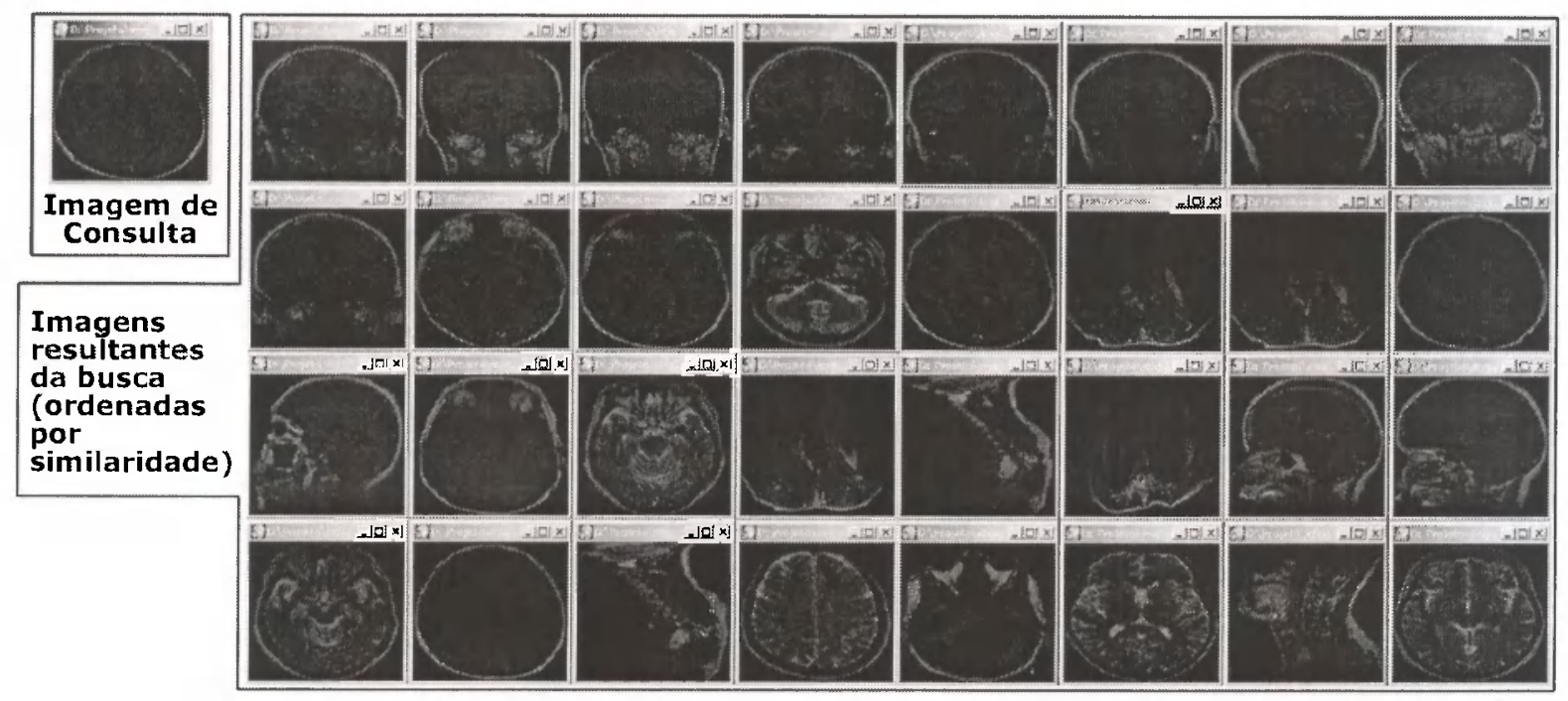

Figura 5.8: Consulta 32-Nearest Neighbors utilizando a abordagem BIC.

O Histograma Métrico recuperou as 32 imagens mais similares à imagem de consulta e através da Figura 5.9 pode-se comparar a eficácia das abordagens. As imagens, independente do grau de alteração de seu brilho foram recuperadas sem qualquer problema, pelo Histograma Métrico.

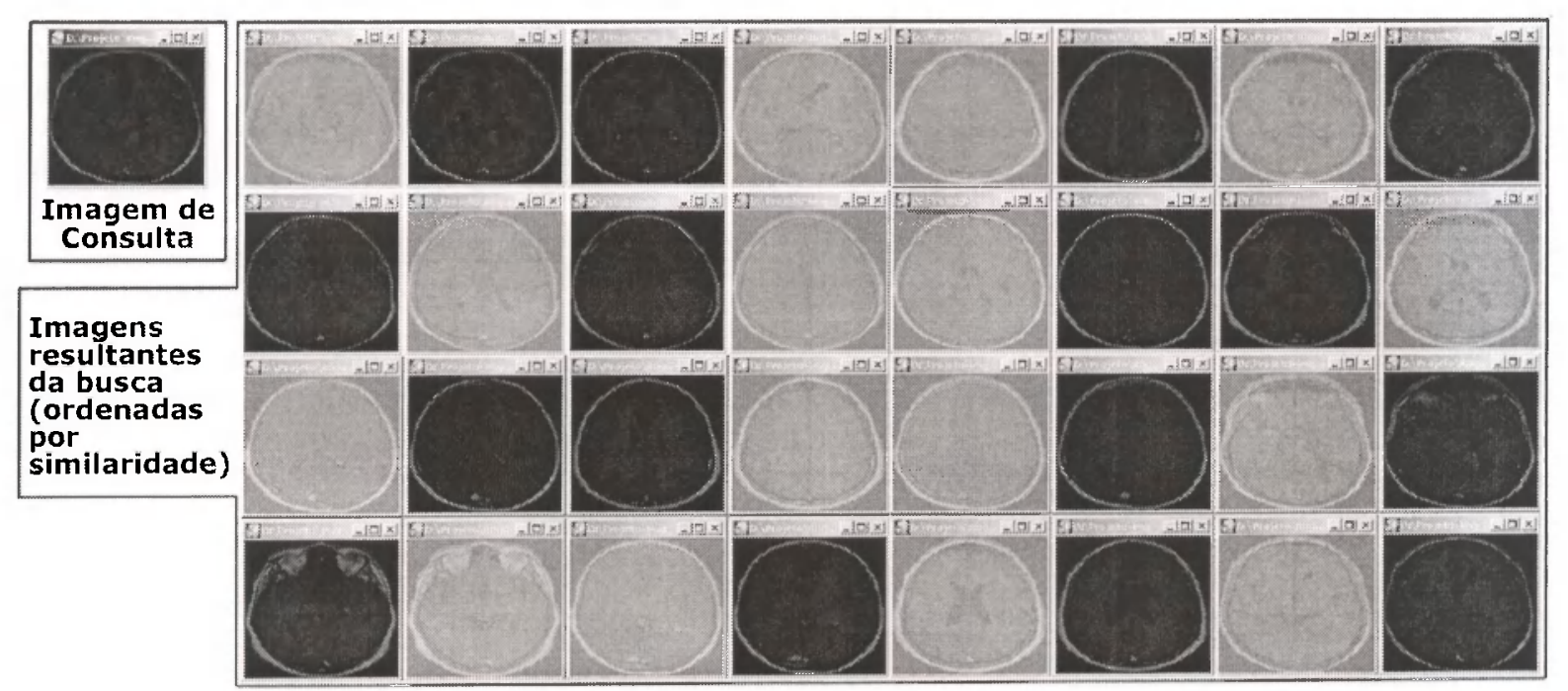

Figura 5.9: Consulta 32-Nearest Neighbors utilizando a abordagem do Histograma Métrico. 


\subsection{O Sistema de Recuperação de Imagens do Hospital das Clínicas de Ribeirão Preto}

O Sistema de Recuperação de Imagens Similares - SRIS-HC foi desenvolvido com a finalidade de demonstrar a viabilidade da técnica de recuperação de imagens por conteúdo no Hospital das Clínicas da Faculdade de Medicina de Ribeirão Preto da Universidade de São Paulo (HCFMRP/USP). Além disso, tal funcionalidade é um recurso adicional de um Sistema PACS, uma vez que os sistemas PACS tradicionais não suportam ainda esse recurso de grande interesse que é a busca de imagens similares e a recuperação por conteúdo.

O projeto original do SRIS foi desenvolvido em [Rosa, 2002] e está sendo continuado por este presente trabalho. As funcionalidades implementadas no protótipo foram adaptadas para este sistema, deixando-o mais robusto nas consultas por similaridade.

O SRIS-HC foi desenvolvido como uma extensão do Sistema de Informação em Radiologia (RIS) do Serviço de Radiodiagnóstico do HCFMRP/USP - o Sistema de Laudo Eletrônico. Assim, as funcionalidades do sistema original foram mantidas totalmente, inclusive o padrão dos módulos de consultas do Sistema de Laudo Eletrônico, que é a porta para a integração com os demais Sistemas de Informação Hospitalar do hospital, e com o mini-PACS que vem sendo desenvolvido, conforme ilustra a Figura 5.10.

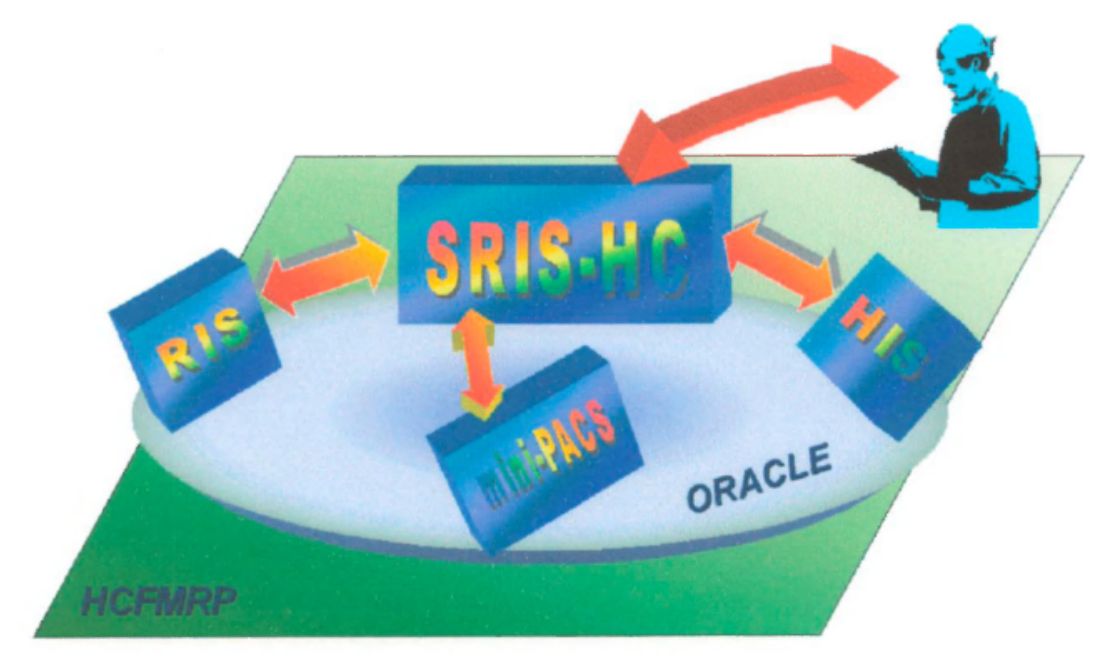

Figura 5.10: Integração SRIS-HC com RIS, HIS e mini-PACS do HCFMRP/USP.

Devido à integração do SRIS-HC com o Sistema de Laudo, é possível fazer consultas por similaridade, visualizando além das imagens resultantes da consulta, todas as informações relativas ao exame feito (tais como data, local de realização, clínica, região, modalidade, 
cquipamento e informações do paciente), inclusive o laudo médico do exame. O SRIS-HC permite ainda consultar um exame e visualizar todas as imagens do exame em pequenos thumbnails.

O sistema deverá aumentar a freqüencia com que os médicos farão uso de pesquisa de imagens de outros estudos dos pacientes com o intuito de auxiliar na interpretação do estudo corrente. Esse aumento na utilização desses recursos deve-se ao fato de que, disponibilizando o acesso ao sistema através das estaçōes de trabalho localizadas em qualquer local do hospital, os médicos poderão pesquisar as imagens sem terem que se dirigir ao Serviço de Radiodiagnóstico para solicitar as imagens que desejam visıulizar, ocorrendo uma redução do esforço necessário para se fazer busca de imagens.

Para tanto, é necessário quo a recuperação e disponibilização das imagens consultadas scja rápida e eficiente, sendo necessário o uso de estruturas de indexação que possibilitem a indexação e recuperação das imagens de forma otimizada. Essa otimização é conseguida através do armazenamento de todas as informaçōes relativas à innagern como seus vetores de características e a própria imagem. As características e as imagens são armazenadas ntilizardo seqüencia de bytes: ammazenando-as na base de dados no tipo de dados BLOB (Binary Large Object).

As imagens são indexadas e recuperadas através de características extraídas das mesmas. O SRIS-HC suporta atualmente duas técnicas de extração de características de imagens baseadas na distribuição dos nívcis de cinza: o histograma tradicional e o Histograma Métrico. As características sáo extraídas e armazenadas na base de daclos juntanente com as imagens para que possam ser armazenadas na estrutura métrica Slim-trec. É atravós da Slim-tree que essas características são indexadas c consultadas.

O processo global do SRIS-HC consistiu em armazenar as imagens na base de dados, rolacionando-as com o exame do Sistcma de Laudo Elctrônico através da chave do cxame contida no arquivo DICOM das imagens (conforme ilustra a Figura 5.11). Fstando as imagens armazenadas na base, relacionadas com os exames radiológicos, é possível fazer consultas baseadas no conteúdo das imagens exibindo as inagens resultantes da pesquisa juntamente com todas as informações relativas ao exame que gerou cada imagem, inclusive o laudo médico do exame. Como atualmente o Sistema de Laudo Eletrônico abrange somente as informações textuais do exame, O SRIS-HC poderá ser adotado como uma extensão do mesmo, uma vez que irá permitir uma consulta mais completa dos exames radiológicos, exibindo além das informaçōes textuais, todas as imagens pertencentes ao cxame. 


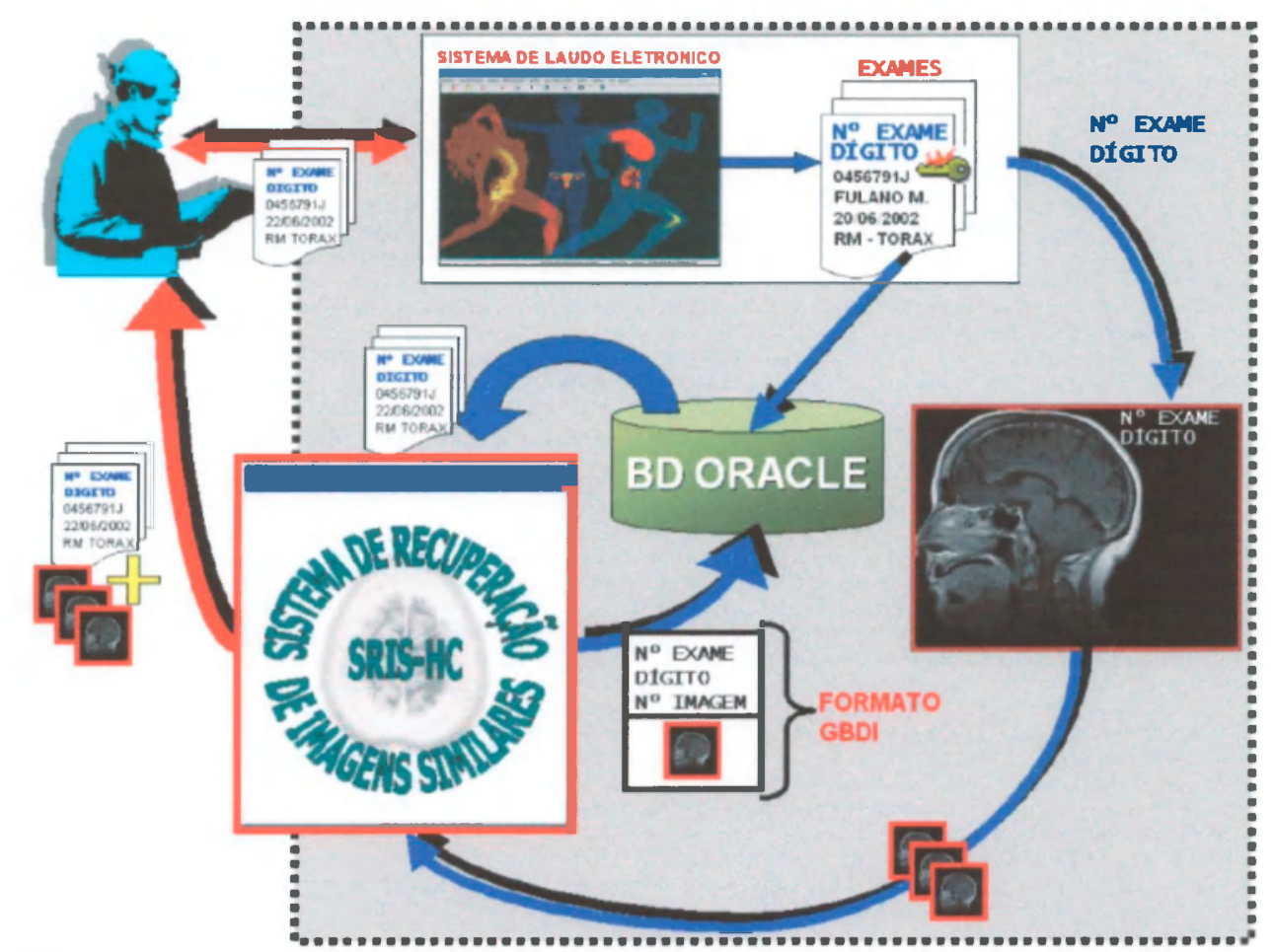

Figura 5.11: Processo global do Sistema de Recuperação de Imagens Similares - SRIS-HC.

\subsubsection{Arquitetura do SRIS-HC}

O SRIS-HC é composto dos seguintes módulos principais [Rosa, 2002]:

1. Módulo de Armazenamento das Imagens e Características Extraídas;

2. Módulo de Extração e Armazenamento de Características das Imagens Posterior ao Armazenamento;

3. Módulo de Montagem da Árvore Slim-tree;

4. Módulo de Consulta de Imagens Similares (núcleo do sistema);

5. Módulo de Consulta de Exames dos Pacientes e Respectivas Imagens e Laudos Médicos;

6. Módulo de Visualização de Logs de Armazenamento;

7. Módulo de Acesso ao Sistema;

A Figura 5.12 permite uma visão geral dos módulos que compõem o SRIS-HC. 


\section{SISTEMA DE RECUPERAÇÃO DE IMAGENS SIMILARES}
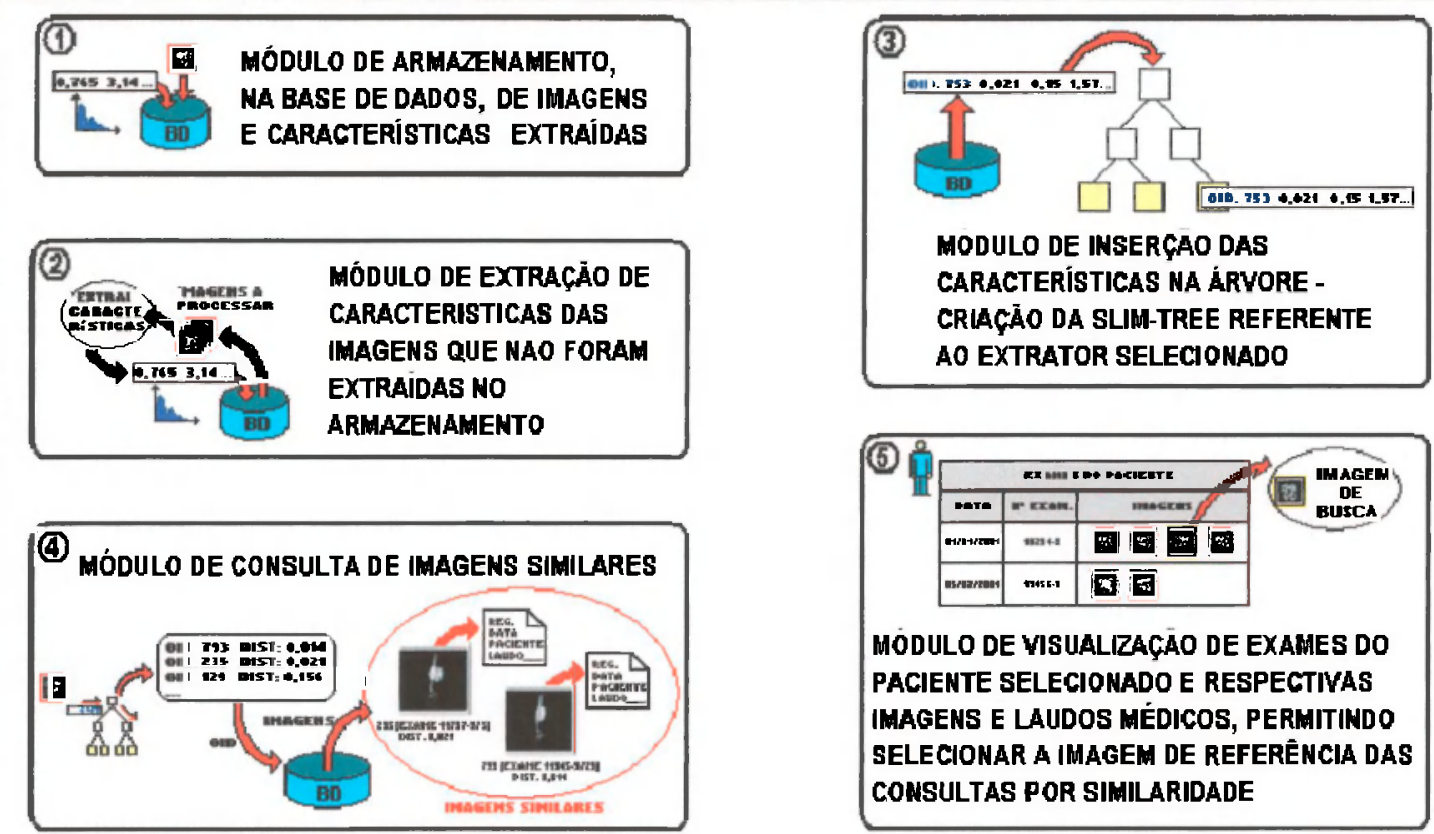

MODULO DE VISUALIZACÄO DE EXAMES DO PACIENTE SELECIONADO E RESPEGTIYAS IMAGENS E LAUDOS MÉDICOS, PERMITIMDO SELECIONAR A IMAGEM DE REFERÉNCIA DAS CONSULTAS POR SIMILARIDADE
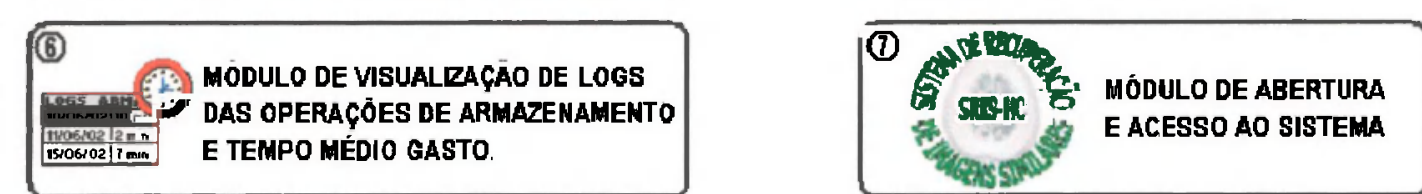

Figura 5.12: Arquitetura do SRIS-HC.

Os módulos do SRIS serão descritos a seguir. As funcionalidades que foram incorporadas ao sistema serão descritas em seus respectivos módulos. Um detalhamento maior pode ser obtido em [Rosa, 2002].

Armazenamento das Imagens e Características Extraídas

As imagens são armazenadas na base de dados e processadas, extraindo as suas características. Estas são também armazenadas para consultas posteriores. O armazenamento pode ser feito de diferentes maneiras: por uma base de dados já pronta pelo sistema de laudos ou por arquivos DICOM.

Este módulo foi alterado para dar suporte a imagens GBDI. Como as imagens DICOM possui tags nas quais são armazenadas informações relativas ao exame, a inserção na base de dados é feita de maneira automática. Porém, o formato GBDI armazena simplesmente o mapa de pixels da imagem e informações relativas exclusivamente à imagem, não podendo, 
portanto, realizar sua inserção automática. A alteração do módulo consistiu em adicionar um item permitindo assim que as imagens fossem adicionadas em exames nos quais não haviam imagens cadastradas. Esse procedimento foi realizado apenas para a validação do sistema de recuperação por similaridade. As imagens eram agrupadas aleatoriamente em conjuntos de 40 imagens por exame. Como haviam dois tipos de imagens (as originais e as com brilho sinteticamente alterado), cada exame possui 80 imagens armazenadas. A Figura 5.13 apresenta a interface que realiza o armazenamento.

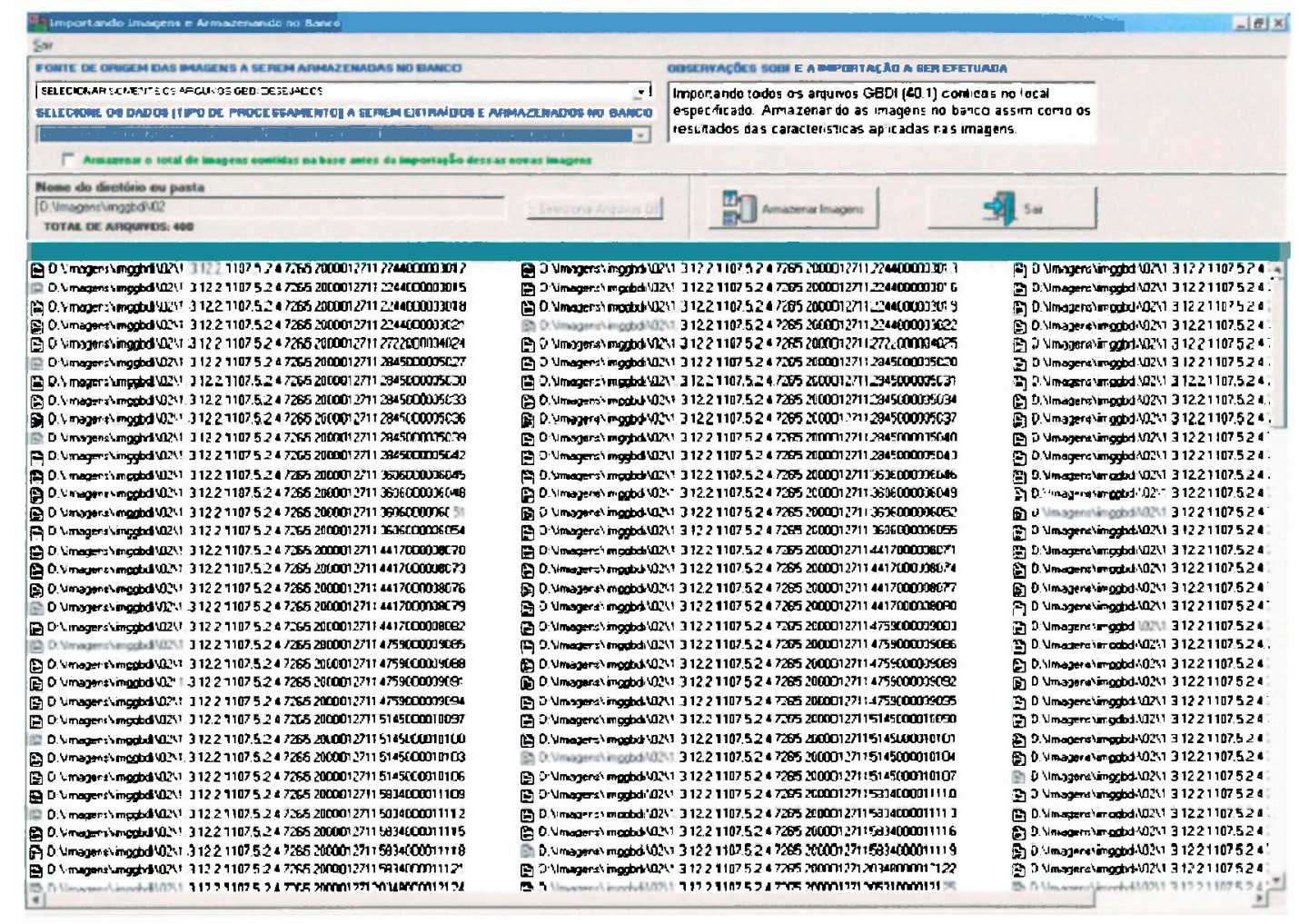

Figura 5.13: Interface em que as imagens GBDI são inseridas para validação.

Antes de iniciar o armazenamento da primeira imagem, é gerado um registro de log (o $\log$ de armazenamento é inicializado), para que o número desse registro seja armazenado junto com as imagens e as características. Este log conterá inclusive uma breve descrição da operação de armazenamento, fornecida pelo usuário, conforme possibilita o módulo de armazenamento de imagens e características. 


\section{Extração e Armazenamento de Características das Imagens Posterior ao Arma-}

zenamento

Neste módulo, é possivel sclecionar o extrator a ser aplicado nas imagens ainda não processadas (extraindo as características) ou selecionar todos os extratores ativos. Após esta operação, seleciona-se todas as imagens existentes na base que não possuem características extraídas através dos extratores ativos selecionados, retornando um conjunto de imagens a ser processado. A partir deste conjunto serão obtidas as características das imagens referentes a cada extrator e armazenadas na base. Além disso, essa operação irá gerar um log de armazenamento contendo a data e hora de início e fim da armazenagem. É possivel também saber quais características ou inragens foram cnvolvidas nesse processo.

A alteração do Histograma Métrico foi realizada na biblioteca DicomLib. Este módulo a utiliza para realizar a extração do características e não foi necessária nenhuma modificação neste. Como as imagens armazenadas anteriormente no banco já haviam passado pelo processso de extração de caract crística, clas não sofreram a alteração proposta.

\section{Montagem da Árvore Slim-tree}

Antes de iniciar alguma consulta, a Slim-tree deve ser montada. É necessário escolher por qual característica ela será estruturada e então é iniciada sua construção. O tempo médio de inserção é de, aproximadamente, 50 segundos para 18.000 imagens. Após a inserção, a árvore estará pronta para ser utilizada e cste processo não será mais necesséríro durante a sessão do consultas, inclusive o acesso a csto módulo de montagem da árvore ó bloqueado. A menos cluc o usuário saia do sistema e retorne novamente, essa rotina não será mais executada.

\section{Consulta de Imagens Similares (núcleo do sistema)}

Este módulo é considerado o núcloo do SRIS-HC, pois engloba lodos os demais módulos (que foram desenvolvidos para possibilitar a exccução de consultas por similaridade). É através desse módulo que as consultas por similaridade (k-Nearest Neighbor Query ou Range Query) são executadas e as iniagens semelhantes à imagem de reforencia sĩo recuperadas.

Para cxccutar uma consult a por sirnilaridade é necessário fornecer a imagem de referência (ou do busca) a ser utilizada. Através da imagem de busca, executa-se nma busca por imagens similares (cm Histogramas Métricos on tradicionais, conforme extrator sclecionado) à imagem de referencia, de acordo com os critérios de consulta fornecidos (tipo de consulta, número de imagenss similares, ou faixa de similaridade). A imagem de reforoncia das consultas 
pode estar armazcnada no baurco (cm formato GBDI) on no computador do usuário (que obrigatoriamente deverja ser no padrão DICOM). O sistema foi adicionado de alguns recursos que permitem realizar consultas através de arquivos nos formatos GBDI e JPEG, além do DICOM que já era utilizado. Essa funcionalidade ó bastante útil enn vista de que o Grupo de Bases de Dados e de Imagens utiliza o formato GBDI com frequiencia e o formato .JPEG é um dos mais difundidos para armazenamento de irnagens.

Após selecionar uma imagen de referência, o sistema vorifica se a mesma possui a característica previarmente selecionada na montagem da Slim-tree, já extraída e armazenada na base. Se a característica já cstiver na base, a mesma será convertida em um objeto de busca da Slim-tree. Caso contrário, a imagem passará pelo processo de extração dessa característica, sendo então armazenado na base o vetor de caractcrísticas resultante (para evitar que a mesma imagem passe por esse processo caso seja selecionada novamente). Após o armazenamento da característica extraída, esta será convertida no objeto de busca da Slim-tree. A partir daí, o processo de consulta é único, de acordo com os critérios de pesquisa fornecidos pelo usuário (tipo da consulta, número de imagens desejadas, ou faixa de similaridade a que devam se encontrar as imagens resultantes).

\section{Consulta de Exames dos Pacientes e Respectivas Imagens e Laudos Médicos}

O módulo de consulta de exames de pacientes e respectivas imagens e laudos médicos foi desenvolvido, originalmente, mantendo o padrão do módulo de consulta de exames de pacientes do Sistema de Lando Eletrônico, com o recurso adicional de visualização de todas as imagens dos exames, em miniaturas, com a possibilidade de visualizar uma imagem desejada em seu tamanho original [Rosa, 2002].

A finalidade do módulo foi permitir ao usuário selecionar uma imagem de um exame de um paciente para servir como imagem de referência das consultas por similaridade, além de permitir consultar exames de pacientes com as imagens associadas.

Se o exame possuir imagens armazenadas na base (uma ve que é uma base de testo e que nem todos os exames possucm imagens associadas), basta dar um duplo clique no exame desejado para visualizar as imagens em miniaturas. Caso o usuário queira visualizar a imagem em seu tambaho natural basta dar um duplo clique sobre a miniatura.

Para cada exame selecionado, efetua-se uma busca na base de dados de todas as imagens, montanıdo então as miniaturas a serem exibidas. Una vez montadas as miniaturas do exame. pode-se salvá-las em un arquivo, de tal forma que a próxima vez que o mesmo exame for selecionado, não haverá necessidade de montar miniaturas das imagens, que é um processo 
lento, uma vez que as imagens do exame serão sempre as mesmas. As Figuras 5.14 e 5.15 apresentam o laudo e as imagens proveniente de um exame.

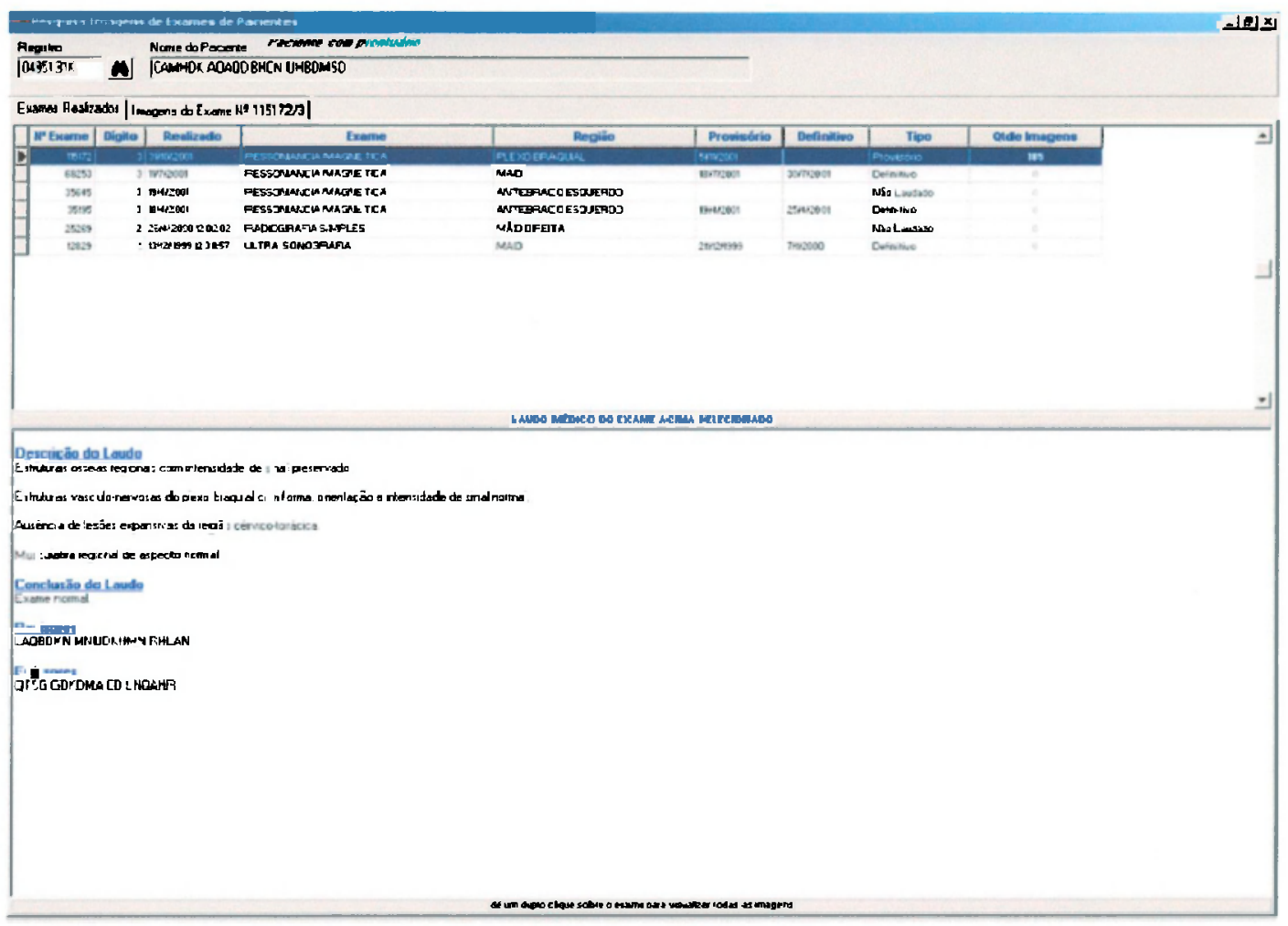

Figura 5.14: Tela de consulta ao laudos de um paciente e suas respectivas informações.

\section{Visualização de Logs de Armazenamento}

O módulo de Visualização de Logs de Armazenamento foi desenvolvido para que possa fornecer uma estimativa do tempo necessário para se armazenar as imagens, as características extraídas ou ambas.

Nesse módulo é possível visualizar também o total de imagens envolvidas no processo, seja nos processos de armazenamento das imagens (armazenamento parcial ou total) ou no processo de extração das características posterior ao armazenamento. Além disso, uma outra informação adicional é o tempo médio gasto no processo todo referente ao log.

A Figura 5.16 ilustra todas as informações contidas no módulo de visualização de logs. Note que no final da tela pode-se visualizar a descrição do log selecionado (corrente), descrição essa que o usuário fornece antes do armazenamento das imagens, ou que o sistema gera na tela de extração das características. 


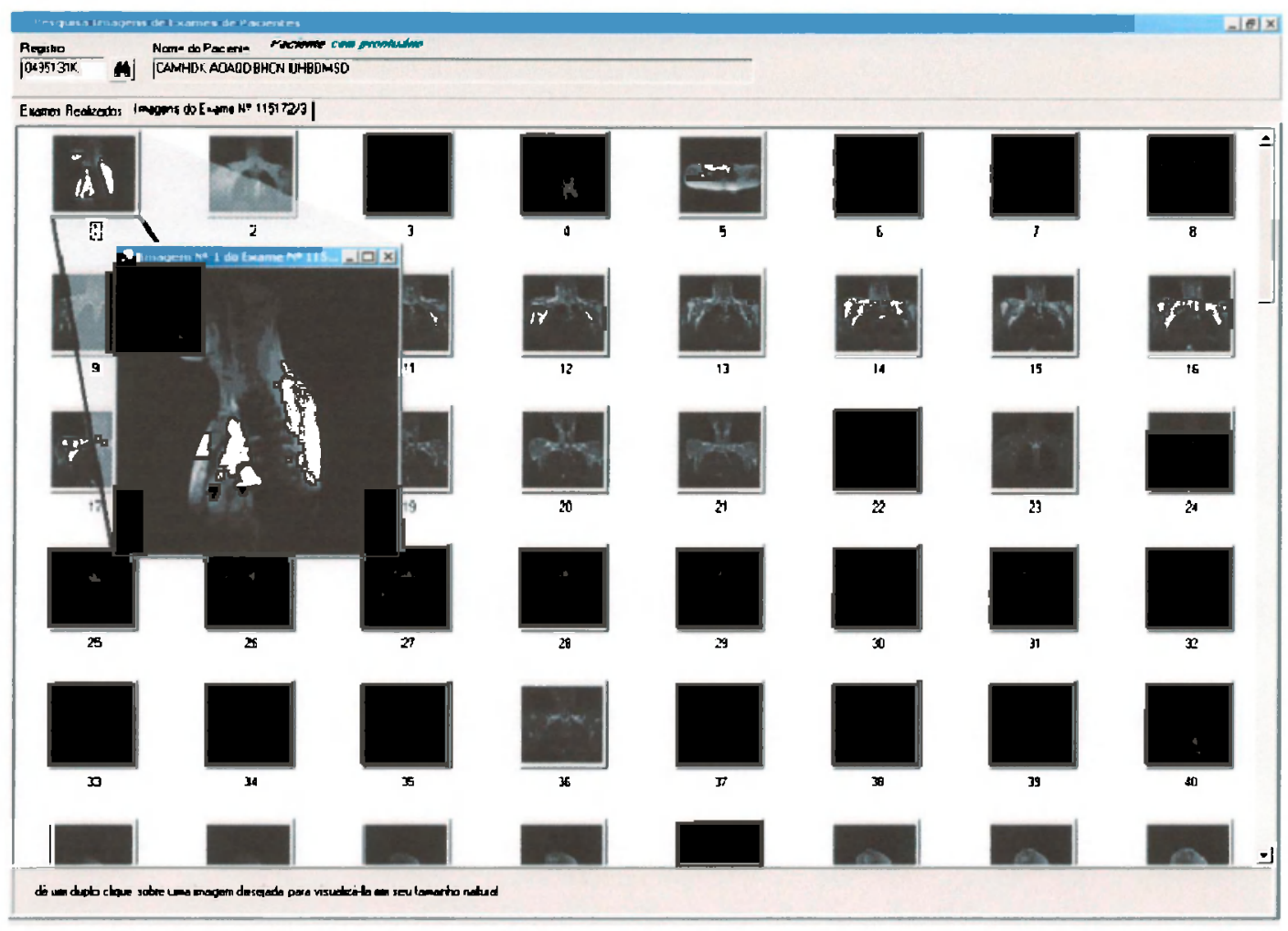

Figura 5.15: Tela das imagens em miniatura (thumbnails) do exame e a primeira imagem em tamanho natural.

Os processos de armazenamento nos quais ocorrem erros antes da finalização do log, não possuem na Figura a data e hora do término do processo. Além disso, em sua inicialização armazena-se o total de imagens que serão processadas e, na finalização, o total que foi realmente processado. Sendo assim, caso dê erro antes do término da operação, essa informação estará desatualizada [Rosa, 2002].

\section{Acesso ao Sistema}

Referente às políticas de seguranças do sistema, o SRIS-HC foi desenvolvido em conformidade com os demais sistemas do HCFMRP. É necessário que o usuário possua um nome-de-usuário e senha, adquirido junto ao Centro de Informações e Análises do HCFMRP, para estar utilizando os demais sistemas existentes no Hospital das Clínicas [Rosa, 2002].

Este módulo foi modificado para ser possível a ligação de diversas bases de dados. Para isso foi adicionado um campo onde o usuário deverá escolher a base que desejará usar.

O módulo de acesso ao sistema (Figura 5.17) é a tela de conexão do usuário com a base de dados, onde são solicitadas as informações para validar o acesso a tela principal do SRIS-HC. 


\begin{tabular}{|c|c|c|c|c|c|c|}
\hline \multicolumn{5}{|c|}{ Visualiza logs de armazenamento de imagens e car acteristicas processadas } & \multicolumn{2}{|c|}{$-\ln \mid x$} \\
\hline \multicolumn{2}{|c|}{ 6. MOSTRRA TODOS OS LOGS DE AFMAZENAMENTO } & \multicolumn{2}{|c|}{ C MOSTRAR TODOS OS LOGS APARTIRDODIA: } & \multirow{2}{*}{ 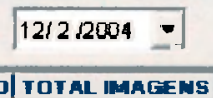 } & \multicolumn{2}{|l|}{8 Pesquisar } \\
\hline$[\mu=\mathbf{L O G}]$ & TERMINO & TIPO DE OPERACRO & |TEMPOGASTO| & & MERIA [SEG] I MAGGEM | & 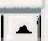 \\
\hline $8627 / 7 / 200217: 27: 29$ & $27 / 7 / 200217: 30: 09$ & SOMENTE CARACTERISTIICAS & $2 \mathrm{~m} 40 \mathrm{~s}$ & 0 & 0.00 & \\
\hline $8727 / 7 / 200217.38 .33$ & & SOMENTE CARACTERISTICAS & & 10390 & 0.00 & \\
\hline 92 4/8/2002 13:19:44 & 4/8/2002 14:43:56 & SOMENTE CARACTERISTIICAS & $1 \mathrm{~h} 24 \mathrm{~m} 12 \mathrm{~s}$ & 4631 & 1.09 & \\
\hline $934 / 8 / 200214: 47: 45$ & 4/8/2002 15:53:25 & SOMENTE CARACTERISTICAS & $1 \mathrm{~h} 5 \mathrm{~m} 41$ s & 2973 & 1.33 & \\
\hline $974 / 8 / 200216: 35: 45$ & & SOMENTE CARACTERISTICAS & & 2786 & 0.00 & \\
\hline 98 4/8/2002 16:41:23. & $4 / 8 / 200217: 30-42$ & SOMENTE CARACTERISTICAS & $49 \mathrm{~m} 20 \mathrm{~s}$ & 2786 & 1.06 & \\
\hline 100 14/1/2004 23:13:45 & 14/1/2004 23:16:05 & IMAGENS E CARACTERISTICAS & $2 \mathrm{~m} 20 \mathrm{~s}$ & 800 & 0.18 & \\
\hline $10114 / 1 / 200423.1947$ & $14 / 1 / 200423.22 .41$ & IMAGEENS E CARACTERÍSTICAS & $2 m 55 s$ & 800 & 0.22 & \\
\hline $10214 / 1 / 200423: 24: 53$ & 14/1/2004 23:27:16 & IMAGENS E CARACTERISTIICAS & $2 \mathrm{~m} 23 \mathrm{~s}$ & 800 & 0.18 & \\
\hline $10314 / 1 / 200423.27: 38$ & $14 / 1 / 200423.29 .53$ & IMAGGENS E CARACTERISTIICAS & $2 m 16 s$ & 800 & 0.17 & \\
\hline 104 14/1/2004 23:30:44 & $14 / 1 / 200423: 3231$ & IMAGENS E CARACTERISTICAS & $1 \mathrm{~m} 48 \mathrm{~s}$ & 800 & 0.14 & \\
\hline $10514 / 1 / 200423: 33: 27$ & $14 / 1 / 200423.35 .43$ & IMAGGENS E CARACTERISTICAS : & $2 \mathrm{~m} 16 \mathrm{~s}$ & 800 & 0.17 & \\
\hline 106 14/1/2004 23: $36: 39$ & 14/1/2004 23:38:21 & IMAGENS E CARACTERISTIICAS & $1 \mathrm{~m} 43 \mathrm{~s}$ & 800 & 0.13 & \\
\hline $10714 / 1001014298926$ & $174.9,9070934917$ & MSEETS E CDFALTEFIBTICAS & Pr: $A B:$ & 800 & 0.13 & \\
\hline $10814 / 1 / 2004234247$ & $14 / 1 / 200423: 44: 44$ & IMAGENSS E CARACTERISTICAS & $1 \mathrm{~m} 58 \mathrm{~s}$ & 800 & 0.15 & \\
\hline 109 14/1/2004 27.45:39 & $14 / 1 / 20042347: 53$ & IMAGENSS E CARACTERISTICAS : & $2 \mathrm{~m} 15 \mathrm{~s}$ & 800 & 0.17 & $\Rightarrow$ \\
\hline \multicolumn{7}{|c|}{ JESCPICACOO DO LOG ACIMA SELECIONADO } \\
\hline ittando todos os arquivos GE & OI (40:1) cantidas no ha & cal especificado & & & & \\
\hline
\end{tabular}

Figura 5.16: Tela da apresentação dos logs do banco de imagens.

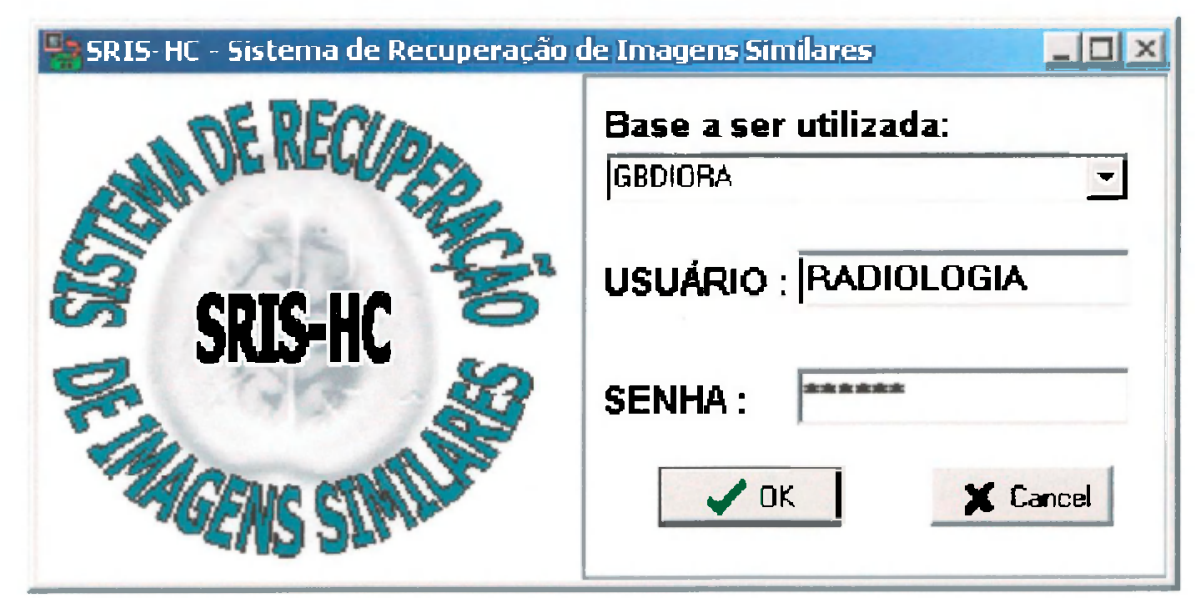

Figura 5.17: Tela de conexão do usuário com a base de dados e acesso ao SRIS-HC.

\subsection{Resultados}

A seguir serão apresentados os resultados obtidos com a implementação final no SRIS-HC. A abordagem BIC não foi adicionada ao sistema, tendo em vista que seus resultados não foram satisfatórios, como ressaltado na seção 5.2.5. 
Os experimentos foram realizados em um conjunto de 18.874 imagens, sendo que 10.390 já estavam na base de dados original e 8.484 foram inseridas para a realização de testes e experimentos. Deste último conjunto de imagens, metade delas (4242) tiveram seu brilho alterado linearmente em 100 unidades de brilho. $\mathrm{O}$ conjunto inserido para experimentos teve um diferencial qualitativo muito grande em relação ao armazenado na base. As imagens na base foram armazenadas integralmente, com grande parte da imagem sendo o fundo negro. As inseridas, tiveram o recorte de sua área útil (MBB - Minimum Boundary Box), melhorando a qualidade das informações de cores. Um exemplo do que foi armazenado pode ser observado na Figura 5.18.

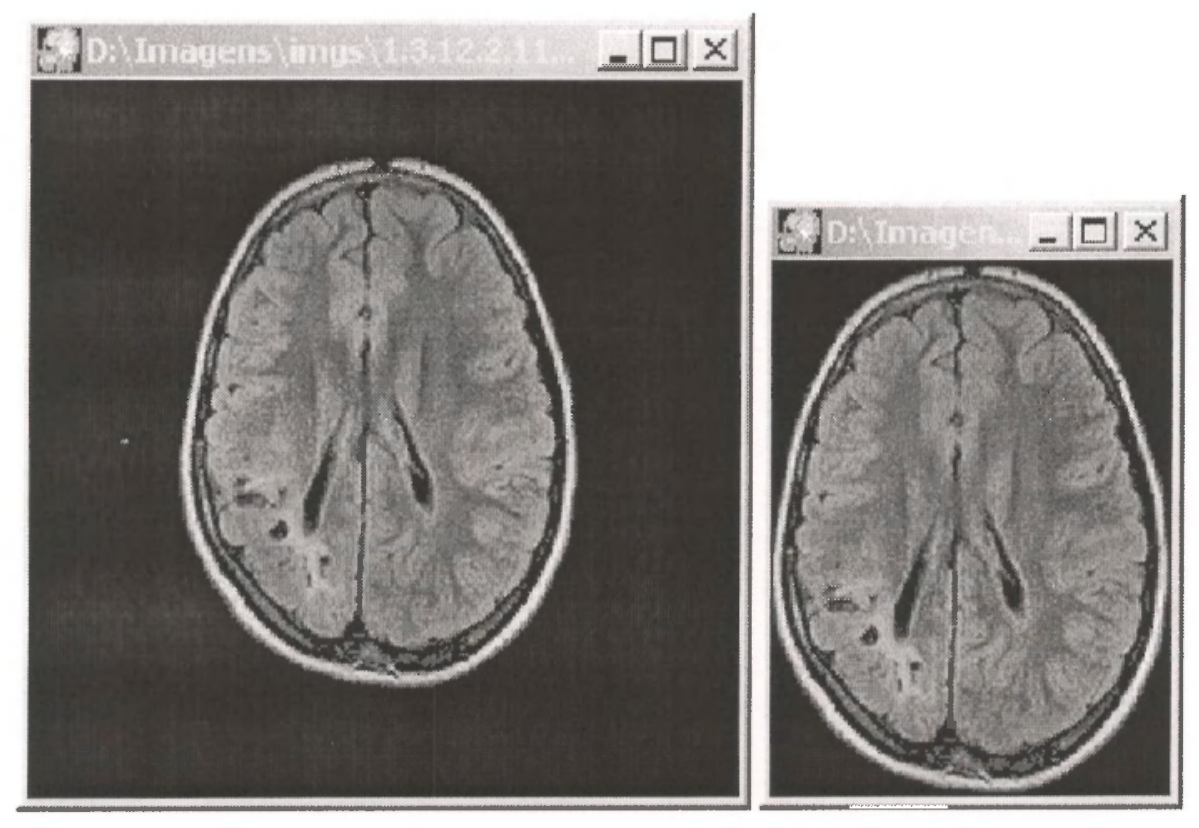

Figura 5.18: Imagem original de crânio (esquerda) e a mesma com o recorde do MBB (Minimum Boundary Box).

A montagem da Slim-tree com esse total de imagens foi de 44 segundos. Um tempo considerado tolerável, já que, com a adoção da árvore, as consultas são realizadas muito mais rapidamente. O computador utilizado é apresentado na Tabela 5.2.

Os experimentos foram divididos em 4 casos. Em todos os casos utilizou-se uma imagem de referência aleatória e realizou-se a consulta no sistema através do histograma normalizado e métrico adaptado. Tanto a consulta aos vizinhos mais próximos quanto a consulta por abrangência foram realizadas. Todas as imagens de referência apresentadas estão em seu tamanho original. 


\begin{tabular}{|l|l|}
\hline \multicolumn{2}{|c|}{ Característica do computador utilizado nos experimentos } \\
\hline Processador & Intel Pentium 4A, 2433 MHz \\
\hline Sistema Operacional & Microsoft Windows 2000 Professional \\
\hline Memória do Sistema & 1024 MB (DDR SDRAM) \\
\hline Adaptador gráfico & NVIDIA RIVA TNT2 Model 64/Model 64 Pro (32 MB) \\
\hline Disco rígido & MAXTOR 4K080H4 (80 GB, 5400 RPM, Ultra-ATA/100) \\
\hline Base de dados & Oracle9i Database Release 2 (9.2) for Windows \\
\hline Compilador & Borland C++ Builder Enterprise Suite Versão 5.0 \\
\hline
\end{tabular}

Tabela 5.2: Configuração do computador utilizado para os experimentos.

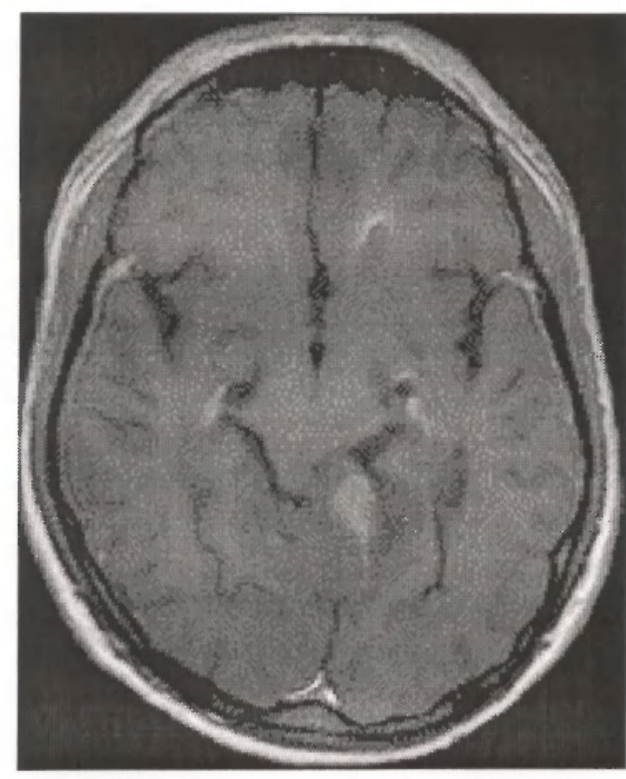

Uma consulta aos 48 vizinhos nıa:s próximos foi realizadia. Á inagem de referência foi a de um crâni s, escolhida aleatoriamente (Figura 5..9). O tempo gasto para realizar as conisultas nunca ul-

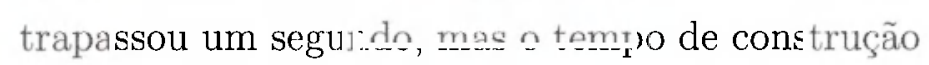
das jennelas dos resul.tados varia de écordo corı o número de imagens 'thumbnails) que será obstrvado. As irnagens de refirências foram nseridas para a const.lta através $\mathrm{l}$ is opção "Selecionar imagem na pasta do computarlor" e estavam no formato GBDI. Cons ultas através do formato DICCM I JPEG também sũo pormitidas, mas como a extrią̧̧̃ do característica da imagem de referência possui um custo Figura 5.19: Imagem de referência para computacional ínfimo tendo o mesmo desempenho, o primeiro caso. optou-se por utilizar as imagens GBDI.

O resultado da consulta pode ser observado através da Figura 5.20, onde foi utilizado uma consulta aos 40 vizinhos mais próximos através do histograma normalizado. As imagens recuperadas são próximas à de consulta, porém ela está susceptível a variações de brilho. Isso pode ser observado nos resultados pois nenhuma das imagens com o brilho alterado na base estava contida no conjunto do resultado. Uma consulta por abrangência também foi realizada com raio de 0.3 unidades e seu resultado pode ser observado através da Figura 5.21.

O Histograma Métrico adaptado produziu resultados bem distintos do histograma normalizado. A consulta foi realizada com os mesmo parâmetros do anterior. A variação de brilho não trouxe problemas na recuperação de imagens, como pode ser observado nas Figuras 5.22 e 5.23 . 


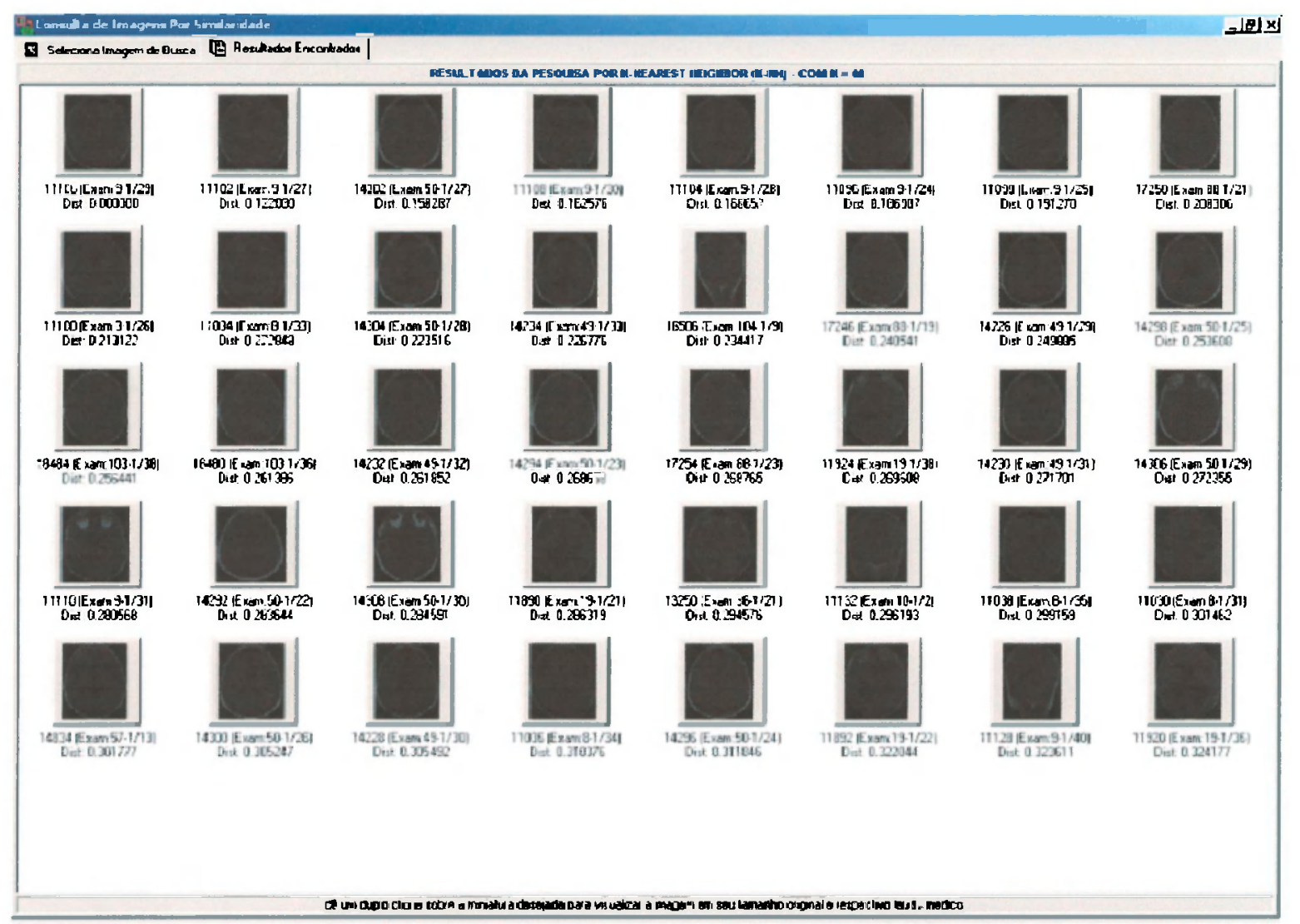

Figura 5.20: Resultado da consulta aos 40 vizinhos mais próximos utilizando o histograma normalizado.

Um resumo dos testes realizados é apresentado na Tabela 5.5. As imagens dos resultados obtidos não constam neste capítulo (caso 2, 3 e 4) mas estão no Apêndice A.

\subsection{Considerações Finais}

Este Capítulo apresentou o trabalho desenvolvido e as modificações efetuadas no SRIS-HC, além da evolução do sistema, desde o seu protótipo até a implementação final.

Descreveu-se como o Histograma Métrico adaptado pode ser invariante às mudanças de brilho, tornando-o uma abordagem compacta, e eficiente para a recuperação de imagens médicas que são obtidas por processos distintos de aquisição. O Histograma Métrico utiliza buckets de tamanho variável, diferentemente das abordagens tradicionais que restringem a quantidade de bins. Além disso utiliza uma métrica baseada na diferença de áreas entre histogramas normalizados.

O principal componente para aprimorar o histograma e deixá-lo invariante ao brilho é 


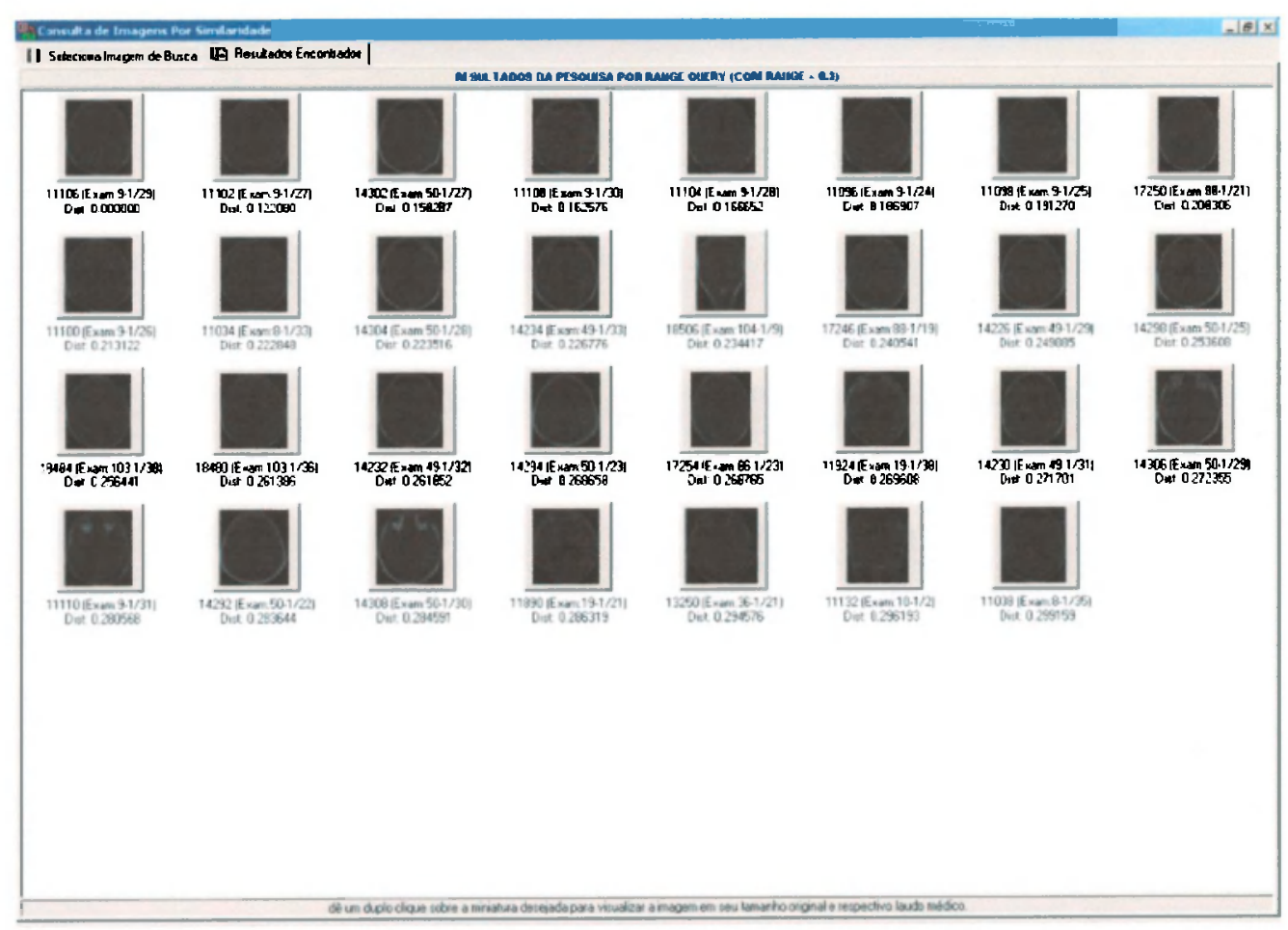

Figura 5.21: Consulta por abrangência com raio de 0.3 utilizando o histograma normalizado.

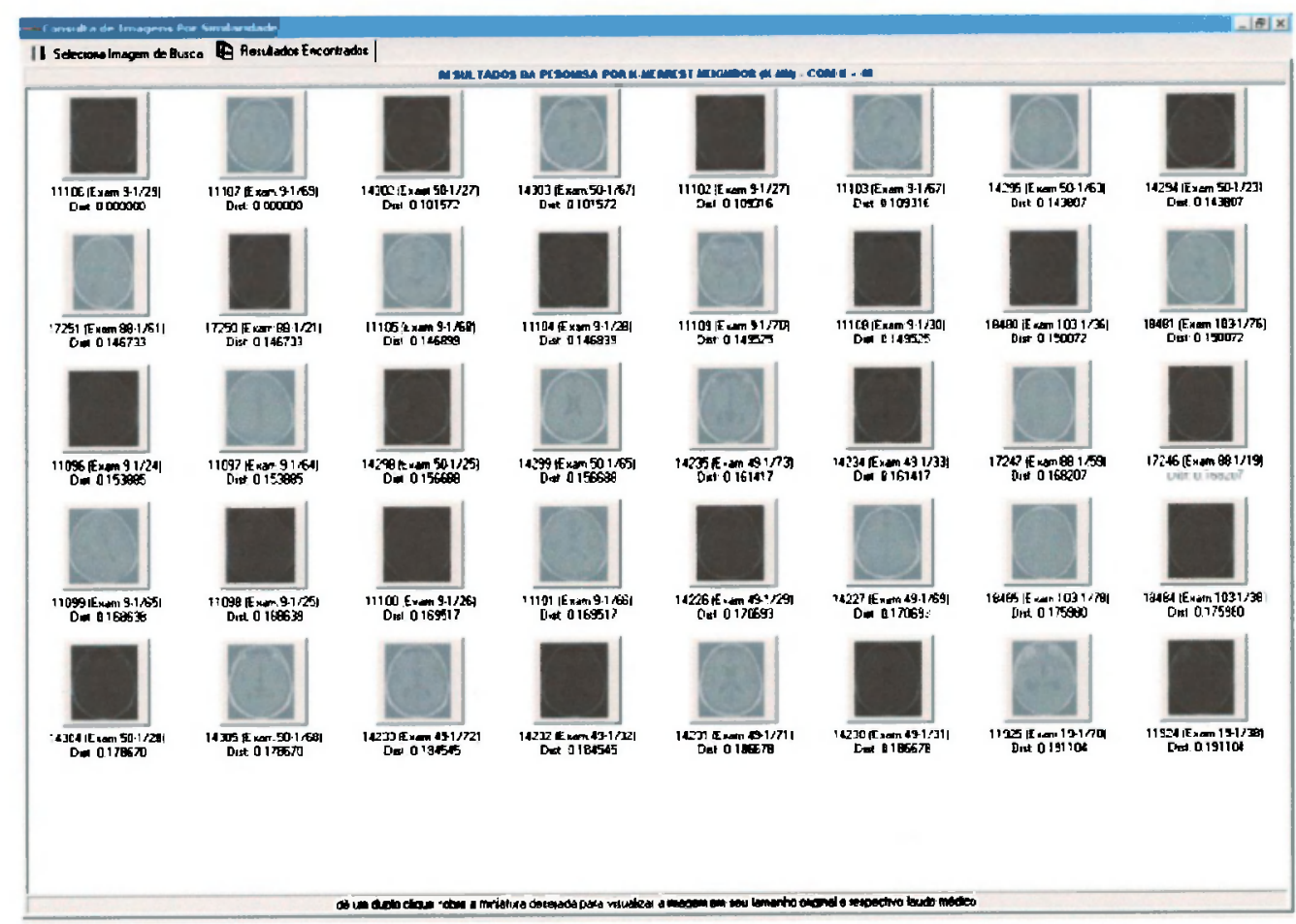

Figura 5.22: Consulta aos vizinhos mais próximos através do Histograma Métrico adaptado. 


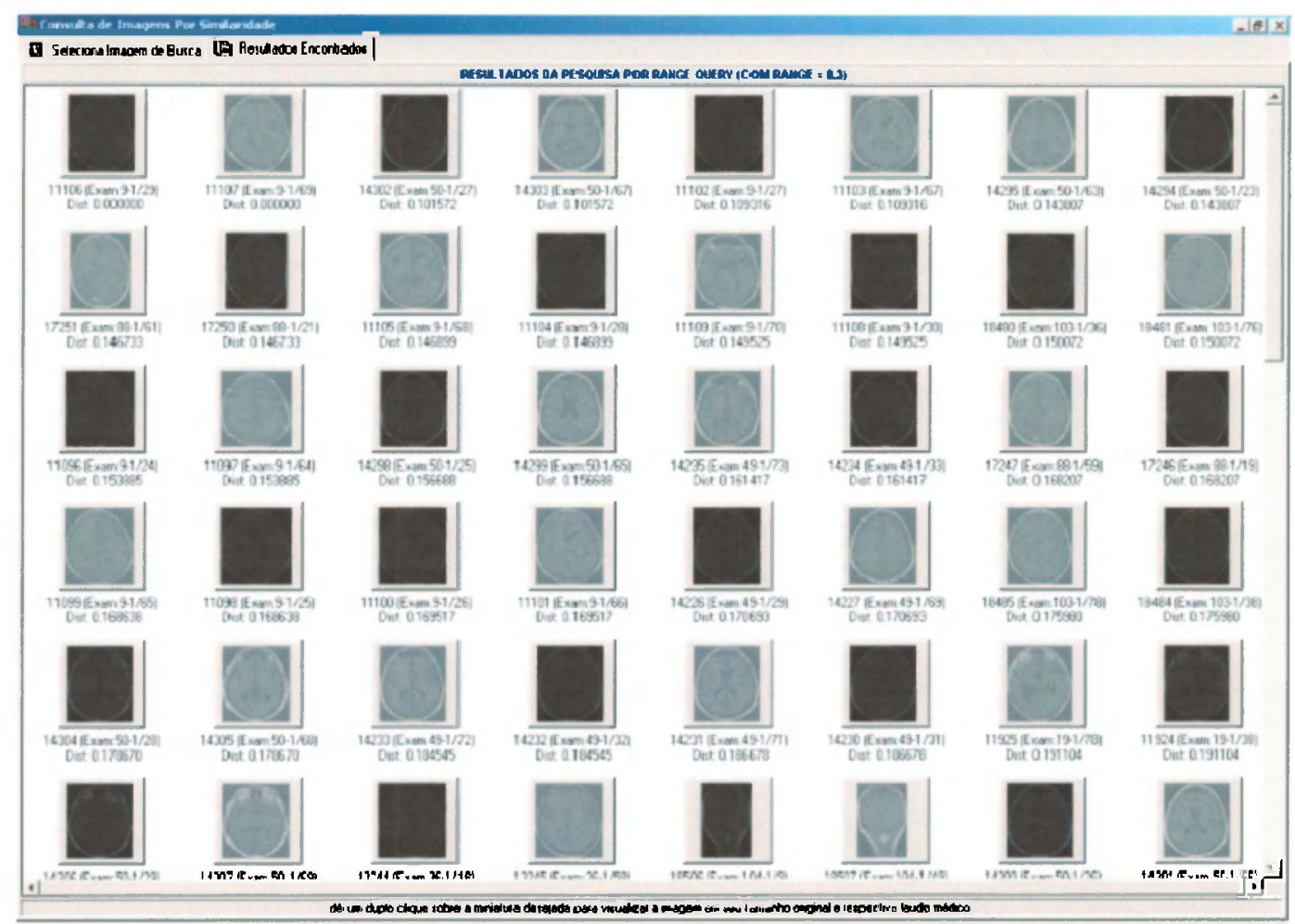

Figura 5.23: Consulta por abrangência com raio de 0.3 utilizando o Histograma Métrico adaptado.

especificar um número limite utilizado para ignorar valores não significativos. Esse valor gira em torno de $0,5 \%$ do valor total do histograma. Os resultados mostram que a abordagem utilizada é eficiente e supera claramente abordagens já consolidadas como o BIC.

A recuperação de imagens, através de formas dos objetos presentes na mesma, poderá ser incorporada a este sistema. A grande dificuldade de utilizar abordagens baseadas na forma é o alto custo e pouca precisão de segmentação automática dos objetos de interesses nas imagens. 


\begin{tabular}{|l|l|l|l|l|l|l|l|}
\hline Caso & $\begin{array}{l}\text { T'ipo de histo- } \\
\text { grama na Ár- } \\
\text { vore Métrica }\end{array}$ & Consulta & Critério & $\begin{array}{l}\text { Imagens } \\
\text { Resul- } \\
\text { tantes }\end{array}$ & $\begin{array}{l}\text { Tempo } \\
\text { de busca }\end{array}$ & $\begin{array}{l}\text { Tempo } \\
\text { de visua- } \\
\text { lizaçáo }\end{array}$ & Figura \\
\hline 1 & normalizado & $k-n n$ & $\mathrm{k}=40$ & 40 & $<1 \mathrm{~s}$ & $8 \mathrm{~s}$ & 5.20 \\
\hline 1 & normalizado & $r q$ & $\mathrm{r}=0,3$ & 31 & $<1 \mathrm{~s}$ & $6 \mathrm{~s}$ & 5.21 \\
\hline 1 & métrico & $k-n n$ & $\mathrm{k}=40$ & 40 & $<1 \mathrm{~s}$ & $7 \mathrm{~s}$ & 5.22 \\
\hline 1 & métrico & $r q$ & $\mathrm{r}=0,3$ & 130 & $<1 \mathrm{~s}$ & $23 \mathrm{~s}$ & 5.23 \\
\hline & & & & & & \\
\hline 2 & normalizado & $k-n n$ & $\mathrm{k}=40$ & 40 & $<1 \mathrm{~s}$ & $6 \mathrm{~s}$ & $\mathrm{~A} .2$ \\
\cline { 2 - 8 } & normalizado & $r q$ & $\mathrm{r}=0,3$ & 43 & $<1 \mathrm{~s}$ & $8 \mathrm{~s}$ & $\mathrm{~A} .3$ \\
\hline 2 & métrico & $k-n n$ & $\mathrm{k}=40$ & 40 & $<1 \mathrm{~s}$ & $7 \mathrm{~s}$ & $\mathrm{~A} .4$ \\
\hline 2 & métrico & $r q$ & $\mathrm{r}=0,3$ & 279 & $<1 \mathrm{~s}$ & $86 \mathrm{~s}$ & $\mathrm{~A} .5$ \\
\hline & & & & & & & \\
\hline 3 & normalizado & $k-n n$ & $\mathrm{k}=40$ & 40 & $<1 \mathrm{~s}$ & $7 \mathrm{~s}$ & $\mathrm{~A} .7$ \\
\hline 3 & normalizado & $r q$ & $\mathrm{r}=0,3$ & 5 & $<1 \mathrm{~s}$ & $<1 \mathrm{~s}$ & $\mathrm{~A} .8$ \\
\hline 3 & métrico & $k-n n$ & $\mathrm{k}=40$ & 40 & $<1 \mathrm{~s}$ & $7 \mathrm{~s}$ & $\mathrm{~A} .9$ \\
\hline 3 & métrico & $r q$ & $\mathrm{r}=0,3$ & 22 & $<1 \mathrm{~s}$ & $2 \mathrm{~s}$ & $\mathrm{~A} .10$ \\
\hline & & & & & & & \\
\hline 4 & normalizado & $k-n n$ & $\mathrm{k}=40$ & 40 & $<1 \mathrm{~s}$ & $19 \mathrm{~s}$ & $\mathrm{~A} .12$ \\
\hline 4 & normalizado & $r q$ & $\mathrm{r}=0,3$ & 30 & $<1 \mathrm{~s}$ & $18 \mathrm{~s}$ & $\mathrm{~A} .13$ \\
\hline 4 & métrico & $k-n n$ & $\mathrm{k}=40$ & 40 & $<1 \mathrm{~s}$ & $28 \mathrm{~s}$ & $\mathrm{~A} .14$ \\
\hline 4 & métrico & $r q$ & $\mathrm{r}=0,3$ & 110 & $<1 \mathrm{~s}$ & $51 \mathrm{~s}$ & $\mathrm{~A} .15$ \\
\hline
\end{tabular}

Tabela 5.3: Resumo dos resultartos obtidos nos oxperimentos. 


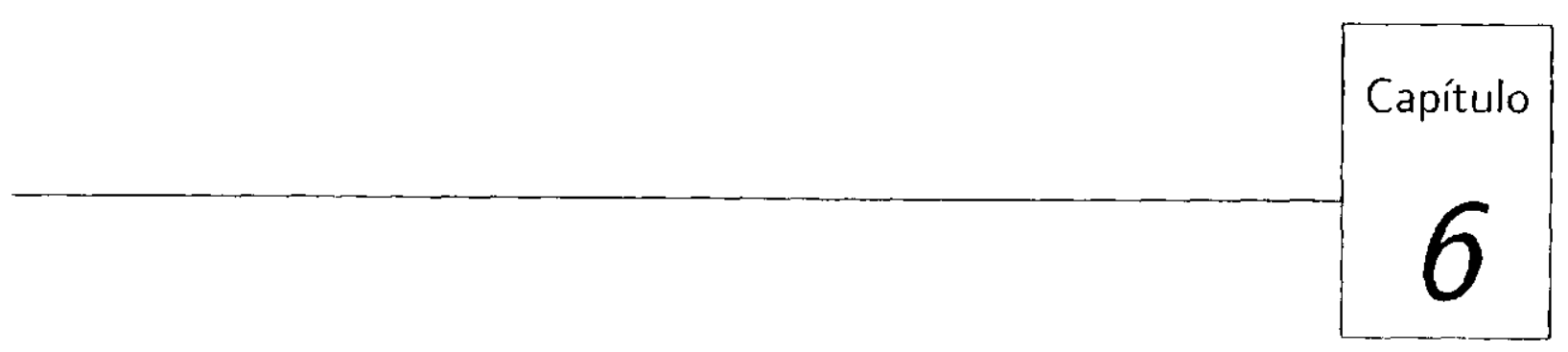

\section{Conclusão e Trabalho Futuros}

\subsection{Considerações Finais}

Sistemas de recuperação de imagens por conteúdo (CBIR) têm se tornado muito importantes para o desenvolvimento de diversas áreas científicas de utilizam imagens. O reconhecimento de objetos através de imagens tem sido empregado não só na medicina, mas cm sistemas industriais, de navegação, de segurança ou até em reconhecimento de supcrfícies. Na área médica, sistemas CBIR avaņ̧an rapidamonte, pois a potencialidade de aplicações é bastante grande, desde utilização para ensino e estudo de casos até suporte ao diagnóstico por imagens. Além disso, o fato de anxiliar a qualidade de vida com a introdução de sistemas tecnológicos, traz uma motivação social adicional.

Este trabalho apresentou o desenvolvimento de uma técnica de extração de características de imagens, que está sendo incorporada a um sistema de recuperaça de imagens médicas por conteúdo. Tal técnica foi desenvolvida modificando uma proposta inicial de tratamento de histogramas de brilho (Histogramas Métricos), sendo que esta nova técnica foi testada e comparada com outra baseada também em histogramas (BIC). Além da extensāo realizada no sistema SRIS-HC para incorporar tal técnica, foi também desenvolvido um protótipo de avaliação que utilizado para validar a técnica e comparar com outras propostas cm desen- 
volvimento no GBDI. Deve-se ressaltar que a pesquisa bibliográfica efetuada foi de fundamental importância já que apresentou o estado-da-arte nos sistemas CBIR. Tais sistemas foram analisados e verificados quais poderiam ser aplicados na área médica. Infelizmente, poucos sistcmas tratarn con exclusividade imagens monocromáticas (tons de cinza) e menos ainda imagens médicas, ondo a variabilidade de intonsidades de cinza pode dor baixa. Essa característica traz o problema de que as imagens são homogêneas, não havendo muita discrepância entre informações de imagens distintias. Apesar dos problemas de recuperação das imagens médicas, o presente trabalho apresentou resultados satisfatórios, mesmo comparado com sistemas da literatura.

A utilização do sistema no Iospital das Clínicas permite que os médicos avaliem e comparem diagnósticus anteriores, possibilitando um melhor tratamento ao paciente. A integração do SRIS-HC junto ao sistema de laudo possibilita também uma ferramenta de enssino e validação de diagnóstico médico podendo ser usado por especialistas do HCRP que é um hospitial escola.

\subsection{Trabalhos Futuros}

As téenicas de extração de características baseadas em histograma mapeiam a distribuiçino global de brilho das imagens e, dessa forma, atuam como $u$ miltro inicial do conjunto de imagens que possa se qualificar a responder consultas por similaridade. Técnicas mais avançadas, baseadas en textura e forma, podem ser incorporadas para atuarem como um processo scundário de seleção do conjunto de imagens resultantes, ou mesmo como um processo inicial, conforme desejado. A incorporação de métodos como forma e contorno da imagem estão em descnvolvimento no GBDI-USP e poderão ser integradas ao sistema SRISHC. Por utilizar biblioteras desenvolvidas pelo próprio grupo de pesquisa como a DicomLib, a adição de componentes pode ser realizada de mancira simples e fácil.

Un estudo mais detalhado sobre as reais necessidades dos médicos poderia ajudar a desenvolver sistemas mais amplos e gerais para as diversas modalidades médicas. A rejeição ao uso de ferramentas computacionais autonáticas ainda existe em diversos setores da socicdade e mosmo en contros médicos. A introdução do sistema, que hoje está restrita a um ambiente de testes, para ser utilizado no cotidiano da prática médica traria informaçõos vitais para a sua expansão e boa utilização. O sistema contou con a opinião de diversos profissionais da área, mas ainda nã̃o foi testado no dia-a-dia de um hospital onde as imagens geradas diarianente podem chegar a de\%ena de milhares. 


\section{Referências Bibliográficas}

[Albuz et al., 2001] Albuz, E., Kocalar, E., and Khokhar, A. A. (2001). Scalable color image indexing and retrieval using vector wavelets. IEEE Transactions on Knowledge and Data Engineering, 13(5):851 861

[Aslandogan and Yu, 1999] Aslandogan, Y. A. and Yu, C. 'T. (1999). Techniques and systems for image and video retrieval. IEEE Transactions on Knowledge and Duta Engineering, $11(1): 56-63$

[Beckmann et al., 1990] Beckmann, N., Kriegel, H.-P., Schneider, R., and Seeger, B. (1990). The $\mathrm{r}^{*}$-tree: An efficient and robust access method for points and rectangles. In $A C M$ Int'l Conference on Dala Management (SIGMOD), pages 322331.

[Brown, 1992] Brown, L. G. (1992). A survey of image registration techniques. ACM Computing Surneys, 24(4):325-376.

[Bruxcelli and Mich, 2001j Brunelli, R. and Mich, O. (2001). Histograms analysis for image retrieval. Pattern Recognition, 34(8).

[Bueno, 2002] Bueno. J. M. (2002). Suporte à Recuperação de Imagens Médicas baseada em Contéúdo através de Histogramas Métricos. Tese de doutorado, Universidade de São Paulo.

[Campo, 2002] Campo, C. Y. (2002). Utilização de histogramas adaptativos para recuporação de imagens por conteúdo em um sistema pacs. Qualificação de mestrado, ICMC USP 
[Campo and Traina, 2003i Campo, C. Y. and Traina, A. M. J. (2003). Uma abordagem eficiente para recuperação de imagens médicas, cd-rom Cd-rom. III Workshop de Informática Médica, Fortaleza - Ceará.

[Cao and Huang, 2000] Cao, X. and Huang, H. (2000). Current status and future advances of digital radiography and pacs. IEEE Engineering in Medicine and Biology Magazine, $9(5): 80-88$.

[Caritá, 2002] Caritá, E. C. (2002). Vinculação de imagens para busca e visualização a partir de sistema de informução em radiologia (ris). dissertação, Departamento de Engenharia Flétrica da Escola de Fngenharia de São Carlos - Universidade do São Paulo (USP), São Carlos.

[Caritá and Marques, 2000] Caritá, F. C. and Marques, P. M. A. (2000). Vinculação de imagens para busca e visualização a partir do sistema de informação em radiologia (ris). In VII Congresso Brasileiro de Informática em Saúde e do II Simpósio Internacional de Sistemas de. Informação Hospitalar, São Paulo - SP.

Castleman, 1996] Castleman, K. R. (1996). Digital Image Processing. Prentice-Hall Inc.

[Chan and McCarty, 1990] Chan, K. and McCarty, K. (1990). Aspects of the statistical texture analysis of medical ultrasound images. In Ultrasound Instrumentation, IEE Colloquium on, pages 3/1-3/3. Application Theoretical or Mathematical. TY - CONF.

[Chua et al., 1997] Chua, T. S., Tan, K.-L., and Ooi, B. C. (1997). Fast signature-based color-spatial image retrieval. In Multimedia Computing and Systems '97. Proceedings., IEEE International Conference on, pages 362-369, Dcpt. of Inf. Syst. \& Comput. Sci., Nat. Univ. of Singapore, Singapore. Practical Theoretical or Mathematical Experinental. TY - CONF.

[Chávez et al., 2001] Chávez, E., Navarro, G., Baeza-Yates, R., and Marroquín, J. I. (2001) Searching in metric spaces. to appear in the ACM Computing Surveys.

[Ciaccia and Patella, 1998] Ciaccia, P. and Patella, .1. (1998). Bulk loading the m-tree. In ADC Australasian Database Conference, pages $15 \cdot 26$.

[Ciaccia et al., 1997a] Ciaccia, P., Patclla, M.. Rabitti, F., and Zezula, P. (1997a). Indexing metric spaces with m-tree. In Atti del Quinto Convegno Nazionale, SEBD, pages 67-86, Verona, Italy. 
[Ciaccia et al., 1997b] Ciaccia, P., Patclla, M., and Zezula, P. (1997b). M-tree: An efficient access method for similarity search in metric spaces. In Jarke, M., editor, Intl. Conf. on Very Large Databases (VLDB), pages 426-435, Athens, Greece.

[Claude et al., 2001] Clande, J., Pouletaut, P.: Huault, S., and Boulanger, J. (2001). Integrated color and texture tools for colposcopic image segmentation. In Image Processing, 2001. Proceedings. 2001 International Confercnce on, volume 2, pages $311314 \mathrm{vol}$.2. Application. 'TY - CONF.

[Faloutsos, 1996] Faloutsos, C. (1996). Searching Multimedia Dalabases by Content. Kluwer Academic Publishers, Boston, MA.

[Faloutsos and Kamel, 1994] Faloutsos, C. and Kamel, I. (1994). Beyond uniformity and independence: Analysis of $r$-trees using the concept of fractal dimension. In ACM Symp. on Principles of Database Systems (PODS), pages 4-13, Minneapolis, MN. ACM Press.

[Furuie et al., 1999] Furuie, S.. Bertozoo, N., Figueiredo, J., and Yamaguti, M. (1999). Archiving and retrieving long-term cineangiographic images in a pacs. Computers in Cardiology, pages 435.438 .

[G. Günther, 1999] G. Günther, R. A. B. (1999). Large-scale pac systems. In Verlag, S., editor, Filmless Radiology, page 21. F.L.Siegel, R.M.Kolodner, New York.

[Gonzalez and Woods, 1993] Gonzalez, R. C. and Woods, R. E. (1993). Digital Image Processing. Addison-Wesley.

[Gudivada and Raghavan, 1995] Gudivada, V. N. and Raghavan, V. V. (1995). Design and evaluation of algorithms for image retrieval by spatial similarity. ACM Transactions on Information Systems, 13(2):115-144.

[Guttman, 1984] Guttman, A. (1984). R-tree: A dynamic index structure for spatial searching. In ACM Int'l Conference on Data Management (SIGMOD), pages 47 57, Boston, MA. ACM PRess.

[Haralick et al., 1973] Haralick, R. M., Shanmugan, K. S., and Dunstcin, 1. (1973). Textura] features for image classification. IEEE Trans. SMC, 3(6):610 621 .

[Jain and Dubes, 1988] Jain, A. K. and Dubes, R. C. (1988). Algorithms for clustering data. Prentice-Hall Inc, Englewood Cliffs, NJ. 
[Keogh, 2002 Keogh, E. J. (2002). Fxact indexing of dynamic time warping. In Bernstein, P. A. et al., editors, VLDP 2002: proceedings of the Twenty-Eighth International Conference on Very Large Data Bases, Hong Kong SAR, China, 20-23 August 2002, pages 406 417, Los Altos, CA 94022, USA. Morgan Kaufmann Publishors.

[Korn et al., 1996] Kom, F., Sidiropoulos, N., Faloutsos, C., Siegel, E. L., and Protopapas, Z. (1996). Fast nearest neighbor search in medical image databases. In Intl. Conf. on Very Large Databases (VLDB), pages 215-226, Bombay, India. Morgan Kaufmam.

[Krishnamachari and Abdel-Mottaleb, 1998; Krishnamachari, S. and Abdel-Mottaleb, M. (1998). A scalable algorithm for image retrieval by color. In Image Processing, 1998. ICIP 98. Proceedings. 1998 International Conference on, pages 119-122 vol.3, Philips Lab., Briarcliff .Manor, NY, USA. Practical. TY - CONF.

[Kruskal, 1956] Kruskal, J. B. (1956). On the shortest spanning subtree of a graph and the traveling salesman problem. Proc. American Math Soc., 7:48 50.

[Lima et al., 1998] Lima, L. R. S. d., Laender, A. H. F., and Ribeiro-Neto, B. A. (1998). A hierarchical approach to the automatic categorization of medical documents. In $A C M$ CIKM, pages 132-139, Bethosda, Maryland.

[Loew, 2000] Loew, M. H. (2000). Fealure Extraction, chapter 5. SPIE, Belligham, WA, m.sonka and j. michacl fitzpatrick edition

[Marques and et. al, 2004] Marques, P. M. d. A. and et. al (2004). Projeto ciupe-grupo de estudos em sistemas para auxílio ao diagnóstico por imagem. Internet.

[Marques et al., 2000] Marques, P. M. d. A., Santos, A. C., Júnior, J. E., Goes, W. M., and Castro, C. R. (2000). Implantação de um sistema de informação em radiologia em hospital univeristário. Radiologia Brasileira, 33:155-160

[Marsh, 1997] Marsh, A. (1997). Euromed - the creation of a telemedical information society. In 10' IEEE Symposium on Computer Based Medical Systems, pages 86-91, Maribor, Slovenia.

[Moghaddam et al., 2000] Moghaddam, B., Biermann, H., and Margaritis, D. (2000). Innage retrieval with local and spatial queries. In Image Processing, 2000. Proceedings. 2000 International Conference on, wolume 2, pages 542-545 vol.2, Mitsubishi Electr. Res. Lab., USA. Theoretical or Mathematical. I'Y - CONF. 
[Pass et al., 1996, Pass: G., Zabih, R., and Miller, J. (1996). Comparing images using color coherence vector. In ACM Multimedia, pages 65-73, Boston, MA. ACM Press.

[Petrakis and Faloutsos, 1997] Petrakis, F. G. and Faloutsos, C. (1997). Similarity searching in medical image databases. IEEE Transactions on Knowledge and Data Engineering. 9(3): $435-447$.

[Petrakis et al., 2001] Petrakis, E. G., Faloutsos, C., and Lin, K.-I. D. (2001). Imagemap: An image indexing method based on spatial similarity. IEEE Trans. on Knowledge and Data Engineering, to appoar.

[Pressman, 2002] Pressman, R. S. (2002). Engenharia de Software. McGraw-Hill, Rio de Janciro, 5.exi. ralion

[Rao et al., 1999] Rao, A., Srihari, R., and Zhang, Z. (1999). Spatial color histograms for content-based image retrieval. In Tools with Artificial Intelligence, 1999. Proceedings. 11th IFEE International Conference on, pages 183 186. Practical Theoretical or Mathematical Experimental. TY - CONF.

[Rosa, 2002] Rosa, N. A. (2002). Uma abordagem prática e eficiente de consultas por similaridade para suporte a diagnóstico por imagens. Master's thesis, Universidade de São Paulo, São Carlos.

[Rubner and Tomasi, 2000] Rubner, Y, and Tomasi, C. (2000). Perceptual Metrics for Image Database Navigation. Kluwer Academic Publishers, Boston.

[Russ, 1995] Russ, J. C. (1995). The Image Processing Handbook. CRC Press, Boca Raton, 2nd edition.

[Siegel, 1999] Siegel, E. L. (1999). Current state of the art and future trends. In Sicgel, E. L. and Kolodner, R. M., editors, Filmless Radiology, pages 3-20. Springer Verlag, Now York City, NY.

[Siegel and Kolodner, 1999] Siegel, E. L. and Kolodner, R. M. (1999). Filmless Radiology. Springer Verlag, New York City, NY.

[Siegel and Reiner, 1999] Siegel, E. L. and Reiner, B. I. (1999). Challenges associated with the incorporation of digital radiography into a picture archival and communicaton system. Journal of Digital Imaging, 12(2):6 8. 
[Smeulders et al., 2000] Smeulders, A. W. M., Worring, M., Santini, S., Gupta, A., and Jain. R. (2000). Content-based image retrieval at the end of the early years. IEEE Transactions on Patterns Analysis and Machine Intelligence, 22(12).

[Stehling et al., 2000] Stehling, R. O., Nascimento, M. A., and Falcaõ, A. X. (2000). On "shapes" of colors for Content-Based image retricval. In Proceedings of the ACM 2nd Intl. Multimedia Information Retricval 2000 Workshop, pages 171 174, Los Angeles, CA ACMPress.

[Stehling et al., 2002] Stehling, R. O., Nascimento, M. A., and Falcão, A. X. (2002). A compact and efficient image retrieval approach based on border/interior pixel classification. In Proceedings of the eleventh international conference on Information and knowledge. management, pages 102-109. ACM Press.

[Stricker and Dimai, 1996] Stricker, M. and Dimai, A. (1996). Color indexing with weak spatial constraints. In Storage and Retrieval for Image and Video Databases IV - SPIE, volume 2670, pages 29-41, San Jose - CA.

[Sung et al., 2000] Sung, M., Kim, M., Sung: M.-W., Kim, E., and Yoo, J. (2000). Comed: A real-time collaborative medicine system. In 13th IEEE Symposium on Computer-Based Medical Systems (CBMS'O0), Houston, Texas. IEEF Computer Society.

[Swain and Ballard, 1991] Swain, M. J. and Ballard, D. H. (1991). Color indexing. IJCV: International Journal of Computer Vision, 7:11-32.

[Theodoridis and Koutroumbas, 1999] Theodoridis, S. and Koutroumbas, K. (1999). Pattern Recognition. Academic Press, New York.

[Traina, 2001] Traina, A. J. (2001). Suporte à Visualização de Consultas por Similaridade em Imagens Médicas através de Estruturas de Indexação Métrica. Tese de livre-docento cm computação, Instituto de Ciências Matemática e de Computação - Universidade de São Paulo, São Paulo - Brasil.

[Traina et al., 2002a] Traina, A. J. M., Traina, Caetano, J., Bueno, J. M., and Marques, P. M. d. A. (2002a). The motric histogram: A new and efficient approach for content-based image retrieval. In Sixth IFIP Working Conference on Visual Database Systems, Brisbane, Australia. 
[Traina et al., 2002b] Traina, Caetano, J., Traina, A. J. M., Faloutsos, C., and Seeger, B. $(2002 \mathrm{~b})$. Fast indexing and visualization of metric datasets using slim-trees. IEEE Transactions on Knowledge and Data Engineering, to appear.

[Traina et al., 2000] Traina, Caetano, J., Traina, A. J. M., Seeger, B., and Faloutsos, C. (2000). Stim-trees: High performance metric trees minimizing overlap between nodes. In Zaniolo, C., Lockemann, P. C., Scholl, M. H., and Grust, T., editors, Intl. Conf. on Extending Database Technology: volume 1777 of Lexture Notes in Computer Science, pages 51-65, Konstanz, Germany. Springer.

[Tuceryan and Jain, 1993] Tuceryan, M. and Jain, A. (1993). Texture Analysis. in Handbook of Pattern Recognition and Computer Vision (C.H. Chen, L.F. Pau, and P.S.P Wang, eds), pages 235-276. World Scientific Publishing Company.

[Vailaya, 2000] Vailaya, A. (2000). Semantic Classification in Image Databases. Phd. dissertation, Michigan State University.

[Wilson and Martinez, 1997] Wilson, D. R. and Martinez, T. R. (1997). Improved heterogeneous distance functions. Journal of Artificial Intelligence Rescarch, 6:1 34.

Yamamoto et al., 1999] Yamamoto, H., Iwasa, H., Yokoya, N., and Takemura, H. (1999). Content-based similarity retricval of images based on spatial color distributions. In Image Analysis and Processing, 1999. Proceedings. Inlernational Conference on: pages 951-956, Grad. Sch. of Inf. Sci., Nara Inst. of Sci. \& Technol., Japan. Theoretical or Mathematical. TY - CONF 


\section{Demais Resultados}

A seguir são apresentados os resultados para os casos 2,3 e 4 .

\section{A.1 Caso 2}

A imagem de referência do caso 2 é apresentada na Figura A.1 e o resultado de suas consultas nas Figuras A.2, A.3, A.4 e A.5.

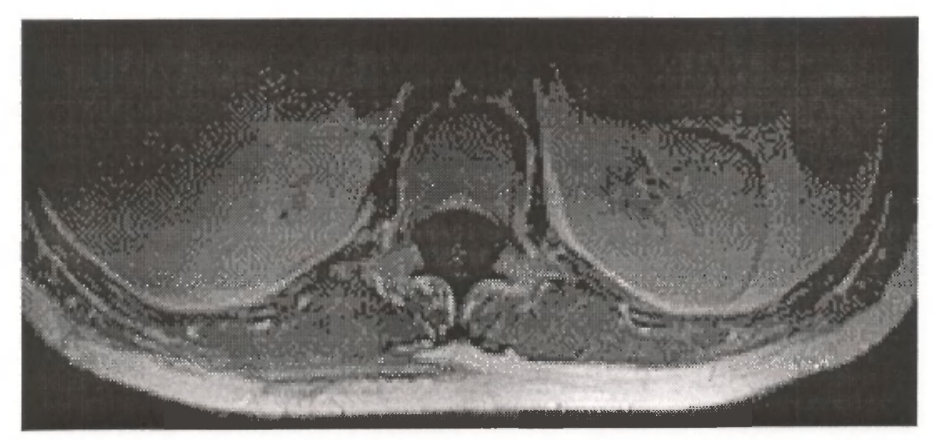

Figura A.1: Imagem de referência do Caso 2. 


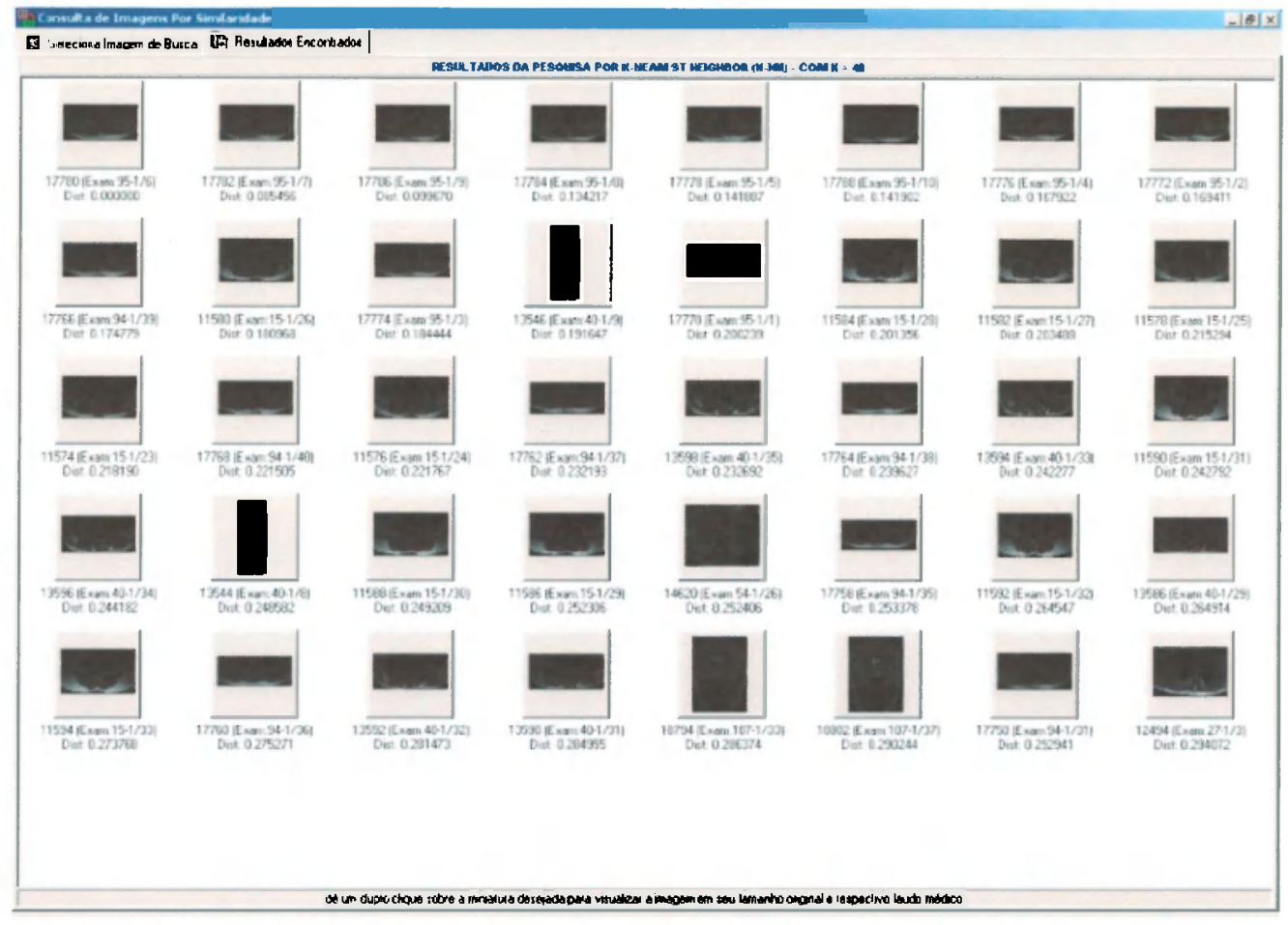

Figura A.2: Consulta aos 40 vizinhos mais próximos utilizando o histograma normalizado.

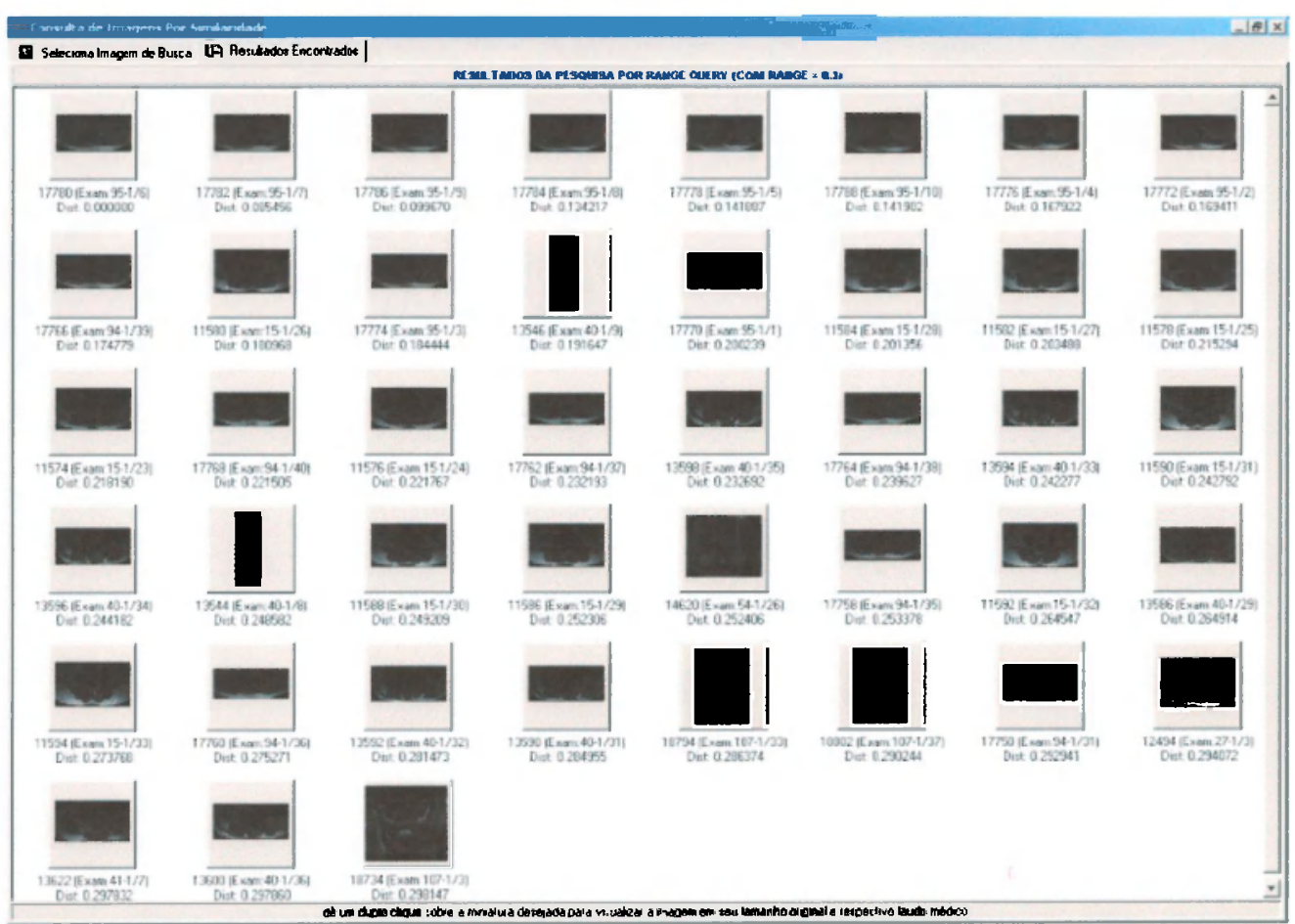

Figura A.3: Consulta por abrangência $(r=0.3)$ utilizando o histograma normalizado. 


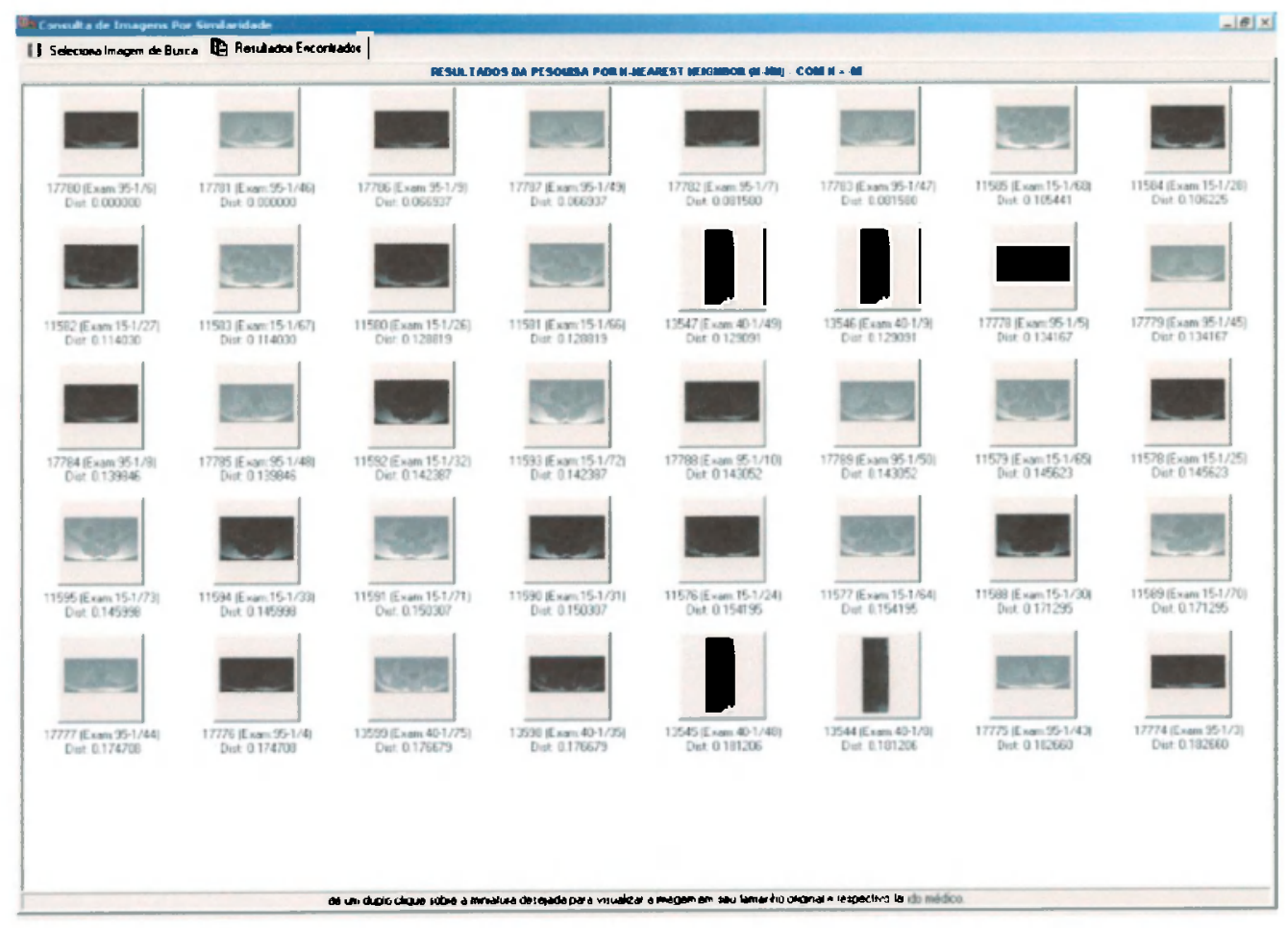

Figura A.4: Consulta aos 40 vizinhos mais próximos utilizando o Histograma Métrico adaptado.

\section{A.2 Caso 3}

A imagem de referência do Caso 3 é apresentada na Figura A.6 e o resultado de suas consultas nas Figuras A.7, A.8, A.9 e A.10.

\section{A.3 Caso 4}

A imagem de referência do Caso 4 é apresentada na Figura A.11 e o resultado de suas consultas nas Figuras A.12, A.13, A.14 e A.15. 


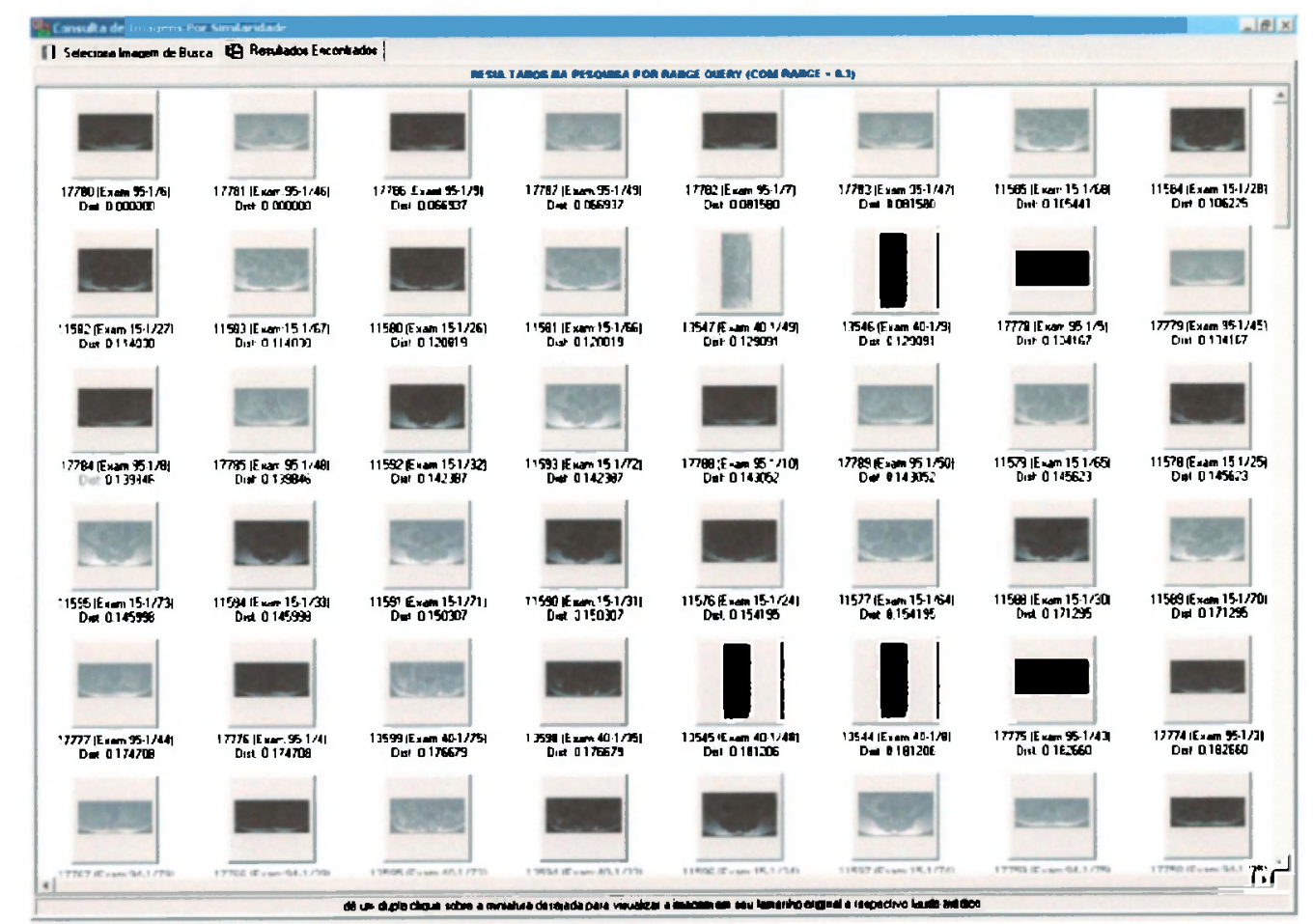

Figura A.5: Consulta por abrangência $(r=0.3)$ utilizando o Histograma Métrico adaptado.

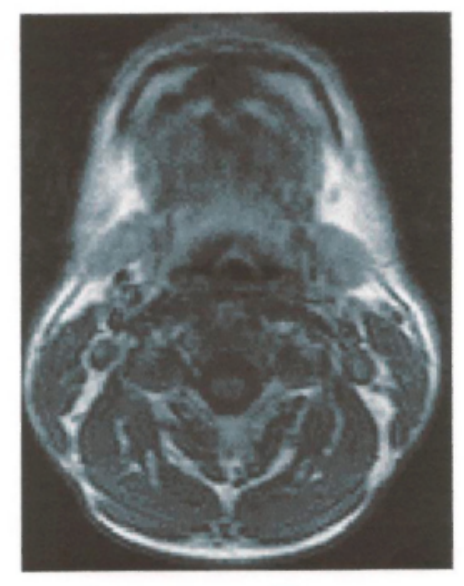

Figura A.6: Imagem de referência do Caso 3. 


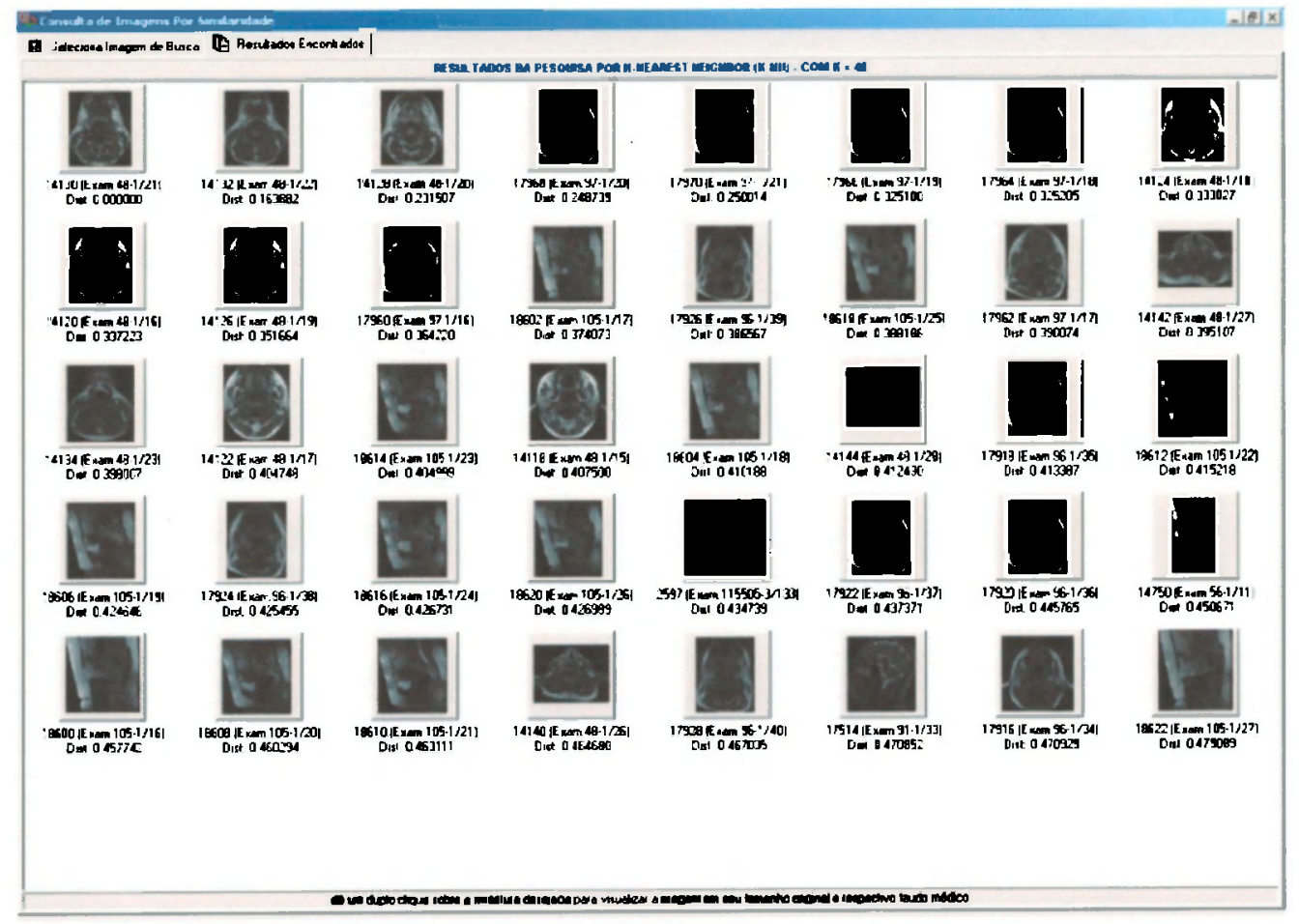

Figura A.7: Consulta aos 40 vizinhos mais próximos utilizando o histograma normalizado.

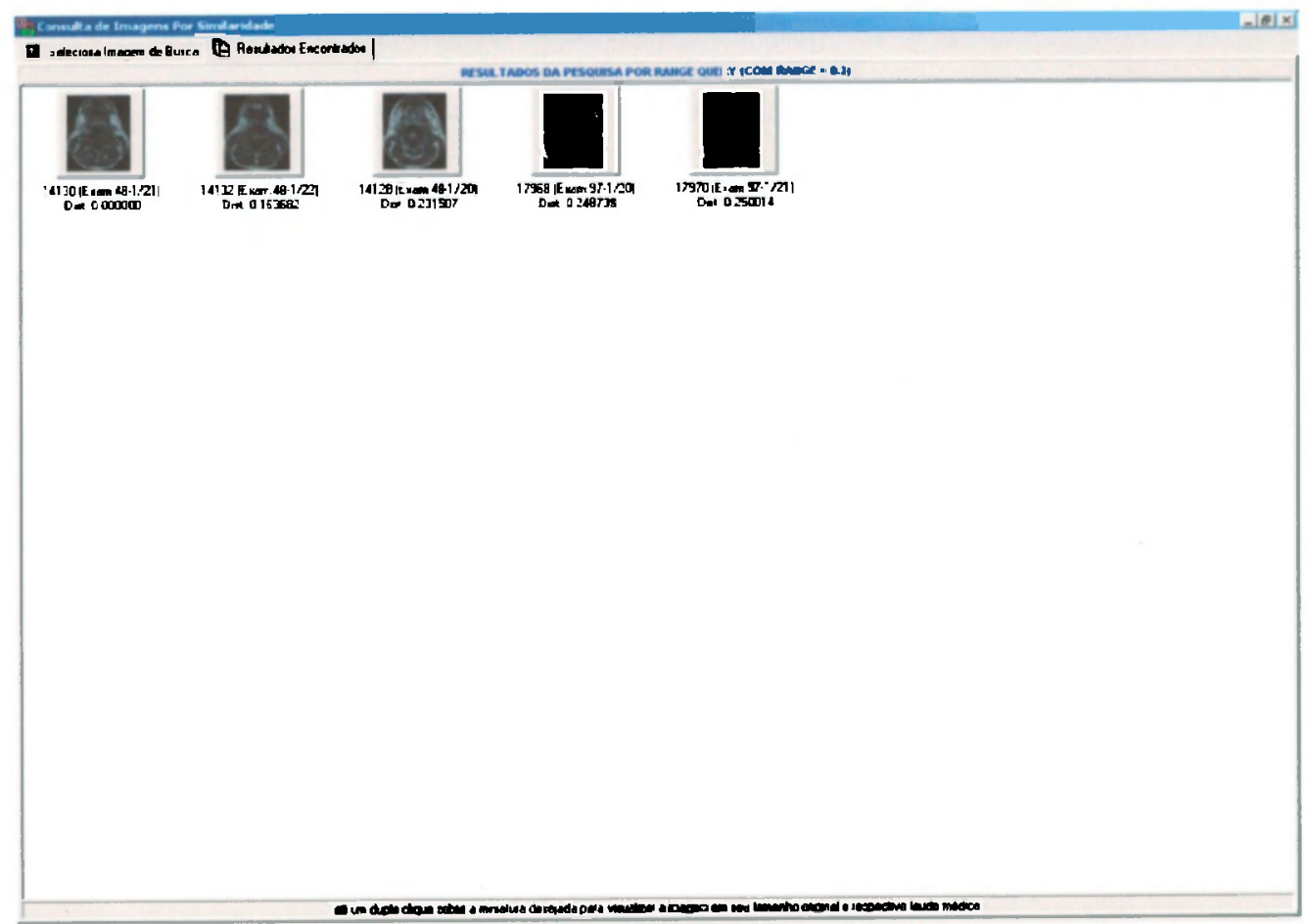

Figura A.8: Consulta por abrangência $(r=0.3)$ utilizando o histograma normalizado. 


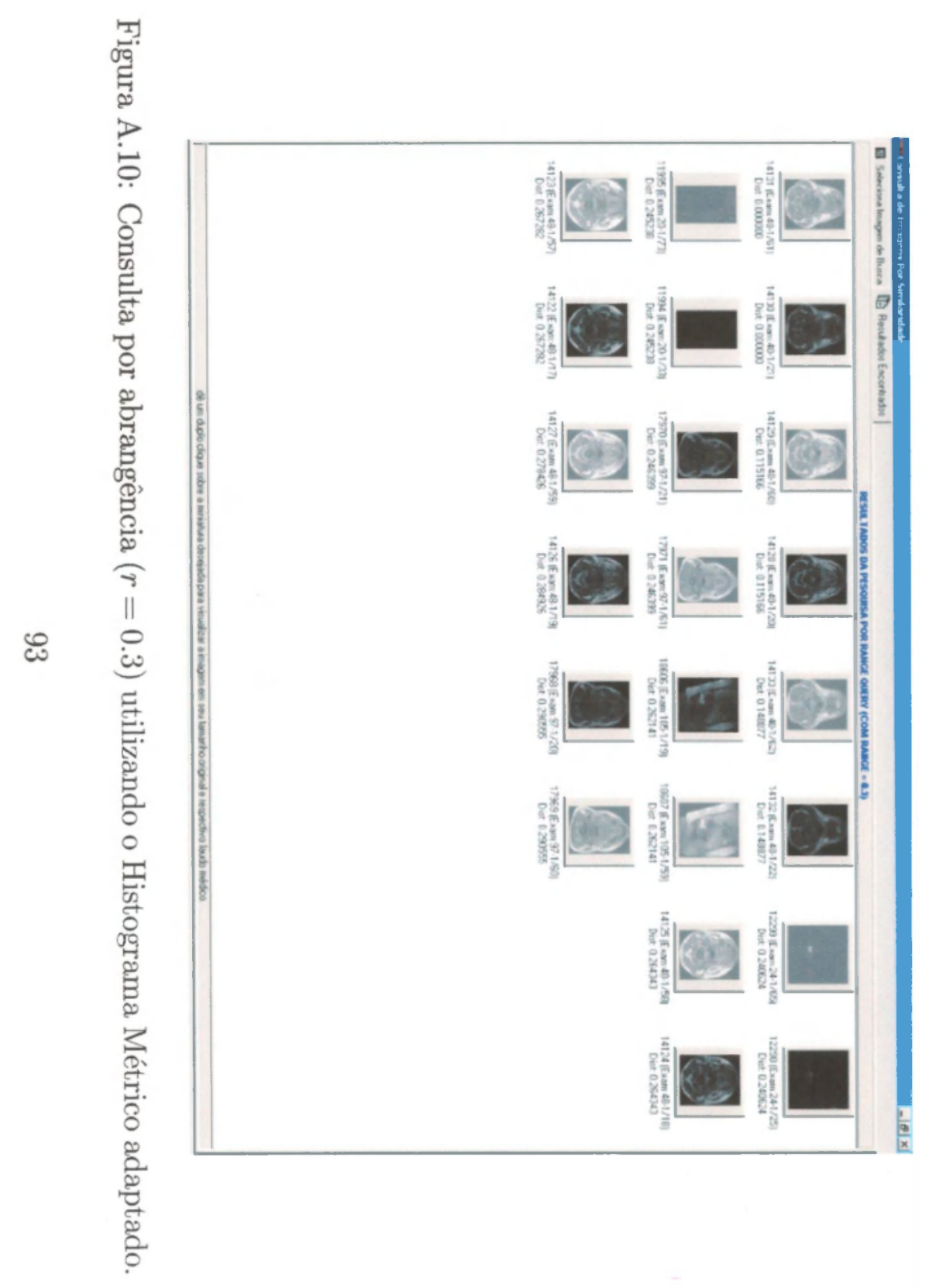




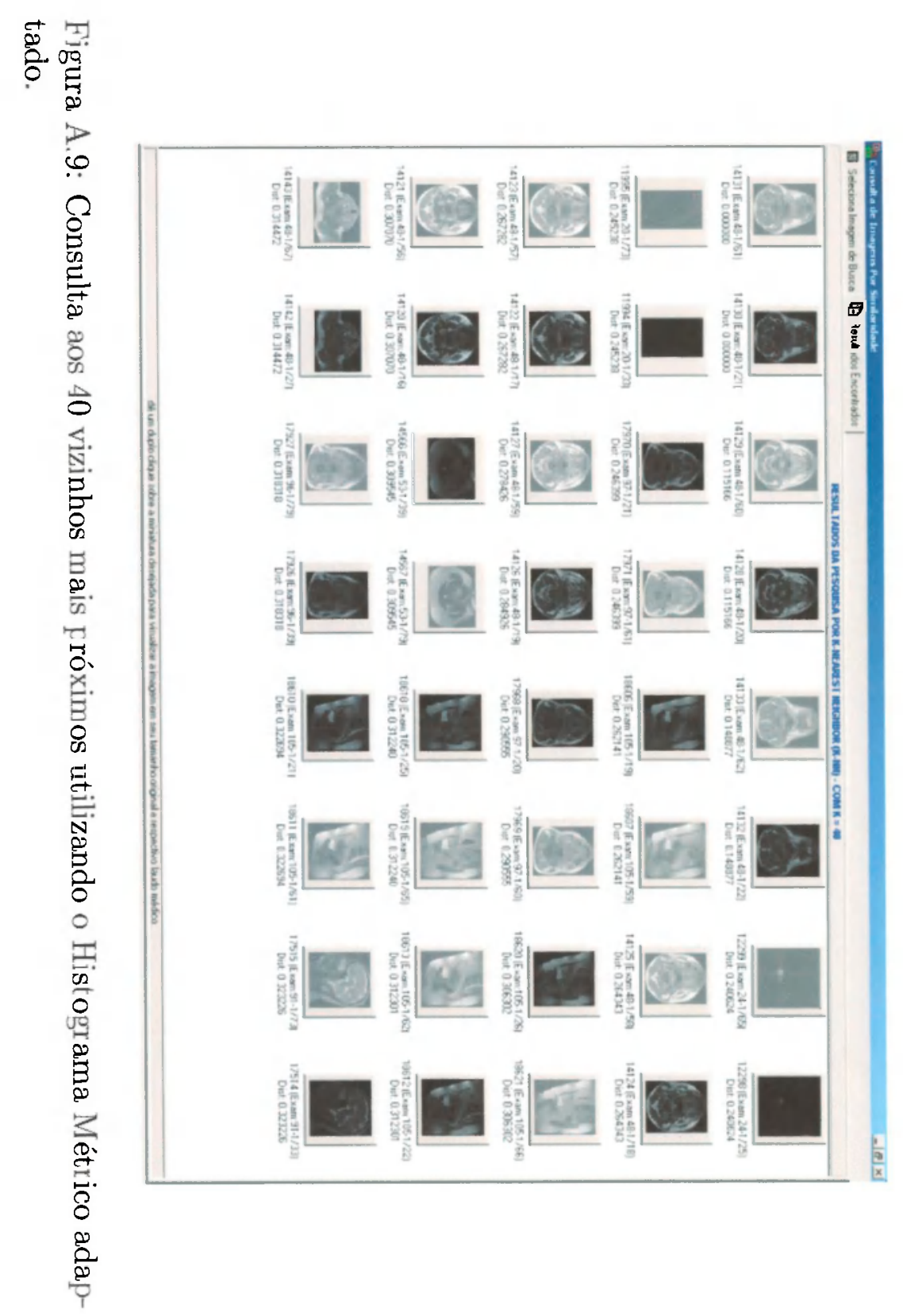




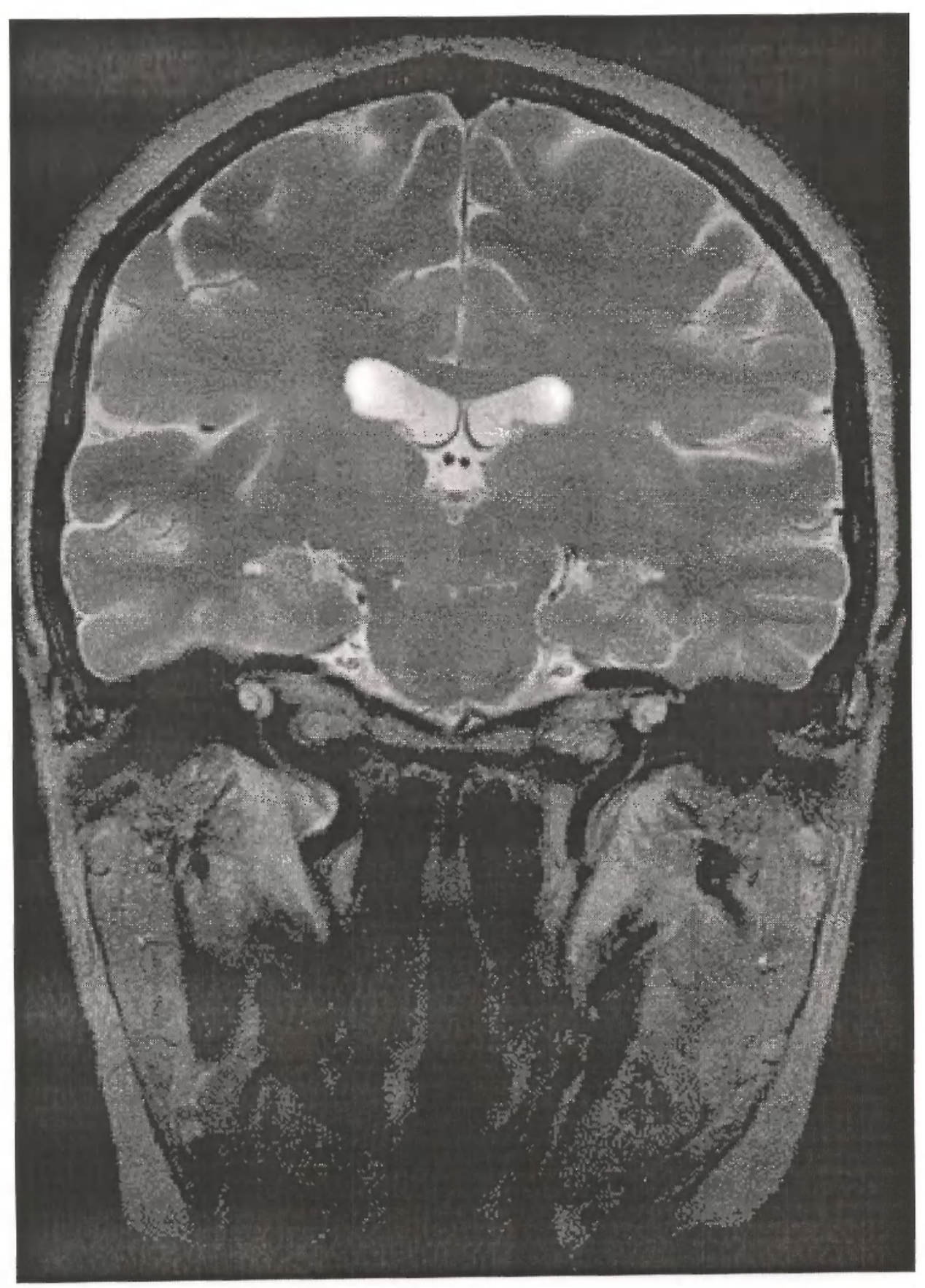

Figura. A.11: Imagem de referência do Caso 4. 


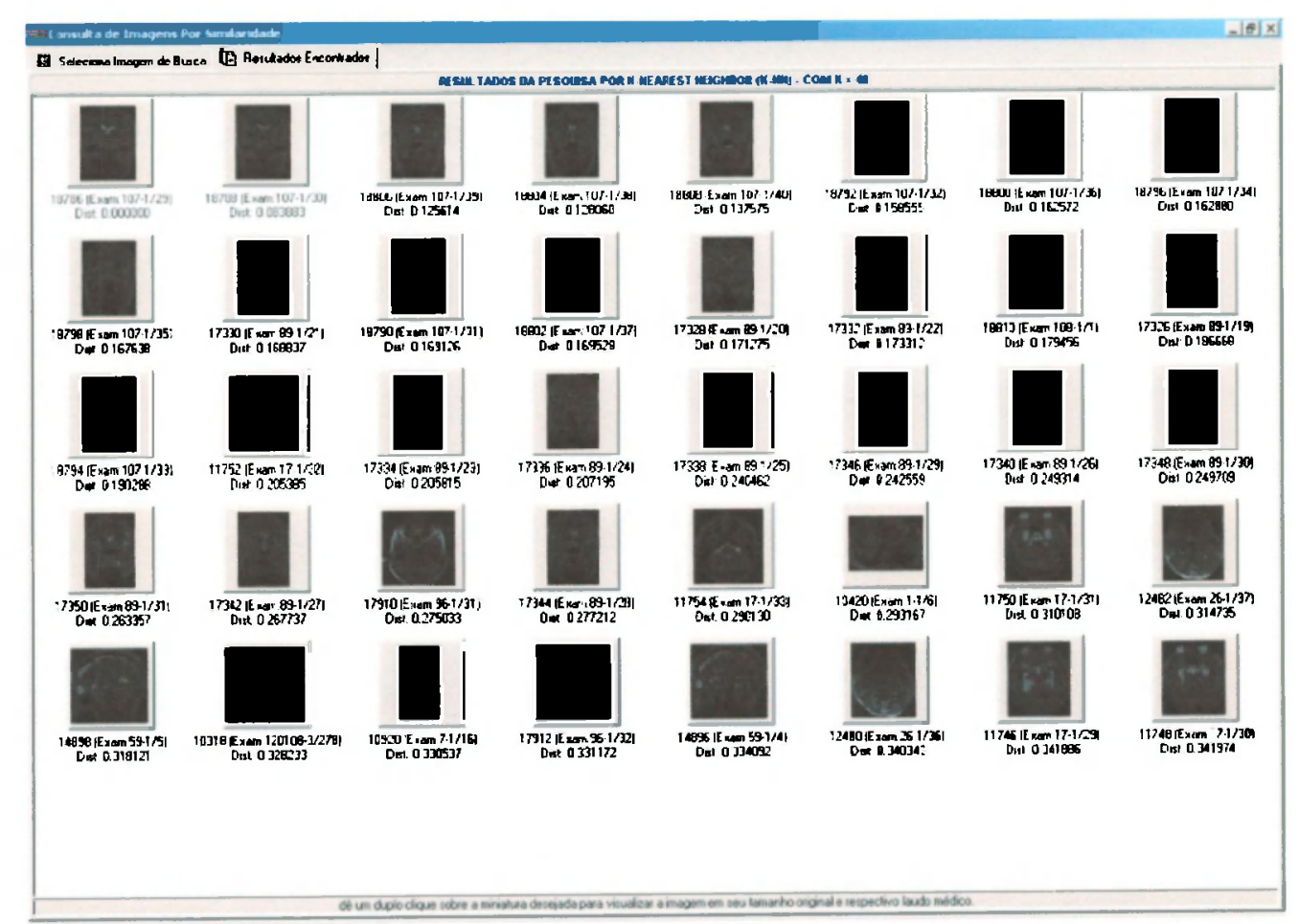

Figura A.12: Consulta aos 40 vizinhos mais próximos utilizando o histograma normalizado.

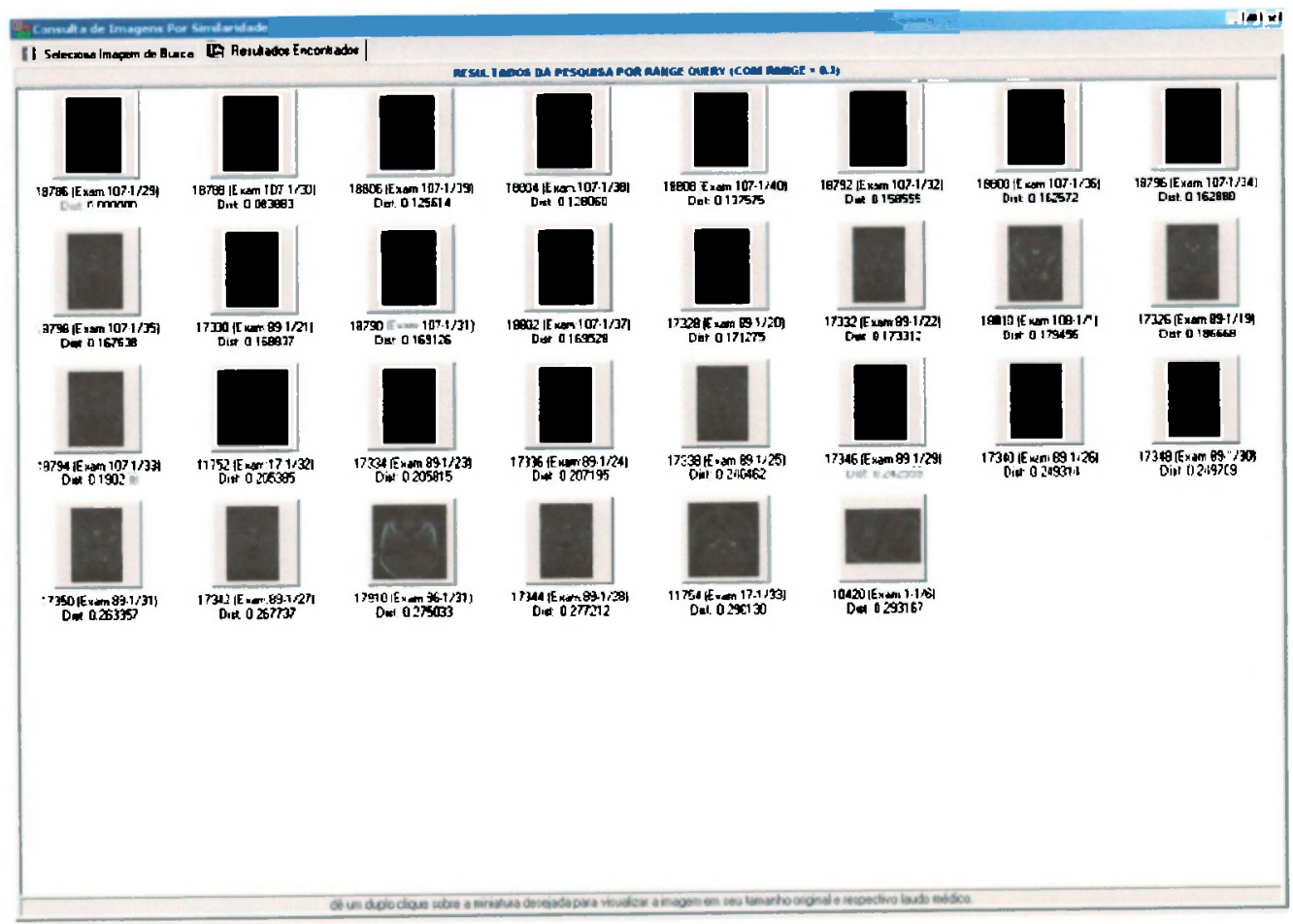

Figura A.13: Consulta por abrangência $(r=0.3)$ utilizando o histograma normalizado. 